\title{
TRANSIENT FLUID AND HEAT FLOW MODELING IN COUPLED WELLBORE/RESERVOIR SYSTEMS
}

\author{
A Dissertation \\ by \\ BULENT IZGEC \\ Submitted to the Office of Graduate Studies of \\ Texas A\&M University \\ in partial fulfillment of the requirements for the degree of \\ DOCTOR OF PHILOSOPHY
}

May 2008

Major Subject: Petroleum Engineering 


\title{
TRANSIENT FLUID AND HEAT FLOW MODELING IN COUPLED WELLBORE/RESERVOIR SYSTEMS
}

\author{
A Dissertation \\ by \\ BULENT IZGEC \\ Submitted to the Office of Graduate Studies of \\ Texas A\&M University \\ in partial fulfillment of the requirements for the degree of \\ DOCTOR OF PHILOSOPHY
}

\begin{abstract}
Approved by:
Chair of Committee, Committee Members,

Ding Zhu

Robert A. Wattenbarger

A. Dan Hill

Richard L. Gibson

Head of Department, Stephen A. Holditch
\end{abstract}

May 2008

Major Subject: Petroleum Engineering 


\begin{abstract}
Transient Fluid and Heat Flow Modeling in Coupled Wellbore/Reservoir Systems.

(May 2008)

Bulent Izgec, B.S., Ankara University; M.S., Texas A\&M University

Chair of Advisory Committee: Dr. Ding Zhu
\end{abstract}

Modeling of changing pressure, temperature, and density profiles in a wellbore as a function of time is crucial for design and analysis of pressure-transient tests (particularly when data are gathered above perforations), real-time management of annular-pressure buildup (ABP) and identifying potential flow-assurance issues. Other applications of this modeling approach include improving design of production tubulars and artificial-lift systems and gathering pressure data for continuous reservoir management.

This work presents a transient wellbore model coupled with a semianalytic temperature model for computing wellbore-fluid-temperature profile in flowing and shutin wells. The accuracy of the analytic heat-transfer calculations improved with a variableformation temperature model and a newly developed numerical-differentiation scheme. Surrounding formation temperature is updated in every timestep up to a user specified distance to account for changes in heat-transfer rate between the hotter wellbore fluid and the cooler formation. Matrix operations are not required for energy calculations because of the semianalytic formulation. This efficient coupling with the semianalytic heattransfer model increased the computational speed significantly.

Either an analytic or a numeric reservoir model can be coupled with the transient wellbore model for rapid computations of pressure, temperature, and velocity. 
The wellbore simulator is used for modeling a multirate test from a deep offshore well. Thermal distortion and its effects on pressure data is studied using the calibrated model, resulting in development of correlations for optimum gauge location in both oil and gas wells.

Finally, predictive capabilities of the wellbore model are tested on multiple onshore wells experiencing annular-pressure buildup problems. Modeling results compare quite well with the field data and also with the state-of-the-art commercial wellbore simulator. 


\section{DEDICATION}

This work is dedicated to my mom

Fatma Karaca

\& my wife

Hilal Ozcan 


\section{ACKNOWLEDGEMENTS}

I would like to express my sincere appreciation for Dr. Zhu and Dr. Hill for their academic guidance, constructive suggestions and constant support throughout this study.

I would also like to thank Dr. Wattenbarger and Dr. Gibson for serving as my committee members and for their invaluable comments.

I am grateful to Shah Kabir and Rashid Hasan for walking with me throughout every step of the study and for sharing their knowledge on the subject.

I am grateful to my brother, Omer Izgec, for his support and help with all the phases of the work, and especially for taking care of everything in College Station.

I would also like to thank Dr. Schechter and Dr. Erwin Putra for supporting the initial part of my PhD studies at Texas A\&M University.

Finally I am grateful to our unit manager Brain Llewellyn, my team leaders, Peter Clark, Zuwa Omoregie and Dave Strait, our previous general manager Janeen Judah for their kind support of my PhD. I am also thankful to Xiaowei Wang and Myrt Cribbs for sharing their applied and theoretical knowledge with me. 


\section{TABLE OF CONTENTS}

ABSTRACT

1.1 Background ...................................................................................... 1

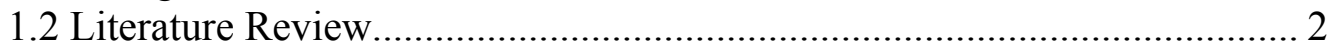

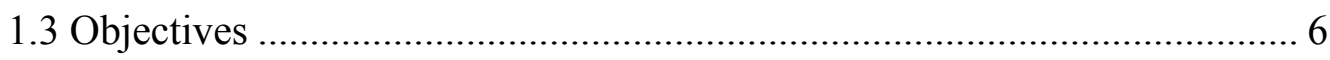

CHAPTER II WELLBORE FLUID TEMPERATURE MODEL ............................... 8

2.1 SemiAnalytic Fluid-Temperature Model ................................................ 8

2.1.1 Energy Balance for Wellbore Fluid ........................................ 8

2.1.2 Energy Balance for Wellbore Fluid and Tubular Systems .......... 10

2.1.3 Analytic Heat Transfer Models.................................................. 13

2.1.3.1 Drawdown .............................................................. 13

2.1.3.2 Buildup................................................................ 16

2.1.3.3 Buildup with After-Flow Effects ............................... 18

2.1.3.4 Buildup with Vertical Heat Transfer............................ 21

2.1.3.5 Comparison with Ramey's Model .............................. 24

2.2 Numerical Differentiation for Short Term Tests ..................................... 27

2.3 Heat Transfer Rate in Annulus .............................................................. 31

2.4 Formation-Temperature Updating …................................................ 35

CHAPTER III WELLBORE AND RESERVOIR FLOW MODEL ........................... 38

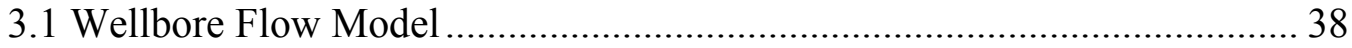

3.1.1 Mass and Momentum Balance ................................................ 38

3.1.2 Wellbore Mass and Velocity Distribution ................................. 39

3.2 Reservoir Model........................................................................ 42

CHAPTER IV ANNULAR-PRESSURE BUILDUP MODEL .................................. 43 
4.1 Transient Behavior of Annular Pressure Buildup ................................... 43

4.2 Accounting for Fluid Expansion in Annuli............................................... 44

4.3 Heat Transfer Calculations in Annuli and Around Wellbore ..................... 48

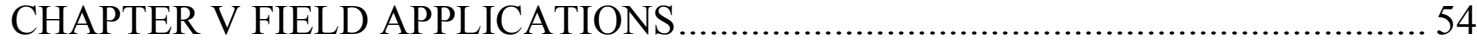

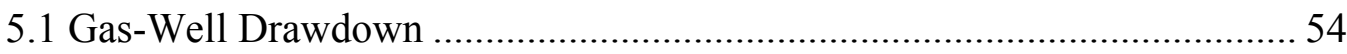

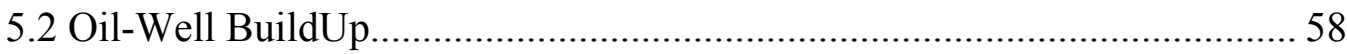

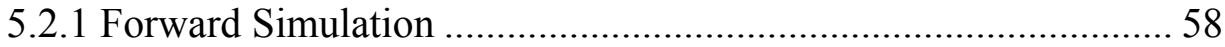

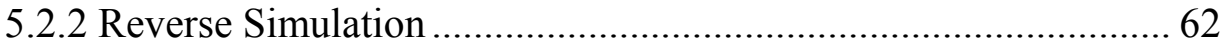

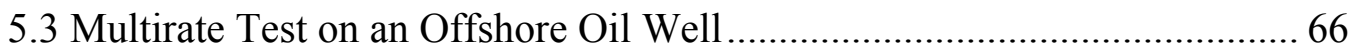

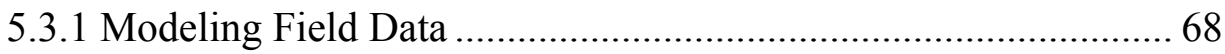

5.3.2 Optimal Location of Permanent Downhole Gauge..................... 71

5.4 Effect of Gauge Location on Pressure-Transient Analysis....................... 72

5.4.1 Oil Well...................................................................................... 72

5.4.1.1 Drawdown Response .............................................. 73

5.4.1.2 Buildup Response ................................................. 76

5.4.2 Gas Well......................................................................... 78

5.5 Annular Pressure Buildup for an Onshore Well ...................................... 84

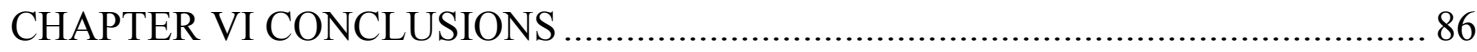

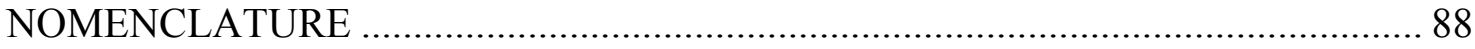

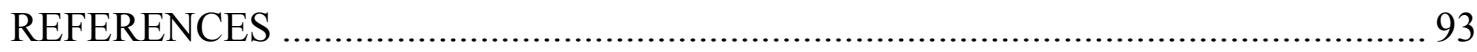

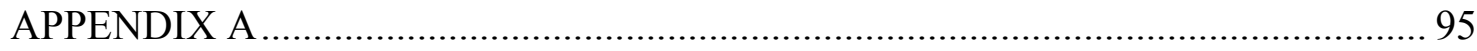

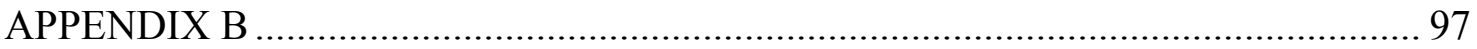

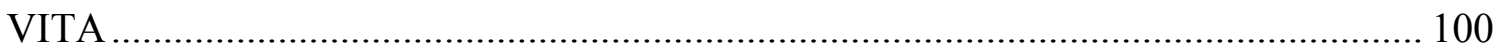




\section{LIST OF TABLES}

Page

Table 5.1 Range of sensitivity variables for design of experiments for oil................. 75

Table 5.2 Range of sensitivity variables for design of experiments for gas................ 79 


\section{LIST OF FIGURES}

Figure 2.1 Control volume used to derive heat transfer equations. ......................... 8

Figure 2.2 Control volume and nodes for heat conduction in vertical direction. ....... 21

Figure 2.3 Drawdown test for low production rate................................................ 26

Figure 2.4 Multirate drawdown test for a maximum rate of $16,000 \mathrm{stb} / \mathrm{D}$............... 26

Figure 2.5 Heat transfer by natural convection in annulus................................... 32

Figure 2.6 Iterative procedure for calculating annulus heat transfer rate .................. 34

Figure 2.7 Conductive heat transfer through the volume element taken at the formation/wellbore interface............................................................ 36

Figure 3.1 Mass and velocity distribution in the wellbore..................................... 39

Figure 4.1 Wellbore grids in vertical and lateral directions.................................... 48

Figure 5.1 Wellhead temperature during a gas-well drawdown test ....................... 54

Figure 5.2 Bottomhole pressure during a gas-well drawdown test.......................... 55

Figure 5.3 Temperature profile during gas-well drawdown test............................ 55

Figure 5.4 Density profile during a gas-well drawdown test................................. 56

Figure 5.5 Changes in $L_{R}$ during gas-well buildup test....................................... 56

Figure 5.6 Changes in $L_{R}$ during gas-well drawdown test ................................... 57

Figure 5.7 Error on calculated WHT during gas-well drawdown test...................... 57

Figure 5.8 Formation temperature profiles calculated at different locations around the wellbore during drawdown ........................................................ 58

Figure 5.9 Wellhead pressure of oil well \# 1 during buildup ................................. 59

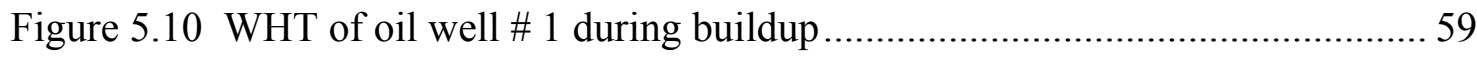

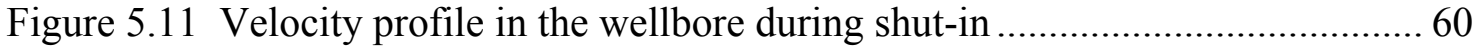

Figure 5.12 Temperature profile in the wellbore during an oil-well buildup test........ 60

Figure 5.13 Density profile in the wellbore during an oil-well buildup test............... 61

Figure 5.14 Changes in formation temperature profiles around the wellbore calculated from volume elements with different sizes 
Figure 5.15 Comparison of WHT with the computed values in reverse simulation, oil-well \# 2 ............................................................................................ 63

Figure 5.16 Comparison of BHP with that translated from WHP by reverse simulation, oil well \# 2 . 63

Figure 5.17 Comparison of WHP/WHT obtained by forward simulation, oil well \# 2 74

Figure 5.18 Wellhead leak during a shut-in test .............................................. 75

Figure 5.19 Simulated wellbore during a multi-rate test ....................................... 67

Figure 5.20 Test history showing cleanup period ............................................... 68

Figure 5.21 Geothermal gradient and sea water temperature profile.......................... 68

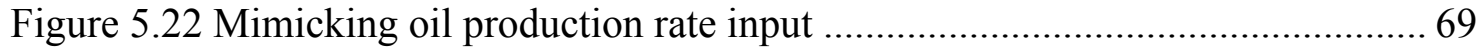

Figure 5.23 Matching bottomhole pressure ........................................................ 70

Figure 5.24 Matching temperature at the midpoint of the flow string ........................ 70

Figure 5.25 Matching pressure at the midpoint of the flow string............................ 70

Figure 5.26 Downhole gauge placement configurations ...................................... 71

Figure 5.27 Temperature and density profiles in the wellbore ................................ 73

Figure 5.28 Temperature and viscosity profiles in the wellbore ............................... 74

Figure 5.29 Error on semilog slope as a function of depth...................................... 74

Figure 5.30 Pareto chart for oil-well drawdown for dependent variable $E_{m^{*}} \ldots \ldots \ldots \ldots \ldots . . . . .76$

Figure 5.31 Error on semilog slope for drawdown and buildup as a function of

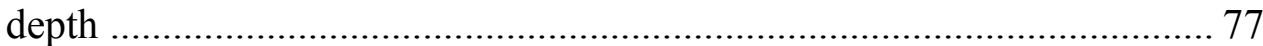

Figure 5.32 Log-log plot for buildup in an oil well ........................................... 77

Figure 5.33 Pareto chart for oil-well buildup for the dependent variable $E_{m} * \ldots \ldots \ldots \ldots . . . .78$

Figure 5.34 Pressure at the mudline and bottomhole for a deepwater gas well ........... 79

Figure 5.35 Derivative diagnosis of gas-well buildup for a gauge at 3,000 ft away from sandface ......................................................................... 80

Figure 5.36 Pressure and temperature behavior at the mudline .............................. 81

Figure 5.37 Pressure and temperature behavior 2,000 ft below the mudline .............. 81

Figure 5.38 Pareto chart gas-well drawdown for the dependent variable $E_{m^{*}} \ldots \ldots \ldots \ldots . . . .82$

Figure 5.39 Comparison of converted BHP responses (2,000 ft off-bottom and the mudline) with the true response 83 
Page

Figure 5.40 Wellhead pressure response shows both slugging and thermal effects .... 84

Figure 5.41 Wellhead temperature during production............................................ 84

Figure 5.42 Annulus pressure during production ................................................... 85 


\section{CHAPTER I}

\section{INTRODUCTION}

\subsection{BACKGROUND}

Transient pressure and temperature behavior in a wellbore develops as the hot fluid from the reservoir moves upward, exchanging heat with the surrounding formation. Because of heat exchange between the reservoir fluid and surrounding formation, the temperature profile in the wellbore does not remain constant with time. The changes in the temperature profile during flow and shut-in periods also lead to a changing density profile throughout the wellbore that affects the pressure profile as well.

In this study, we will develop a coupled wellbore/reservoir simulator. This simulator will entail simultaneous solution of mass, momentum, and energy balance equations, providing pressure and temperature as a function of depth and time for a predetermined surface flow rate.

Modeling of changing pressure, temperature, and density profiles in the wellbore as a function of time is crucial for design and analysis of pressure-transient tests, particularly when data are gathered away from perforations or in deepwater setting, and for identifying potential flow-assurance issues. Other applications of this modeling approach include improving design of production tubulars and artificial-lift systems, gathering pressure data for continuous reservoir management and estimating flow rates from multiple producing horizons and real-time monitoring of well stability.

This dissertation follows the style of the SPEREE Journal. 


\subsection{LITERATURE REVIEW}

A coupled wellbore/reservoir simulator entails simultaneous solution of mass, momentum, and energy balance equations, providing pressure and temperature as a function of depth and time for a predetermined surface flow rate. This work presents a finite-difference transient wellbore simulator coupled with a semianalytic temperature model for computing wellbore-fluid-temperature profile in flowing and shut-in wells. The literature review on temperature models will be followed by wellbore models.

Estimation of temperatures in a wellbore during injection or production is a recurring problem in petroleum engineering. Examples are the prediction of bottomhole temperatures of injection fluids and of wellhead temperatures in gas and oil wells. Almost all practical methods for calculation of temperature profiles in the wellbores go back to the work by Ramey (1962) on wellbore heat transmission published in early 1960's.

In that paper, Ramey presented an analytical equation for wellbore temperatures based on a simplified heat balance. Assuming steady-state flow of an incompressible single phase fluid, he dropped the kinetic energy term. Also, under these assumptions the loss in potential energy becomes approximately equal to the increase in enthalpy.

Apart from his analytical temperature equation, Ramey also proposed a simple procedure to estimate an overall heat-transfer coefficient for wellbore heat losses comprising both transient heat resistances in the formation and near wellbore heat resistances. This method couples heat-transfer mechanisms in the wellbore and transient thermal behavior of the reservoir. Temperature equations for injection of either singlephase incompressible hot liquid or single-phase ideal gas flow have been identified. Satter (1965) later included the effect of phase change during steam injection operations. In Ramey's method the transient thermal behavior of the reservoir is determined by solution of the problem of radial heat conduction in an infinite cylinder. The resistances to heat flow in the wellbore, caused by presence of tubing wall, tubing insulation, fluid in 
the casing/tubing annulus, casing wall, and cement are incorporated in an overall heattransfer coefficient.

Willhite (1967) suggested a method for the determination of the overall heattransfer coefficient. His paper presents comparison of calculated and measured casing temperatures during steam injection. Shiu and Beggs (1980) developed an empirical correlation for producing oil wells to determine the relaxation distance that Ramey defined. This work is actually an attempt to avoid the complex calculation of the overall heat-transfer coefficient in the wellbore and the transient heat-transfer behavior of the reservoir. Although this correlation simplifies the Ramey method, it should be used with caution as a rough approximation. Sharma et al. (1989) modified the Ramey equation for the case of producing wells with a downhole heater. Finally, Sagar (1991) developed a simplified method suitable for hand calculations based on field data. His model predicts the temperature profiles in two-phase flowing wells assuming steady-state heat transfer within the wellbore. According to Alves et al. (1992) all these methods include critical assumptions related to the thermodynamic behavior of the flowing fluid and thus applicable only for limited operational conditions. Their paper presents a unified equation for flowing temperature prediction, which degenerates into Ramey's equation for ideal gas or incompressible liquid and into the Coulter-Bardon equation, with the appropriate assumptions.

In 1990, Wu and Pruess presented an analytical solution for wellbore heat transmission in a layered formation with different thermal properties without introducing the simplifying assumptions of Ramey. From their example calculations, they observed that the Ramey method is valid at long times but can generate large errors at early times. However, quantification of the conditions under which Ramey's method could be applied was beyond the scope of their paper.

Hagoort (2004) studied the Ramey method and tried to establish criteria for its applicability. He first performed an inspection analysis of the basic wellbore heat 
transmission equations without using the simplifying Ramey assumptions. This entailed the formulation of the equations in dimensionless form and identification of governing dimensionless numbers. Finally he developed a rigorous solution of these dimensionless equations and compared the solution with Ramey solution for various ranges of dimensionless numbers. Also, in the paper Ramey's method for estimation of overall heat transfer coefficients is discussed. The study concludes by showing that Ramey's method is an excellent approximation except for the early transient period in which, the calculated temperatures are significantly overestimated.

Rigorous prediction of the flowing temperature distribution in a wellbore is complex. It requires the simultaneous solution of continuity, momentum, and conservation of energy equations. The numerical algorithms apply a double iterative procedure on both temperature and pressure for solving the three conservation equation simultaneously and require knowledge of the thermodynamic behavior of the flowing fluid. The solution is further complicated by the interaction between the wellbore and the reservoir at the perforations.

Almehaideb et al. (1989) studied the effects of multiphase flow and wellbore phase segregation during well testing. They used a fully implicit scheme to couple the wellbore and an isothermal black-oil reservoir model. The wellbore model accounts only for mass and momentum changes with time. Similarly, Winterfeld (1989) showed the simulations of buildup tests for both single and two-phase flows in relation to wellbore storage and phase redistribution. Fairuzov et al. (2002) model formulation also falls into this category. 
Miller (1980) developed one of the earliest transient wellbore simulators, which accounts for changes in geothermal-fluid energy while flowing up the wellbore. In this model, mass and momentum equations are combined with the energy equation to yield an expression for pressure. After solving for pressure, density, energy, and velocity are calculated for the new timestep at a well gridblock. Hasan and Kabir presented wellbore/reservoir simulators for gas, oil and two-phase flows (2002). Their formulation consists of solution of coupled mass, momentum, and energy equations, all written in finite-difference form, and requires time-consuming separate matrix operations. In all cases, the wellbore model is coupled with an analytic reservoir model. Fan et al. (2000) developed a wellbore simulator for analyzing gas-well buildup tests. Their model uses a finite-difference scheme for heat transfer in vertical direction. The heat loss from fluid to the surroundings in radial direction is represented by an analytical model. 


\subsection{OBJECTIVES}

An efficient and accurate wellbore model can be used for studying various problems such as flow-assurance issues including formation of wax, hydrate, asphaltene and timing of chemical injection, translating pressure-transient data when gathered above the perforations, production rate estimation by just using wellhead temperatures, and prediction of annular pressure buildup occurring in most subsea completed wells due to thermal expansion of trapped annulus fluids.

The main objective of this work is to develop a robust finite-difference transient wellbore simulator coupled with an analytic temperature model for computing wellborefluid-temperature and pressure profiles in flowing and shut-in wells.

In this model, matrix operations are eliminated for the energy calculations with the development of analytic temperature formulations. This efficient coupling with the analytic heat-transfer model provided the much needed gain in computational speed for industry applications. The analytic temperature formulations are fit-for-purpose models and can be turned on or off depending on the type of the problem studied. For short term well tests a numerical differentiation scheme is developed in addition to the pure analytical solutions.

The accuracy of the flowing fluid calculations is improved by accounting for transient heat flow through the surrounding formation. This application requires generation of radial grids around each wellbore segment. The numbers of radial grids and distance to be covered into the formation are user inputs.

The new wellbore model is used to develop a comprehensive understanding of the gauge-placement issue. Initially, a field example from a deepwater asset is reproduced to demonstrate the simulator's capabilities. Calculations show that thermal effects are exacerbated by increasing flow rate and increasing gauge distance from the perforations.

A detailed uncertainty analysis revealed clues on the effect of perforation-togauge distance to extract formation parameters. Simple correlations are developed for 
designing gauge placement in many environments. We probed both oil and gas flow problems in a systematic way to arrive at simple design tools for rapid evaluation of acceptable gauge depth. In this context, the role of secondary gauge located at the mudline is examined.

Another part of this study attempts to address the annular pressure buildup issue for subsea completed wells. Pressure from fluid expansion is a natural occurrence in all wells. An explanation for the cause and effect of this type of pressure in addition to the cause and effect of pressure from external sources are examined. 


\section{CHAPTER II}

\section{WELLBORE FLUID TEMPERATURE MODEL}

\subsection{SEMIANALYTIC FLUID-TEMPERATURE MODEL}

The analytic heat-transfer model used in this study was initially presented by Hasan et al. (2005) for transient gas-well testing. The present work includes the extension of the formulation to liquid phase. Also, the assumptions of zero mass flux during a buildup and constant mass flux during a drawdown have been replaced by variable-rate formulations, which, in turn, gave us the flexibility to mimic energy transport during afterflow and multirate tests. For shut-in tests a new formulation for the heat conduction in vertical direction has also been developed.

\subsubsection{Energy balance for wellbore fluid}

Temperature difference between the wellbore fluid and the surrounding formation results in energy exchange. A general energy balance for either a single or two phase system can be performed on a given volume element as shown in Fig. 2.1.

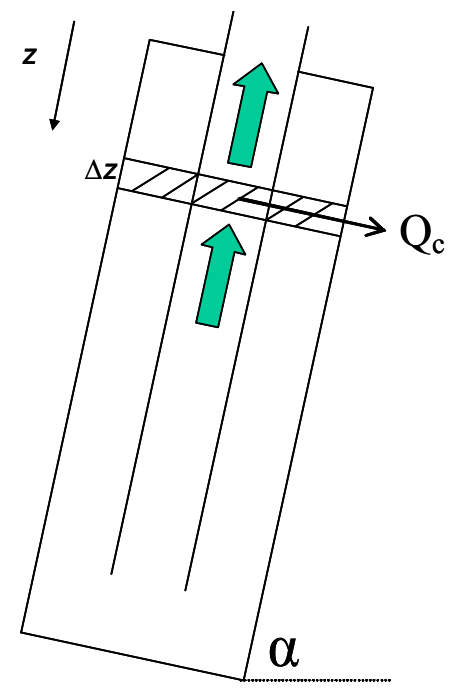

Fig. 2.1 Control volume used to derive heat transfer equations 
The length of the control volume on the figure is $\Delta z$. Fluid enters from $z$ and leaves the control volume at $(z+\Delta z)$. The amount of heat $(w H)$ enters the element at $(z+$ $\Delta z$ ) by convection. Heat loss to the formation by conduction adds the $Q$ term to the equation.

The steady-state energy balance on the control volume gives;

$$
\begin{aligned}
& \left((w H)_{z}-(w H)_{z+\Delta z}\right)+\frac{1}{2 g_{c}}\left(\left(w v^{2}\right)_{z}-\left(w v^{2}\right)_{z+\Delta z}\right)+ \\
& \frac{1}{g_{c}}\left(z(w g \sin \alpha)_{z}-(z+\Delta z)(w g \sin \alpha)_{z+\Delta z}\right)=Q_{c} \Delta z
\end{aligned}
$$

In Eq.2.1 $w$ is mass flux rate, $H$ is enthalpy, $v$ is velocity and $Q$ represents the heat transfer rate between wellbore fluid and formation and is negative for production and positive for injection. The first term on the left gives the amount of heat entering and leaving the control volume by convection. The second and third terms represent the changes in kinetic and potential energy of the system. The only term on the right hand side accounts for the conductive heat lost to the formation.

Dividing by $\Delta z$ and taking the limit as $\Delta z \rightarrow 0$, we have;

$$
\frac{\partial H}{\partial z}+\frac{g \sin \alpha}{g_{c}}+\frac{v}{g_{c}} \frac{\partial v}{\partial z}=Q_{c} / w
$$

For a single phase fluid with no phase changes, enthalpy is a function of pressure and temperature.

$$
\partial H=\frac{\partial H}{\partial T} \partial T+\frac{\partial H}{\partial p} \partial p=c_{p} \partial T-c_{p} c_{j} \partial p
$$


Where $c_{p}$ is the heat capacity of the fluid at constant pressure and $c_{j}$ is the JouleThompson coefficient. Combining Eq.2.3 with Eq.2.2 gives an expression for fluid temperature as a function of depth,

$$
\frac{\partial T_{f}}{\partial z}=c_{j} \frac{\partial p}{\partial z}+\frac{1}{c_{p}}\left[\frac{Q_{c}}{w}-\frac{g \sin \alpha}{g_{c}}-\frac{v}{g_{c}} \frac{\partial v}{\partial z}\right]
$$

\subsubsection{Energy balance for wellbore fluid and tubular systems}

The energy balance is written by noting the conductive heat loss to the formation, plus the convective energy transport into and out of the control volume of unit length. In terms of fluid internal energy, $E$, fluid enthalpy, $H$, fluid mass flow rate, $w$, fluid mass in

control volume, $m$, and the internal energy and the mass of the wellbore system (the tubular and cement sheaths combined $),\left(m^{\prime} E\right)_{w}$, the energy balance equation gives;

$$
Q=\frac{\partial(m E)_{c v}}{\partial t}+\frac{\partial(m E)_{w}}{\partial t}-\frac{\partial}{\partial z}\left[w H+\frac{w v^{2}}{2}-w g z \sin \theta\right]
$$

The first lumped term represents the rise in fluid temperature at any time. The second term on the right side of this equation represents the energy absorbed or released by the tubular material and cement sheets in the wellbore. Omitting this term can lead to serious error as was noted in the literature since it accounts for a significant fraction of the total energy exchange between the wellbore and the formation. The third term on the left side of the equation can be simplified as; 


$$
\begin{aligned}
& \frac{\partial}{\partial z}\left[w H+\frac{w v^{2}}{2}-w g z \sin \theta\right]=w\left[\frac{\partial}{\partial z} H+\frac{\partial}{\partial z} \frac{v^{2}}{2}-g \sin \theta\right] \\
& =w\left[c_{p} \frac{\partial T_{f}}{\partial z}+c_{j} c_{p} \frac{\partial P}{\partial z}+v \frac{\partial v}{\partial z}-g \sin \theta\right]
\end{aligned}
$$

The heat received from or lost to the formation, $Q$, is given by;

$$
Q=w c_{p}\left(T_{e i}-T f\right) L_{R}
$$

In this equation $T_{e i}$ is the initial earth temperature and $T_{f}$ corresponds to the wellbore fluid temperature. $L_{R}$ is the relaxation distance parameter which is given by Eq. 2.8. Relaxation distance parameter $L_{R}$ is related to the solution of diffusivity equation for the formation temperature distribution and details on this derivation is provided in Appendix A.

$$
L_{R}=\frac{2 \pi}{w c_{p}}\left[\frac{r_{t o} U_{t o} k_{e}}{k_{e}+r_{t o} U_{t o} T_{D}}\right]
$$

Respectively $U_{t o}, k_{e}$, and $r_{t o}$ are overall heat-transfer coefficient, formation conductivity and tubing outside radius. Dimensionless temperature is represented by $T_{D}$. Detailed derivation of dimensionless temperature is provided in Appendix A.

The temperature rise of the cement and tubular material may be taken to be a fraction of the rise in the fluid temperature at any time (Hasan and Kabir, 2005). In that case it can be written;

$$
(m E)_{w}=C_{T} *(m E)_{c v}
$$


The thermal storage parameter $C_{T}$ represents the capacity of the wellbore to store or release heat as a multiple of the fluid mass and fluid heat capacity. Using this relationship, the first term on the energy balance equation can be written as;

$$
\frac{\partial}{\partial t}\left[(m E)_{f}+(m E)_{w}\right]=\frac{\partial}{\partial t}\left[m C_{p} T_{f}\left(1+C_{T}\right)\right]
$$

Incorporating Eq. 2.10 into Eq 2.5 the new form becomes

$$
Q=\frac{\partial}{\partial t}\left[m C_{p} T_{f}\left(1+C_{T}\right)\right]-\frac{\partial}{\partial z}\left[w H+\frac{w v^{2}}{2}-w g z \sin \theta\right]
$$

The enthalpy, kinetic energy and potential energy terms can be written using Eq.2.6 as

$$
Q=\frac{\partial}{\partial t}\left[m C_{p} T_{f}\left(1+C_{T}\right)\right]-w\left[c_{p} \frac{\partial T_{f}}{\partial z}+c_{j} c_{p} \frac{\partial P}{\partial z}+v \frac{\partial v}{\partial z}-g \sin \theta\right]
$$

Heat lost to the formation is accounted by Eq.2.7. Incorporating the heat transfer between tubing fluid and formation, the equation becomes

$$
w c_{p}\left(T_{e i}-T f\right) L_{R}=\frac{\partial}{\partial t}\left[m C_{p} T_{f}\left(1+C_{T}\right)\right]-w\left[c_{p} \frac{\partial T_{f}}{\partial z}+c_{j} c_{p} \frac{\partial P}{\partial z}+v \frac{\partial v}{\partial z}-g \sin \theta\right]
$$

Combining Joule-Thompson effect and kinetic energy contribution into a term $\Phi$

$$
w c_{p}\left(T_{e i}-T f\right) L_{R}=\frac{\partial}{\partial t}\left[m C_{p} T_{f}\left(1+C_{T}\right)\right]-w c_{p}\left[\frac{\partial T_{f}}{\partial z}+\phi-\frac{g \sin \theta}{c_{p}}\right]
$$


Upon manipulation the final form of the energy balance equation for fluid temperature in time as a linear differential equation can be written as;

$$
\frac{\partial T_{f}}{\partial t}=\frac{w c_{p} L_{R}}{m c_{p}\left(1+C_{T}\right)}\left(T_{e i}-T_{f}\right)+\frac{w c_{p}}{m c_{p}\left(1+C_{T}\right)}\left[\frac{\partial T_{f}}{\partial z}+\phi-\frac{g \sin \theta}{c_{p}}\right]
$$

The final form of the equation accounts for the energy released or absorbed by the tubulars and cement sheet. Unlike Ramey's approximation the difference between loss in enthalpy and static head is also incorporated.

\subsubsection{Analytic heat transfer models}

\subsubsection{Drawdown}

The differential form of the analytic temperature model can be derived by writing an energy balance on the differential length of the wellbore. In this energy balance equation conductive heat loss to the formation and convective energy transport into and out of the control volume are considered.

An energy balance on the cement sheath, tubulars, and wellbore fluid provides the following expression for fluid temperature in time as presented before.

$$
\frac{\partial T_{f}}{\partial t}=\frac{w c_{p} L_{R}}{m c_{p}\left(1+C_{T}\right)}\left(T_{e i}-T_{f}\right)+\frac{w c_{p}}{m c_{p}\left(1+C_{T}\right)}\left[\frac{\partial T_{f}}{\partial z}+\phi-\frac{g \sin \theta}{C_{p}}\right]
$$

The derivative of fluid temperature with respect to depth can be approximated with solution provided by a steady-state system. The equation for a steady-state system excluding transient terms can be written as 


$$
T_{f}=T_{e i}+\frac{1-e^{(z-l) L_{R}}}{L_{R}} \psi
$$

Where

$$
\psi=g_{G} \sin \theta+\phi-\frac{g \sin \theta}{J g_{c} C_{p}}
$$

The steady-state expression of fluid temperature as a function of depth becomes

$$
\frac{\partial T_{f}}{\partial z}=g_{G} \sin \theta\left[1-e^{(z-L) L_{R}}\right]=g_{G} \sin \theta-e^{(z-L) L_{R}} \psi
$$

Defining a lumped variable $a$ as

$$
a=\frac{w c_{p}}{m c_{p}\left(1+C_{T}\right)}
$$

Incorporating Eqs. 2.17 and 2.18 into 2.15 and using the lumped parameter, the working equation becomes

$$
\frac{\partial T_{f}}{\partial t}=a L_{R}\left(T_{e i}-T_{f}\right)+a\left[g_{G} \sin \theta-e^{(z-L) L_{R}} \psi+\phi-\frac{g \sin \theta}{c_{p}}\right]
$$


Eq. 2.20 can be integrated by using the method of integrating factors. An appropriate form to construct the result of the product rule of differentiation on the lefthand side, the equation can be arranged as,

$$
\frac{\partial T_{f}}{\partial t}+a L_{R} T_{f}=a L_{R} T_{e i}+a\left[g_{G} \sin \theta-e^{(z-L) L_{R}} \psi+\phi-\frac{g \sin \theta}{C_{p}}\right]
$$

The integrating factor is given as

$$
\text { Integrating Factor }=\exp \left\{\int a L_{R} T_{f} \partial t\right\}=e^{a L_{R} t}
$$

Multiplying both sides of Eq. 2.22 by the integrating factor and integrating gives

$$
T_{f}=\frac{1}{e^{a L_{R} t}} \int\left\{a L_{R} T_{e i}+a\left[g_{G} \sin \theta-e^{(z-L) L_{R}} \psi+\phi-\frac{g \sin \theta}{C_{p}}\right] e^{a L_{R} t}\right\} \partial t
$$

The integration constant obtained by integrating Eq. 2.23 can be found by applying the initial condition. At $t=0$, the fluid temperature is assumed to be equal to the initial undisturbed formation temperature, $T_{e i}$. The final form of the analytic fluidtemperature model during production is given by

$$
T_{f}=T_{e i}+\frac{1-e^{a L_{R} t}}{L_{R}}\left[1-e^{(z-L) L_{R}}\right] \psi
$$

Eq. 2.24 provides an expression for fluid temperature as a function of time. By this equation fluid temperature for every well segment can be calculated independently. 


\subsubsection{Buildup}

Shut-in tests are conducted to in wells to estimate the formation permeability, reservoir pressure and size. It is generally assumed that pressure data collected in the wellbore is representative of reservoir excluding any wellbore phenomena. Following well shut-in at the surface afterflow at the sandface can persist for sometime. However, it can be assumed that rate variation with depth becomes negligible quickly. Assuming zero mass flux after shut-in, Eq.2.5 on the wellbore system becomes

$$
Q=\frac{\partial(m E)_{c v}}{\partial t}+\frac{\partial(m E)_{w}}{\partial t}
$$

The heat lost to the formation during shut-in is

$$
Q=w c_{p}\left(T_{e i}-T_{f}\right) L_{R}{ }^{\prime}
$$

The overall heat transfer coefficient for the shut-in excluding the mass flux is defined as;

$$
L_{R}^{\prime}=\frac{2 \pi}{c_{p}}\left[\frac{r_{t o} U_{t o} k_{e}}{k_{e}+r_{t o} U_{t o} T_{D}}\right]
$$

Following the same approach used in drawdown derivations, the differential equation becomes

$$
\frac{\partial T_{f}}{\partial t}=\frac{L_{R}^{\prime}}{m\left(1+C_{T}\right)}\left(T_{e i}-T_{f}\right)
$$

Again defining a lumped parameter $a$ as 


$$
a^{\prime}=\frac{L_{R}^{\prime}}{m\left(1+C_{T}\right)}
$$

Arranging the equation for the integrating factors method, the final expression for fluid temperature after shut-in is

$$
\frac{\partial T_{f}}{\partial t}+a^{\prime} T_{f}=a^{\prime} T_{e i}
$$

The integrating factor for the solution of the partial differential equation is found by

$$
\text { Integrating Factor }=\exp \left\{\int a^{\prime} \partial t\right\}=e^{a t}
$$

Multiplying both sides of Eq. 2.30 by the integrating factor and integrating, gives

$$
T_{f}=\frac{1}{e^{a^{\prime} t}} \int\left\{a^{\prime} T_{e i} e^{a^{\prime} t}\right\} \partial t
$$

Integral Eq.2.32, the final solution for fluid temperature in time is

$$
T_{f}=C e^{-a^{\prime} t}+T_{e i}
$$

The integration constant can be found by applying the initial condition after the shut-in. At $t=\Delta t$, the fluid temperature at current time step $\left(T_{f}^{n+1}\right)$ is assumed to be equal to the previous time level temperature, $T_{f}^{n}$.

The final form of the analytic fluid-temperature model during shut-in period is given by 


$$
T_{f}^{n+1}=\left(T_{f}^{n}-T_{e i}\right) e^{-a t}+T_{e i}
$$

\subsubsection{Buildup with after-flow effects}

This section presents an analytic fluid-temperature model for buildup with afterflow effects. Beginning with Eq. 2.15,

$$
\frac{d T_{f}}{d t}=\frac{{ }^{w c} c_{p}{ }_{R}}{m c_{p}\left(1+C_{T}\right)}\left(T_{e i}-T_{f}\right)+\frac{{ }^{w c} p}{m c_{p}\left(1+C_{T}\right)}\left[\frac{d T_{f}}{d z}+\phi-\frac{g \sin \theta}{C_{p}}\right]
$$

The steady-state expression of fluid temperature as a function of depth is given by Eq.2. 18 .

$$
\frac{d T_{f}}{d z}=g_{G} \sin \theta\left[1-e^{(z-L) L}{ }_{R}\right]=g_{G} \sin \theta-e^{(z-L) L_{R}} \psi
$$

Defining a lumped variable $a$ as in Eq 2.15

$$
a=\frac{w c_{p}}{m c_{p}\left(1+C_{T}\right)}
$$

Using the relaxation parameter, $L_{R}$ definition given in Eq.2.8

$$
L_{R}=\frac{2 \pi}{w c_{p}}\left[\frac{r_{t o} U_{t o} k_{e}}{k_{e}+r_{t o} U_{t o} T_{D}}\right]
$$

where

$$
T_{D}=\ln \left[e^{\left(-0.2 t_{D}\right)}+\left(1.5-0.3719 e^{-t_{D}}\right)\right] \sqrt{t_{D}}
$$


Incorporating Eqs. 2.18 and 2.19 into 2.15, the working equation becomes

$$
\frac{d T_{f}}{d t}=a L_{R} T_{e i}-a L_{R} T_{f}+a\left[g_{G} \sin \theta-e^{(z-L) L}{ }_{R} \psi+\phi-\frac{g \sin \theta}{C_{p}}\right]
$$

Eq. 2.36 can be integrated by using the method of integrating factors. An appropriate form to construct the result of the product rule of differentiation on the left-hand side, the equation can be arranged as

$$
\frac{d T_{f}}{d t}+a L_{R} T_{f}=a L_{R} T_{e i}+a\left[g_{G} \sin \theta-e^{(z-L) L_{R}} \psi+\phi-\frac{g \sin \theta}{C_{p}}\right]
$$

The integrating factor is found by

$$
I=\exp \left\{\int_{R} a L_{f}^{T} d t\right\}=e^{a L_{R} t}
$$

Multiplying both sides of Eq. 2.37 by the integrating factor and integrating gives

$$
T_{f}=\frac{1}{e^{a L_{R} t}} \int\left\{a L_{R} T_{e i}+a\left[g_{G} \sin \theta-e^{(z-L) L_{R}} \psi+\phi-\frac{g \sin \theta}{C_{p}}\right] e^{a L_{R} t}\right\} d t
$$


The integration constant obtained by integrating Eq. 2.39 can be found by applying the initial condition. At $\Delta t=0$, the fluid temperature is assumed to be equal to the fluid temperature prior to shut-in, $T_{f o}$. The final form of the analytic fluid-temperature model is given by

$$
T_{f}=T_{e i}\left(1-e^{-a L_{R} t}\right)+T_{f o} e^{-a L_{R} t}+\frac{1-e^{-a L_{R} t}}{L_{R}}\left[1-e^{(z-L) L_{R}}\right] \psi
$$

This expression can be used to calculate the changes in fluid temperature when the afterflow effects are dominant. Another form for wellbore segments with zero mass flow rate after shut-in can be derived using the same initial condition with zero mass flux throughout the column. The resulting form is given by

$$
T_{f}^{n+1}=\left(T_{f}^{n}-T_{e i}\right) e^{-a t}+T_{e i}
$$




\subsubsection{Buildup with vertical heat transfer}

Most of the temperature models in the open literature account for radial heat loss to the surrounding formation only. During a shut-in test each wellbore grid not only looses heat to the formation but to the upper and lower grid cells as well. Especially for offshore wells vertical heat conduction at the mudline becomes important. In this section we will develop an analytical model to calculate the temperature profile during a buildup test with consideration of vertical heat transfer. Conducting the same energy balance on a given volume element as shown in Fig. 2.2 but accounting for heat conduction in vertical direction gives us the desired formulation.

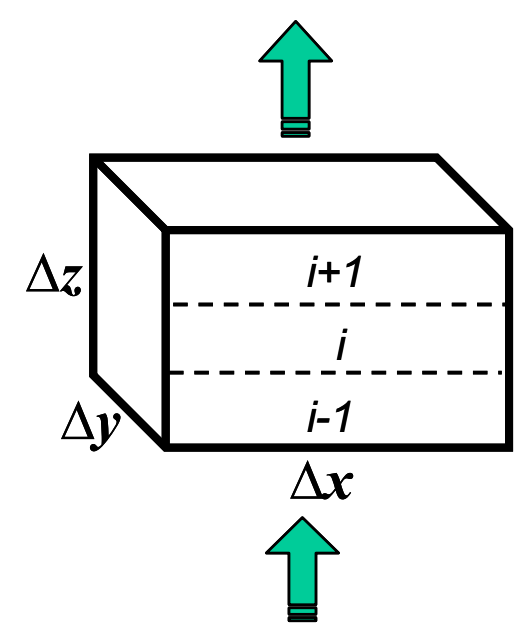

Fig. 2.2 Control volume and nodes for heat conduction in vertical direction

The amount of heat coming in and going out of node " $i$ ” according to Fourier's law is

$$
\begin{aligned}
& \text { Rate of Heat In }=-k A \frac{T_{i-1}^{n}-T_{i}^{n}}{\Delta z} \\
& \text { Rate of Heat Out }=-k A \frac{T_{i}^{n}-T_{i+1}^{n}}{\Delta z}
\end{aligned}
$$


Formation conductivity and flow area is denoted as $k$ and $A$ respectively. Incorporating Eq. 2.41 and Eq.2.42 into a more general energy balance equation for the volume element " $i$ " one can obtain

$$
\begin{aligned}
& \left((w H)_{z}-(w H)_{z+\Delta z}\right)+\frac{1}{2 g_{c}}\left(\left(w v^{2}\right)_{z}-\left(w v^{2}\right)_{z+\Delta z}\right)+\frac{1}{g_{c}}\left((w g \sin \alpha)_{z}-(w g \sin \alpha)_{z+\Delta z}\right) \\
& -k A \frac{T_{i}^{n}-T_{i-1}^{n}}{\Delta z}= \pm Q_{c} \Delta z-k A \frac{T_{i-1}^{n}-T_{i}^{n}}{\Delta z}
\end{aligned}
$$

Upon manipulation and accounting for the energy absorbed or released by the tubular material and cement sheets Eq.2.43 becomes

$$
Q+k A \frac{\Delta T}{\Delta z^{2}}=\frac{\partial(m E)_{c v}}{\partial t}+\frac{\partial(m E)_{w}}{\partial t}-\frac{\partial}{\partial z}\left[w H+\frac{w v^{2}}{2}-w g z \sin \theta\right]
$$

The conduction term is given as

$$
k A \frac{\Delta T}{\Delta z^{2}}=k A \frac{T_{i+1}^{n}-2 T_{i}^{n}+T_{i-1}^{n}}{\Delta z^{2}}
$$

Note that the temperature terms in the conduction equation are evaluated at the old time level. If an iterative scheme is employed the old time values can be used as initial estimates and the conduction term can be evaluated as at new time step.

Incorporating Eq's 2.10 and 2.25 


$$
\frac{\partial T_{f}}{\partial t}=\frac{L_{R}{ }^{\prime}}{m\left(1+C_{T}\right)}\left(T_{e i}-T_{f}\right)+k A \frac{\Delta T}{\Delta z^{2}} \frac{1}{m c_{p}\left(1+C_{T}\right)}
$$

Defining the lumped parameter " $a$ " "as in previous section the final form is

$$
\frac{\partial T_{f}}{\partial t}+a^{\prime} T_{f}=a^{\prime} T_{e i}+k A \frac{\Delta T}{\Delta z^{2}} \frac{1}{m c_{p}\left(1+C_{T}\right)}
$$

This equation can be solved using integrating factors method. Using the same integrating factor defined previously

$$
\text { Integrating Factor }=\exp \left\{\int a^{\prime} \partial t\right\}=e^{a t}
$$

The equation for new time level temperature becomes

$$
T_{f}=\frac{1}{e^{a^{\prime} t}} \int\left\{a^{\prime} T_{e i} e^{a^{\prime} t}+k A \frac{\Delta T}{\Delta z^{2}} \frac{1}{m c_{p}\left(1+C_{T}\right)} e^{a^{\prime} t}\right\} \partial t
$$

Taking the integral

$$
T_{f}=C e^{-a^{\prime} t}+T_{e i}+k A \frac{\Delta T}{\Delta z^{2}} \frac{1}{m c_{p}\left(1+C_{T}\right) a^{\prime}}
$$

Applying the initial condition after the shut-in the integration constant can be written as 


$$
C=T_{f}^{n}-T_{e i}-k A \frac{\Delta T}{\Delta z^{2}}\left(L_{R}^{\prime}\right)^{-1}
$$

\subsubsection{Comparison with Ramey's model}

Almost all practical methods for calculation of temperature profiles in the wellbores go back to the work by Ramey on wellbore heat transmission published in early 1960's. In the original paper, Ramey presented an analytical equation for wellbore temperatures based on a simplified heat balance. As shown previously, beginning with a simple energy balance one can obtain an expression for fluid temperature as a function depth

$$
\frac{\partial T_{f}}{\partial z}=c_{j} \frac{\partial p}{\partial z}+\frac{1}{c_{p}}\left[\frac{Q_{c}}{w}-\frac{g \sin \alpha}{g_{c}}-\frac{v}{g_{c}} \frac{\partial v}{\partial z}\right]
$$

The heat received from or lost to the formation, $Q$, is given by;

$$
Q=-2 \pi r_{t o} U_{t o}\left(T_{f}-T_{w b}\right)
$$

In Ramey's formulation heat loss to the formation is represented as

$$
Q=\frac{-2 \pi k}{f(t)}\left(T_{w b}-T_{e i}\right)
$$

Combining equations 2.52 and 2.53 he obtained

$$
Q=\frac{-w c}{A}\left(T_{f}-T_{e i}\right)
$$


The term " $A$ " is the inverse of parameter " $L_{R}$ " defined by Eq.2.8. Ramey's equation include the time function $f(t)$ which is estimated from plotted solutions for an infinitely long cylinder loosing heat at constant temperature. The shorter version of the solution he provided becomes valid after about one week. Incorporating the "A" parameter into Eq.2.14,

$$
\frac{\partial T_{f}}{\partial z}=\frac{\left(T_{f}-T_{e i}\right)}{A}-\frac{g \sin \alpha}{J c_{p} g_{c}}-\frac{v}{J c_{p} g_{c}} \frac{\partial v}{\partial z}+c_{j} \frac{\partial p}{\partial z}
$$

Ramey assumed steady-state flow of an incompressible single phase fluid; he dropped the kinetic energy term. Also, under these assumptions the loss in potential energy becomes approximately equal to the increase in enthalpy. Eq. 2.55 becomes,

$$
\frac{\partial T_{f}}{\partial z}=\frac{1}{A}\left[T_{f}-\left[T_{e i}-(L-z) g \sin \alpha\right]\right]
$$

Solving Eq.2.56 with integrating factors method and applying the boundary conditions the final form for a producing well is

$$
T_{f}=T_{e i}-g \sin \alpha\left[(L-z)-\left(1-\exp \left(\frac{(z-L)}{A}\right)\right) A\right]
$$

Fig. 2.3 and Fig.2.4 show the comparison with Ramey model for two drawdown tests. The first example is a low rate production for $3000 \mathrm{stb} / \mathrm{D}$ and the second example is a multi-rate test with the maximum production rate of $16,000 \mathrm{stb} / \mathrm{D}$. 


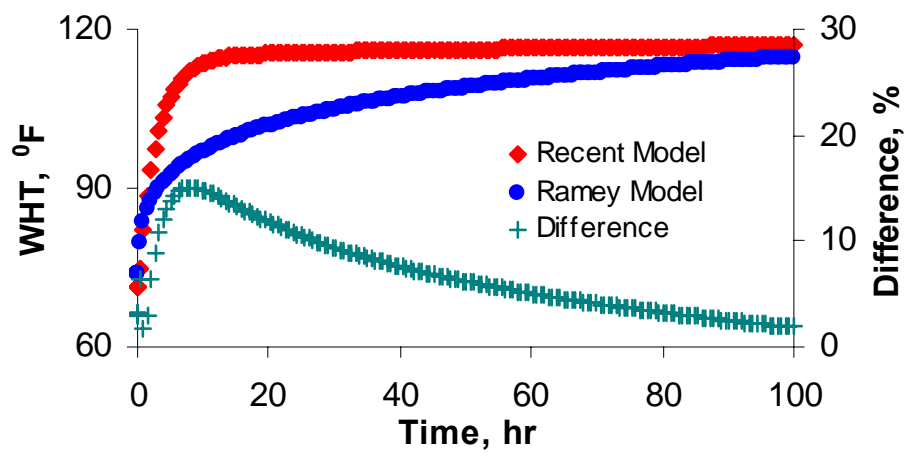

Fig. 2.3 Drawdown test for low production rate

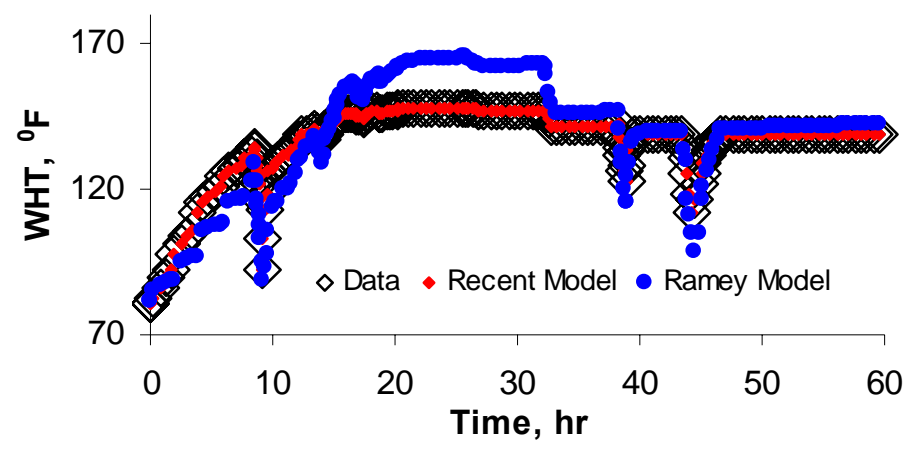

Fig. 2.4 Multirate drawdown test for a maximum rate of $16,000 \mathrm{stb} / \mathrm{D}$ 


\subsection{NUMERICAL DIFFERENTIATION FOR SHORT TERM TESTS}

As shown in previous chapter, the analytic model can be derived by conducting an energy balance on a differential length of a wellbore. In this energy balance equation, conductive heat loss to the formation and convective energy transport into and out of the control volume are considered. The resulting differential equation for change in fluid temperature with respect to time is given by

$$
\frac{\partial T_{f}}{\partial t}=\frac{w c_{p} L_{R}}{m c_{p}\left(1+C_{T}\right)}\left(T_{e i}-T_{f}\right)+\frac{w c_{p}}{m c_{p}\left(1+C_{T}\right)}\left[\frac{\partial T_{f}}{\partial z}+\phi-\frac{g \sin \theta}{C_{p}}\right]
$$

Eq. 2.11 provides an expression for fluid temperature as a function of time, which can be used for both drawdown and buildup calculations after applying the appropriate boundary conditions. This equation needs to be integrated by using the integrating-factors method to obtain an expression for fluid temperature. However, no solution is feasible unless some restrictive assumptions are made. These assumptions are

- Constant relaxation parameter, $L_{R}$

- Steady-state temperature expression for the $\mathrm{d} T_{f} / \mathrm{d} z$ term

The steady-state $\mathrm{d} T_{f} / \mathrm{d} z$ term can provide a misleading trend of computed bottomhole pressures for a transient flow problem at early times. The results obtained from this type of approximation become closer to reality as time increases.

We developed a new approach to improve the analytical fluid-temperature solution. The constant relaxation-parameter assumption is replaced by a hybrid NewtonBackward Euler scheme. The relaxation parameter, $L_{R}$ (Hasan and Kabir, 2002), which is the inverse of the parameter, $A$, defined by Ramey (1962) is given as 


$$
L_{R}=\frac{2 \pi}{w c_{p}}\left[\frac{r_{t o} U_{t o} k_{e}}{k_{e}+r_{t o} U_{t o} T_{D}}\right]
$$

Where

$$
T_{D}=\ln \left[e^{\left(-0.2 t_{D}\right)}+\left(1.5-0.3719 e^{-t_{D}}\right)\right] \sqrt{t_{D}}
$$

Eq. 2.59 suggests that the expression not only contains thermal properties of both the formation and wellbore, but also the dimensionless temperature, $T_{D}$, and overall-heattransfer coefficient, $U_{t o}$. Although $T_{D}$ is a weak function of time at late times, the constant- $L_{R}$ assumption may not work well for early transients, especially for a drawdown test. Because wellbore diameter may vary with depth, the overall heat-transfer coefficient generally depends on axial position. In addition, changes in heat-transfer coefficient of the tubing/casing annular fluid with temperature often cause $U_{t o}$ to be a function of time as well.

Numerical differentiation can be used to eliminate the constant relaxationparameter assumption in analytical fluid temperature model.

Starting with Eq. 2.15, we have

$$
\frac{\partial T_{f}}{\partial t}=\frac{w c_{p} L_{R}}{m c_{p}\left(1+C_{T}\right)}\left(T_{e i}-T_{f}\right)+\frac{w c_{p}}{m c_{p}\left(1+C_{T}\right)}\left[\frac{\partial T_{f}}{\partial z}+\phi-\frac{g \sin \theta}{C_{p}}\right]
$$

Incorporating the steady-state fluid temperature with depth approximation, a general form of the partial differential equation as a function of time and fluid temperature can be written for further development as follows: 


$$
\frac{\partial T_{f}}{\partial t}=f\left(T_{f}, t\right)
$$

In the initial estimation of next time level, the fluid temperature can be obtained from forward Euler method. Forward Euler is given as

$$
T_{f_{j+1}}=T_{f_{j}}+\Delta t f\left(T_{f_{j}}, t_{j}\right)
$$

where $j$ denotes the time index. In the next iteration of new time level, the fluid temperature is obtained from a combined backward Euler-Newton type procedure. Backward Euler introduces an implicit solution and is far more superior to forward Euler in terms of stability because it is unconditionally stable and allows larger time steps. It is given as

$$
T_{f_{j+1}}=T_{f_{j}}+\Delta t f\left(T_{f_{j+1}}, t_{j+1}\right)
$$

With the backward Euler method, the solution becomes iterative because the solution at the new timestep is dependent on itself. The residual form of backward Euler is given by

$$
R=T_{f_{j+1}}-T_{f_{j}}-\Delta t f\left(T_{f_{j+1}}, t_{j+1}\right)
$$

The combined form of backward Euler and Newton-Raphson iteration scheme, shown below, provides an efficient algorithm for faster convergence.

$$
T_{f_{j+1}^{k}}^{k}=T_{f_{j+1}^{k-1}}^{k}-\frac{R}{\partial R / \partial T_{f_{j+1}}}
$$


The iteration index is denoted as " $k$ " and the derivative of the residual equation is given as

$$
\frac{\partial R}{\partial T_{f_{j+1}}}=\frac{\partial}{\partial T_{f_{j+1}}}\left[T_{f_{j+1}}-T_{f_{j}}-\Delta t f\left(T_{f_{j+1}}, t{ }_{j+1}\right)\right]
$$

Incorporating the generalized function defined by Eq. 2.14 and steady-state $\mathrm{d} T_{f} / \mathrm{d} z$ term, we have

$$
\frac{\partial R}{\partial T_{f_{j+1}}}=\frac{\partial}{\partial T_{f_{j+1}}}\left[T_{f_{j+1}}-T_{f_{j}}-\Delta t\left(a L_{R}\left(T_{e i}-T_{f_{j+1}}\right)+a\left[\frac{\partial T_{f}}{\partial z}+\phi-\frac{g \sin \theta}{C_{p}}\right]\right)\right]
$$

The final expression for the derivative of the residual equation is

$$
\frac{\partial R}{\partial T_{f_{j+1}}}=1+\Delta t \frac{w c_{p} L_{R}}{m c_{p}\left(1+C_{T}\right)}
$$

The iteration continues until the difference in fluid temperature obtained from two successive steps approaches predetermined convergence criteria. The solution provided by this methodology is implicit in nature and provides an efficient algorithm for fast convergence and stability. 


\subsection{HEAT TRANSFER RATE IN ANNULUS}

In a well/reservoir system heat is transferred from the wellbore fluid to the formation overcoming the resistances offered by the tubing wall, tubing insulation, tubing-casing annulus casing wall and cement. These resistances are in series and except for the annulus the only heat transfer mechanism involved is conductive heat transfer.

Ramey (1962) and Willhite (1967) presented detailed discussions that lead to the following steady-state equation for heat transfer rate, $d q / d z$ and the wellbore temperature $T_{w b}$. Usually natural convection is the dominant heat transfer mechanism for the fluid in the annulus. Also resistance through the cement layer could be important depending on its thickness. Over-all heat transfer coefficient, $U_{t o}$ in Eq.2.65 is based on the tubing inside area and temperature difference between wellbore fluid and wellbore-formation interface. Heat transfer coefficient represents the resistances offered by different material around tubing.

$$
\frac{d q}{d z}=-\frac{2 \pi r_{t o} U_{t o}}{w}\left(T_{f}-T_{w b}\right)
$$

The derivation of overall heat transfer coefficient assumes that heat flow rate through the each element is same, which corresponds to steady-state behavior. Heat flow through the tubing wall, casing wall and the cement sheath occurs by conduction. However, heat transfer process in the liquid filled annulus is not a steady-state process and involves three different types of heat transfer mechanisms.

Heat is conducted through the fluid contained in the annulus. Radiation and natural convection also takes place. Radiation, natural convection and conduction are independent heat transfer mechanisms. Therefore, the total heat flow in the annulus is the sum of heat transferred by each of those mechanisms. 
Heat transfer by natural convection in the annulus between the tubing and casing is caused by fluid motion as shown in Fig. 2.5.

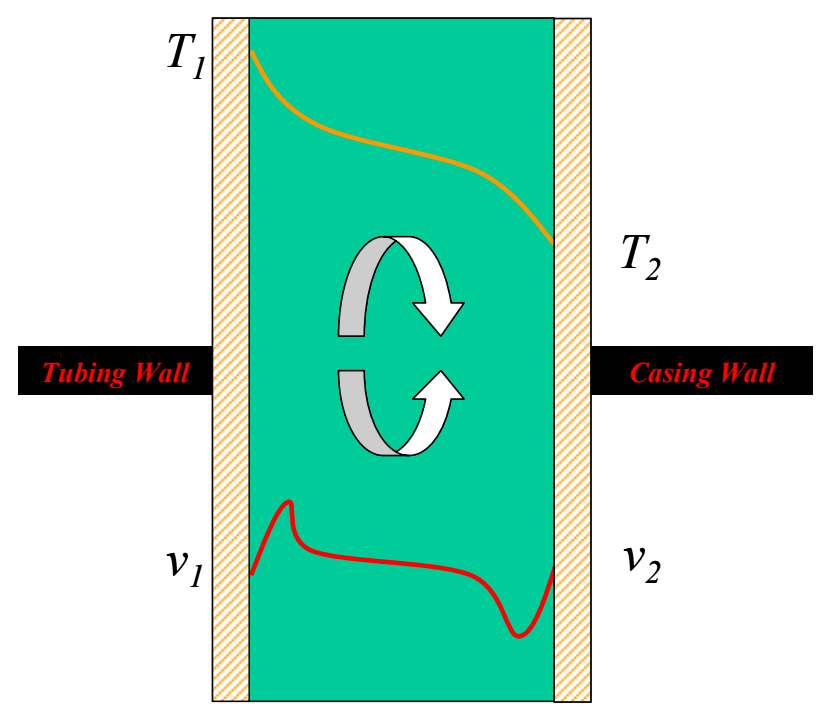

Fig. 2.5 Heat transfer by natural convection in annulus

The fluid motion is resulting from the variation in density with temperature. Hot fluid near the tubing wall is less than the fluid in the center of the annulus and tends to rise. Similarly, the fluid near the casing wall is cooler compared to the fluid in the center and tends to fall under gravitational forces.

In most cases of oil production, the temperature difference across the annulus is small and one needs to consider convective heat transfer only. Unfortunately, no work on natural convection in vertical annular geometry is reported in the literature. This work adapts the correlation proposed by Dropkin and Sommerscales (1965) for heat transfer coefficient for natural convection in fluid between two vertical plates. Their correlation for natural convection is 


$$
h_{c}=\frac{0.049\left(G_{r} P_{r}\right)^{0.33} P_{r}^{0.074} k_{a}}{r_{i n s} \ln \left(r_{c i} / r_{i n s}\right)}
$$

The Grashof number $G_{r}$ in Eq. 2.66 is given by

$$
G_{r}=\frac{\left(r_{c i}-r_{i n s}\right){ }^{3}\left(T_{i n s}-T_{c i}\right) g \rho_{a}^{2} \beta}{\mu_{a}^{2}}
$$

Eq.2.67 reflects the extent of motion of the annulus fluid due to natural convection. Prandtl number, $P_{r}$ on the other hand, is a measure of the interaction between the hydrodynamic boundary layer and the thermal boundary layer. The lower density of the heated fluid next to the tubing wall creates a buoyancy force. The viscous force, working against the buoyancy generates a circular motion of the fluid in the annulus. Iterative solution procedure becomes necessary because casing inside temperature and insulation outside temperatures are unknown.

The iterative calculation procedure starts with assuming the temperature drop across the annulus. Using the assumed temperature drop Grasof number, heat transfer coefficient for natural convection and finally overall heat transfer coefficient can be calculated. Once the overall heat transfer coefficient is calculated the fluid temperature can be estimated by employing the analytic temperature model explained in the previous chapters. The amount of heat lost to the formation can be calculated assuming steadystate heat flow through the resistances between tubing fluid and formation. Temperature drop across the annulus fluid can be updated by Fourier's law of heat conduction. The iterative procedure continues until the desired convergence criterion is reached.

The scheme in Fig.2.6 shows the iterative calculation procedure. 


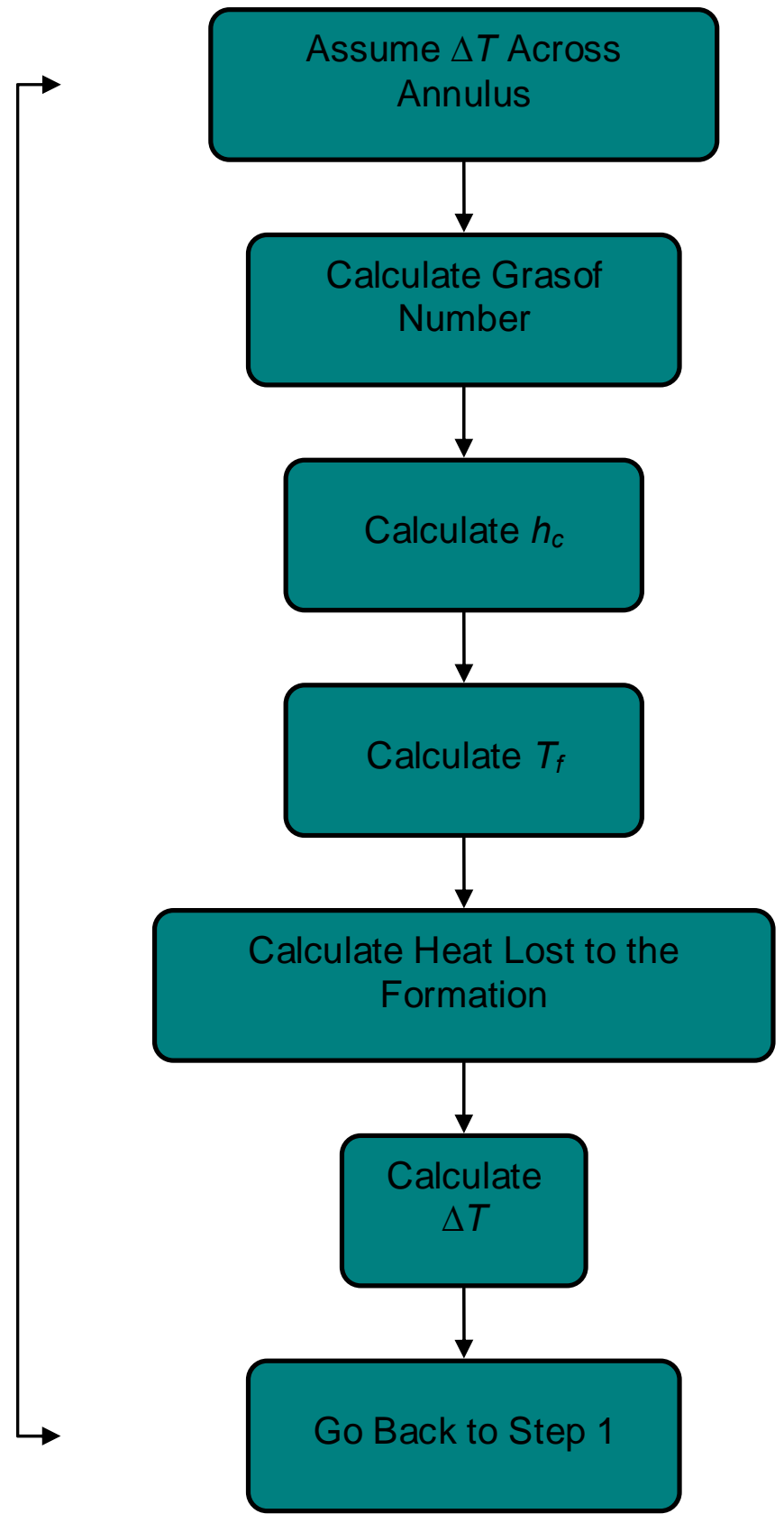

Fig. 2.6 Iterative procedure for calculating annulus heat transfer rate 


\subsection{FORMATION TEMPERATURE UPDATING}

As production continues, heat transfer from the wellbore causes a gradual rise in the temperature of the surrounding formation, which, in turn causes a slow decrease in the rate of heat flow. The same process is true for a buidup period following a drawdown. A methodology to account for this change in heat transfer rate is developed.

The following partial-differential equation in cylindrical coordinates gives variation of formation temperature with radial distance from the well

$$
\frac{\partial^{2} T_{e}}{\partial r^{2}}+\frac{1}{r} \frac{\partial T_{e}}{\partial r}=\frac{c_{e} \rho_{e}}{k_{e}} \frac{\partial T_{e}}{\partial t}
$$

Eq. 2.68 can be solved by assuming three boundary conditions. According to one boundary condition, heat flow at the formation/wellbore interface is governed by Fourier's law of heat conduction, which requires constant-heat flux at all times. However, as the formation partially heats up after the initiation of flow, the driving force for heat flux; that is, the difference between fluid and formation temperatures $(\Delta T)$ is subject to subsequent changes. Consequently, the net heat transfer rate becomes a function of this temperature difference. For a combined multirate and buildup schedules, this temperature difference may never reach steady-state, as postulated by Ramey (1962).

The changes in $\Delta T$ can be accounted for by adjusting the formation temperature using the methodology presented below. Fig. 2.7 depicts the conductive heat transfer from wellbore fluid to the formation and through the volume element at the interface of formation and wellbore. 


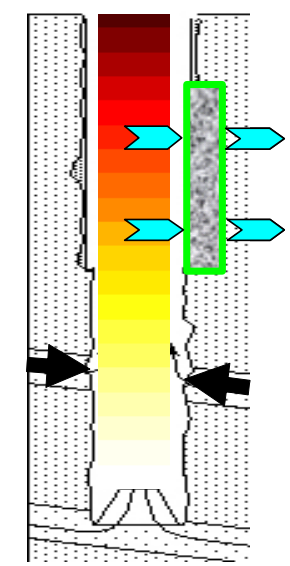

Fig. 2.7 Conductive heat transfer through the volume element taken at the formation/wellbore interface.

An energy balance on small volume element of formation near the wellbore gives

$$
\left\{\begin{array}{c}
\text { Heat Conducted } \\
\text { In }
\end{array}\right\}-\left\{\begin{array}{c}
\text { Heat Conducted } \\
\text { Out }
\end{array}\right\}=\left\{\begin{array}{l}
\text { Change In Energy } \\
\text { In Volume Element }
\end{array}\right\}
$$

The amount of heat conducted out varies with radial distance and is very difficult to model. However, for a small time increment the heat conducted out from the volume element may assumed negligible. Thus,

$$
\left\{\begin{array}{c}
\text { Net Heat Transfer Rate } \\
\text { Per Unit Length of Wellbore }
\end{array}\right\}=\left\{\begin{array}{c}
\text { Change In Energy } \\
\text { within Volume Element }
\end{array}\right\}
$$

With this assumption, the heat-transfer rate at the formation/well interface obtained from semianalytical fluid-temperature model $\left(Q_{z}\right)$ can be used as the net heat accumulation of the volume element. The final form of the equation becomes

$$
Q_{z}=m_{v e} c_{p} \frac{\left(T_{e}\right)^{k+1}-\left(T_{e}\right)^{k}}{\Delta t}
$$


The mass of the volume element is given by $m_{v e}$ and $c_{p}$ is the heat capacity of the formation. Rearranging for formation temperature at new time level

$$
\left(T_{e}\right)^{k+1}=\frac{Q_{z} \Delta t}{m_{v e} c_{p}}+\left(T_{e}\right)^{k}
$$

Eq. 2.72 requires an estimation of the thickness of the volume element, which is used as a history-matching parameter in this work. As the thickness of the volume element is increased, the estimated temperature of the formation approaches the undisturbed earth temperature, $T_{e i}$. in a buildup test. During drawdown, the net heattransfer rate going through the formation volume element increases with time. In that case, decreasing the thickness of the volume element provides an increase in predicted formation temperature around the wellbore.

Typically, a transient test involves a series of flow and shut-in segments. Because thermal diffusion occurs at a much slower rate than its pressure counterpart, the steadystate heat transfer assumption becomes inappropriate. The formulation presented in this study is an attempt to avoid this limitation by updating the formation temperature at every time step as a function of mass flow rate, regardless of flow or shut-in test. 


\section{CHAPTER III}

\section{WELLBORE AND RESERVOIR FLOW MODEL}

\subsection{WELLBORE FLOW MODEL}

\subsubsection{Mass and momentum balance}

Fluid pressure and temperature depend on the fluid velocity. Thus, an accurate estimate of fluid velocity as a function of time and wellbore length is required. Starting with the transient form of conservation of momentum equation and using Fig. 2.2

$$
\begin{aligned}
& \left\{\begin{array}{c}
\text { Change In Momentum } \\
\text { With Time }
\end{array}\right\}=\left\{\begin{array}{c}
\text { Rate of Momentum In } \\
- \text { Rate of Momentum Out }
\end{array}\right\} \\
& +\sum \text { Forces Acting On Volume Element }
\end{aligned}
$$

The fluid enters from node " $z+\Delta z$ "

$$
\begin{gathered}
\Delta x \Delta y \Delta z \frac{(\rho v)^{n+1}-(\rho v)^{n}}{\Delta t}=\Delta x \Delta y\left(\left(\rho v^{2}\right)_{z}-\left(\rho v^{2}\right)_{z+\Delta z}\right)+\Delta x \Delta y\left(\begin{array}{c}
P-P \\
z \\
z+\Delta z
\end{array}\right) \\
-\Delta x \Delta y \Delta z \rho g \sin \theta-\frac{\rho f v^{2}}{d}
\end{gathered}
$$

Dividing by $\Delta x \Delta y \Delta z$;

$$
\begin{aligned}
& \frac{(\rho v)^{n+1}-(\rho v)^{n}}{\Delta t}=\frac{1}{\Delta z}\left(\left(\rho v^{2}\right)_{z}-\left(\rho v^{2}\right)_{z+\Delta z}\right)+\frac{1}{\Delta z}\left(\begin{array}{c}
P-P \\
z-\Delta z
\end{array}\right) \\
& -\rho g \sin \theta-\frac{\rho f v^{2}}{d}
\end{aligned}
$$


And taking the limit as $\Delta z$ approaches zero,

$$
\frac{\partial f(z)}{\partial z}=\lim _{\Delta z \rightarrow \infty} \frac{f(z+\Delta z)-f(z)}{\Delta z}
$$

Final equation becomes;

$$
\frac{\partial(\rho v)}{\partial t}=-\frac{\partial\left(\rho v^{2}\right)}{\partial z}-\frac{\partial(p)}{\partial z}-\rho g \sin \theta-\frac{\rho f v^{2}}{d}
$$

\subsubsection{Wellbore mass and velocity distribution}

The discrete form of the equation can be obtained using the following gridding scheme as shown in Fig.3.1;

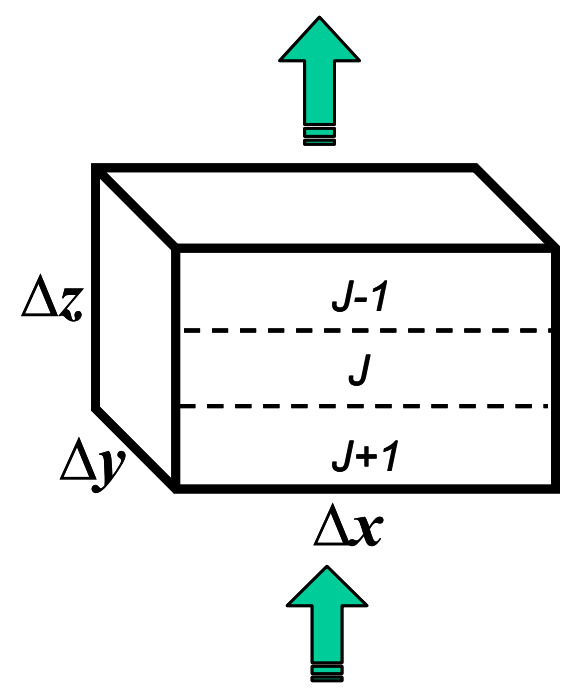

Fig. 3.1 Mass and velocity distribution in the wellbore

The discrete form allows us to write the mid point $(\rho v)_{j+1 / 2}$ as ;

$$
(\rho v)_{j+1 / 2}^{n+1}=(\rho v)_{j+1 / 2}^{n}-\Delta t \beta \Phi_{j}^{n}-\Delta t(1-\beta) \Phi_{j}^{n+1}
$$

where $\Phi_{j}{ }^{n}$ stands for previous timestep variables 


$$
\Phi_{j}^{n}=\frac{\left(\rho v^{2}\right)_{j+1}^{n}-\left(\rho v^{2}\right)_{j}^{n}}{z_{j+1}-z_{j}}+\frac{\left(P_{j+1}-P_{j}\right)^{n}}{z_{j+1}-z_{j}}-\rho_{j+1 / 2}^{n} g \sin \theta-\frac{2 \rho_{j+1 / 2}^{n} f_{j+1 / 2}^{n} v_{j+1 / 2}^{n}}{z_{j+1}-z_{j}}
$$

and $\Phi_{j}{ }^{n+1}$ represents present timestep values

$$
\Phi_{j}^{n}=\frac{\left(\rho v^{2}\right)_{j+1}^{n+1}-\left(\rho v^{2}\right)_{j}^{n+1}}{z_{j+1}-z_{j}}+\frac{\left(P_{j+1}-P_{j}\right)^{n+1}}{z_{j+1}-z_{j}}-\rho_{j+1 / 2}^{n+1} g \sin \theta-\frac{2 \rho_{j+1 / 2}^{n+1} f_{j+1 / 2}^{n+1} v_{j+1 / 2}^{n+1}{ }^{2}}{z_{j+1}-z_{j}}
$$

In Eq. $3.6 \beta$ is the relaxation factor whose values lies between 0 and 1 . Notice that the solution of Eq. 3.6 for the next time step value of mass flux $(\rho v)^{n+1}$ requires values of various properties at next time step again so an iterative solution procedure is required.

We use $b_{n}$ to denote the spatial mid-point mass flux, $(\rho v)_{j+1 / 2}{ }^{n+1}$, and $a_{n}$ for node point values, $(\rho v)_{j+1}^{n+1}$. Further, the flowing relationships among the nodes can be assumed.

$$
\begin{aligned}
& a_{2}=\frac{1}{4}\left(a_{1}+b_{1}+b_{2}+a_{3}\right) \\
& a_{3}=\frac{1}{4}\left(a_{2}+b_{2}+b_{3}+a_{43}\right) \\
& \cdots \cdots . . \\
& a_{n}=\frac{1}{4}\left(a_{n-1}+b_{n-1}+b_{n}+a_{n+1}\right)
\end{aligned}
$$

Separating $b_{n}$ and $a_{n}$ and manipulating, we get 


$$
\begin{aligned}
& -4 a_{2}+a_{3}=-b_{1}-b_{2}-a_{1} \\
& a_{2}-4 a_{3}+a_{4}=-b_{2}-b_{3} \\
& \cdots \cdots . . \\
& -4 a_{n}+a_{n-1}=-b_{n-1}-b_{n}-a_{n+1}
\end{aligned}
$$

Mass flow rates at the top and bottom of the system, $a_{n}$ and $a_{n+1}$ are known. In matrix form Eq. 3.10 can written as,

$$
\left|\begin{array}{ccccc}
-4 & 1 & & & \\
1 & -4 & 1 & & \\
& \cdot & \cdot & \cdot & \\
& & \cdot & \cdot & \cdot \\
& & & 1 & -4
\end{array}\right| \cdot\left|\begin{array}{c}
a_{2} \\
a_{3} \\
. \cdot \\
. \cdot \\
a_{n}
\end{array}\right|=\left|\begin{array}{c}
-b_{1}-b_{2}-a_{1} \\
-b_{2}-b_{3} \\
-b_{3}-b_{4} \\
. \cdot \\
-b_{n-1}-b_{n}-a_{n+1}
\end{array}\right|
$$

The matrix is a tridiagonal; therefore, three vectors can be used to store non-zero elements. The notation can be arranged as follows,

$$
\left|\begin{array}{ccccc}
d_{1} & e_{1} & & & \\
f_{1} & d_{2} & e_{2} & & \\
& f_{2} & \cdot & \cdot & \\
& & \cdot & \cdot & \cdot \\
& & & f_{n-1} & d_{n}
\end{array}\right| \cdot\left|\begin{array}{c}
a_{2} \\
a_{3} \\
. \cdot \\
. \cdot \\
a_{n}
\end{array}\right|=\left|\begin{array}{c}
g_{1} \\
g_{2} \\
. \cdot \\
. . \\
g_{n}
\end{array}\right|
$$

Two-step simple Gaussian elimination can be used to solve the equations. Step one if forward elimination.

$$
\begin{aligned}
& d_{2}=d_{2}-\left(f_{1} / d_{1}\right) k_{1} \\
& g_{2}=g_{2}-\left(f_{1} / d_{1}\right) g_{1}
\end{aligned}
$$


Second step is backward substitution, which is,

$$
\begin{aligned}
& a_{n}=g_{n} / d_{n} \\
& a_{n-1}=\left(g_{n}-e_{n-1} x_{n}\right) d_{n-1}
\end{aligned}
$$

\subsection{RESERVOIR MODEL}

An analytical reservoir model with superposition in time is used to account for fluid flux at the sandface. This formulation can be used for both drawdown and buildup simulations and is given for the liquid case by

$$
q_{n}=q_{n-1}+\frac{p_{i}-p_{w n}}{m\left[P_{D}\left(t_{D n}-t_{D n-1}\right)+s+D q_{n}\right]}-\frac{\sum_{i=1}^{n-1}\left(q_{i}-q_{i-1}\right)\left[p_{D}\left(t_{D n}-t_{i-1}\right)+s+D q_{i}\right]}{p_{D}\left(t_{D n}-t_{D n-1}\right)+s+D q_{n}}
$$




\section{CHAPTER IV}

\section{ANNULAR-PRESSURE BUILDUP MODEL}

\subsection{TRANSIENT BEHAVIOR OF ANNULAR-PRESSURE BUILDUP}

Annular pressure buildup (ABP) is a phenomenon that has been recognized in the oil and gas industry for many years. ABP is the pressure generated by thermal expansion of trapped fluids as they are heated. During production as the temperature increases throughout the wellbore, the trapped fluid, usually drilling mud and spacer, expands.

When wellbore fluids heat up and expand in a closed system, the annular pressure increases significantly. Pressure buildup, caused by fluid thermal expansion in sealed annuli of high pressure/high temperature wells, can have serious consequences such as casing failure or tubing collapse.

Pressure buildup in tubing-casing or casing-casing annuli is, in general, undesirable. Although casing design should take into account high pressures at the casing head, high pressure differences always hold the risk of casing bursting or collapsing at weak points, leading to loss of production or in the worst case loss of well (Oudeman \& Kerem 2006). For this reason, most operating companies adhere to annular-pressuremanagement schemes for onshore and offshore wells, which prescribe bleeding off pressure through the wellhead until a predetermined pressure level is reached.

The annular-pressure-management schemes described above cannot be applied to subsea completed wells since these wells are not equipped with the option to bleed off the annular pressure. Deepwater developments are extremely susceptible to ABP when the differential between mudline temperatures and flowing production temperatures exceeds 125 to $200{ }^{\circ} \mathrm{F}$ depending on the sea water temperature. Furthermore, the high temperatures developing in the well during prolonged production periods aggravate the problem of pressure buildup in annuli since the thermal expansion of the liquids tends to 
increase at higher temperatures. For this reason, accurate prediction of annular pressure buildup in annuli is important.

\subsection{ACCOUNTING FOR FLUID EXPANSION IN ANNULI}

For a well to experience ABP, two conditions are known to exist. First, a sealed annulus or annuli must exist. Commonly a drilled formation is isolated in a cased well. Cement is circulated above the formation, and the top of cement is frequently inside the annulus of the previous casing. When the wellhead is sealed, an isolated volume of liquid is created or trapped. The condition is termed as "trapped fluid". Second, a temperature increase must take place resulting from either production or drilling operations. When the fluid is heated, it begins to expand and can produce a substantial increase in pressure, which can be compounded if more than one annulus is isolated.

Basically the pressure at a specific depth in a trapped column of liquid is determined by the average annulus temperature, the volume of annulus and the amount of fluid trapped. The following expression for a change in pressure in a contained annulus can be written

$$
\Delta p=\frac{\alpha_{l}}{\kappa_{T}} \Delta T-\frac{1}{\kappa_{T} V_{a}} \Delta V_{a}+\frac{1}{\kappa_{T} V_{l}} \Delta V_{l}
$$

Where $\alpha$ is the coefficient of thermal expansion of annular fluid, $\kappa$ is the coefficient of isothermal compressibility, $V_{l}$ is the volume of annular liquid, and $V_{a}$ is the annular volume. According to this expression there are three contributing terms to annular pressure buildup. These are; 
- Thermal expansion, which results in an increase in pressure when the annular volume does not increase sufficiently to accommodate this expansion

- Change of annular volume, by thermal expansion, ballooning, or compression of the casings

- Change in the amount of the fluid in the annulus caused either by liquid leak-of to formation or fluid influx into the annulus

In a sealed annulus the first term, thermal expansion is dominant. The second term, change in annular volume is a downward correction to the first term for about $10 \%$. For a perfectly sealed annulus the last term is eliminated because the amount of liquid remains constant with time. Because the first term or the liquid expansion is by far the most dominant in a sealed annulus, accounting for well over $80 \%$ of pressure increase in most cases, our modeling approaches center around this term.

For thermal expansion term to dominate the ABP the following two conditions need to apply;

- No liquid is lost or added to the annuls

- The walls of annulus are completely rigid, a condition taking place when the casings are cemented to the surface

In the absence of leak-off and changes in annular volume the relevant equation becomes

$$
\Delta p=\frac{\alpha_{l}}{\kappa_{T}} \Delta T
$$


The contribution to ABP is governed by the ratio of isobaric thermal expansion and the isothermal compressibility. Thermodynamically, fluid volume (or density) can be expressed as a function of pressure and temperature as follows.

$$
\partial V=\left(\frac{\partial V}{\partial T}\right)_{p} \partial T+\left(\frac{\partial V}{\partial T}\right)_{T} \partial P
$$

When volume is constant, $d V=0$, and we have,

$$
\left(\frac{\partial V}{\partial T}\right)_{p} \partial T=-\left(\frac{\partial V}{\partial T}\right)_{T} \partial P
$$

Using the definitions of coefficient of thermal expansion and coefficient of isothermal compressibility Eq. 4.4 can be arranged for pressure as

$$
\begin{aligned}
& \alpha \equiv(1 / V)(\partial V / \partial T)_{p} \equiv-(1 / \rho)(\partial \rho / \partial T)_{p} \\
& \kappa \equiv(1 / V)(\partial V / \partial P)_{T} \equiv-(1 / \rho)(\partial \rho / \partial P)_{T} \\
& \partial P=-\frac{(\partial V / \partial T)_{p}}{(\partial V / \partial T)_{T}} \partial T=(\alpha / \kappa) \partial T
\end{aligned}
$$

Along with the annulus fluid temperature, fluid properties ( $\alpha$ and $\kappa)$ will change with depth. For example, near the bottomhole, annulus fluid temperature is high and the temperature increase around that region with producing time (hence $\Delta P$ ) is likely to be small. However, near the wellhead, annulus fluid temperature is initially low, and may rise substantially over a period of production. Hence direct use of Eq. 4.7 will give 
inaccurate results. Accounting for the change in volume of trapped fluid as a function depth the equation becomes;

$$
\partial P=-\frac{(\partial V / \partial T)_{p}}{(\partial V / \partial T)_{T}} \partial T=(\alpha / \kappa) \partial T=\frac{\sum\left(M / \rho^{2}\right)(\partial \rho / \partial T)_{p} \partial T-\{\Delta V\}_{\text {Bleed Off }}}{\sum\left(M / \rho^{2}\right)(\partial \rho / \partial P)_{T}}
$$

In Eq.4.8 the summation is taken over the total number of grids in the simulation model and $M$ is the mass of trapped fluid in $l b m / f t$ for each grid cell of a given annulus. $M$ can be calculated using the following equation.

$$
M \equiv \pi \Delta r^{2} \rho / 144
$$

The "Bleed-Off Volume" is the amount of fluid withdrawn from annulus $\left(f t^{3} /\right.$ Length $)$ during the simulation. The amount of fluid taken out of the system by

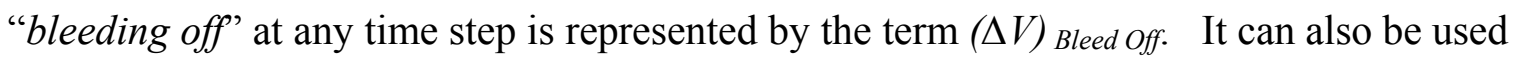
to account for the size of air cushion in the annuli. If there is an air cushion initially and at some point in time fluid withdrawal takes place then this term should represent the summation of those two volumes.

Eq 4.8 also requires relevant temperature profiles for each annulus. The next chapter provides the details on calculation of annulus and formation temperatures around the wellbore. 


\subsection{HEAT TRANSFER CALCULATIONS IN ANNULI AND AROUND WELLBORE}

A numerical simulation model has been developed to calculate temperature and pressure distributions in multiple annuli of a wellbore as shown in Fig. 4.1. In the model wellbore is represented by cylindrical grids in vertical direction to calculate heat and mass flow during production and shut-in. The heat flow from tubing fluid into to the formation can be calculated by generating radial grids around each cylindrical element and solving for conduction equation in finite difference form with the relevant properties.

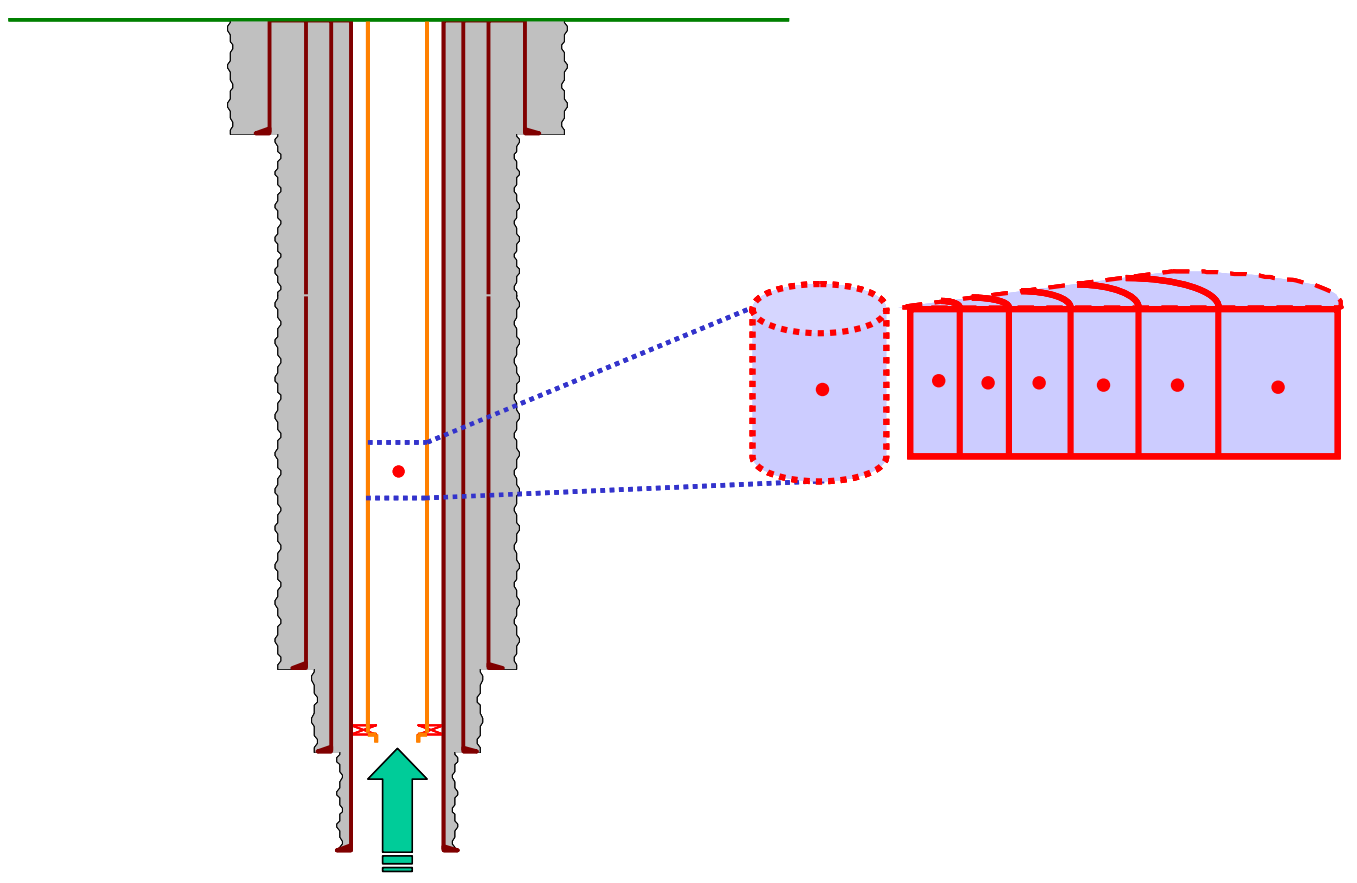

Fig. 4.1 Wellbore grids in vertical and lateral directions.

Single phase constant pressure or constant pressure outer boundary fluid flow solutions for a single well in a given reservoir form a straight line when plotted against the logarithm of radius. This is because equally spaced nodes on logarithmic basis, improves the accuracy of the finite difference solution scheme. Using the analogy 
between heat and fluid flow equations one can generate geometrically spaced radial grids around the wellbore to calculate formation temperature profiles. In that case the outer bounder, represented by the last grid, is not affected by the heat transfer from wellbore and is always at geothermal gradient.

The procedure for generating logarithmically spaced radial grids around the wellbore is as follows

- Calculate a scaling parameter

$$
\beta=\left(\frac{r_{e}}{r_{w}}\right)^{1 /(i \max -1)}
$$

- Calculate initial grid distance

$$
r_{i+1}=\beta r_{i}
$$

- Calculate the remaining grids

$$
r_{i+1 / 2}=\beta r_{i-1 / 2}
$$

and

$$
r_{i}=\sqrt{r_{i-1 / 2} r_{i+1 / 2}}
$$

The maximum distance from wellbore into the formation is given with " $r_{e}$ " and "imax" gives the number of grids around the wellbore. The user can specify any number of grids at any distance into the formation. Once the grid system is constructed radial heat transfer 
into the formation is calculated using finite difference form of transient heat conduction equation.

Starting with the conservation of heat in an unsteady-state radial system

$$
\begin{aligned}
& \text { Rate of Heat In - Rate of Heat Out }= \\
& \text { Increase in Heat Inside Volume Element }
\end{aligned}
$$

Using Fourier's law of heat conduction for volume element " $i$ " rate of heat entering and leaving the control volume is

$$
\begin{aligned}
& \text { Rate of Heat In }=2 k_{i-1} \pi r_{i-1} h \frac{T_{i-1}^{n+1}-T_{i}^{n+1}}{\Delta r_{i}} \\
& \text { Rate of Heat Out }=2 k_{i} \pi r_{i} h \frac{T_{i+1}^{n+1}-T_{i}^{n+1}}{\Delta r_{i+1}}
\end{aligned}
$$

Where $k$ is the thermal conductivity and the accumulation term becomes

$$
\text { Increase in Heat Inside Volume Element }=c \rho \pi \Delta r^{2} h \frac{T_{i}^{n+1}-T_{i}^{n}}{\Delta t}
$$

Density and heat capacity are given with $c$ and $\rho$. Combining Eqs. 4.15, 4.16 and 4.17 the final form of the equation is

$$
2 k_{i-1} \pi r_{i-1} h \frac{T_{i-1}^{n+1}-T_{i}^{n+1}}{\Delta r_{i}}+2 k_{i} \pi r_{i} h \frac{T_{i+1}^{n+1}-T_{i}^{n+1}}{\Delta r_{i+1}}=c \rho \pi \Delta r^{2} h \frac{T_{i}^{n+1}-T_{i}^{n}}{\Delta t}
$$


Defining transmissibility terms with respect to grid in the middle and the thermal diffusivity

$$
\begin{aligned}
& T R_{W}=\frac{2 k_{i-1} \pi r_{i-1} h}{\Delta r_{i}} \\
& T R_{E}=\frac{2 k_{i} \pi r_{i} h}{\Delta r_{i+1}} \\
& \alpha=c \rho \pi \Delta r^{2} h
\end{aligned}
$$

The final form of the equation is implicit in nature and requires matrix solution.

$$
T R_{W}\left(T_{i-1}^{n+1}-T_{i}^{n+1}\right)+T R_{E}\left(T_{i+1}^{n+1}-T_{i}^{n+1}\right)=\alpha \frac{T_{i}^{n+1}-T_{i}^{n}}{\Delta t}
$$

Simultaneous solution of all equations for a particular timestep matrix system should be in the form of;

$$
A \vec{T}=\vec{b}
$$

In Eq. $4.23 A$ is the coefficient matrix, $T$ and $b$ are the column vectors. The new form of the equation is

$$
T R_{W} T_{i-1}^{n+1}-\left(T R_{W}-T R_{E}+\frac{\alpha}{\Delta t}\right) T_{i}^{n+1}-T R_{E} T_{i+1}^{n+1}=-\frac{\alpha}{\Delta t} T_{i}^{n}
$$

Defining a lumped parameter for central node coefficient 


$$
T R_{C}=\left(T R_{W}-T R_{E}+\frac{\alpha}{\Delta t}\right)
$$

The equation becomes

$$
T R_{W} T_{i-1}^{n+1}-T R_{C} T_{i}^{n+1}-T R_{E} T_{i+1}^{n+1}=-\frac{\alpha}{\Delta t} T_{i}^{n}
$$

Eq. 4.27 is the matrix form of Eq.4.26. For this particular case, the given matrix is constructed for four radial grids around one vertical wellbore grid.

$$
\begin{array}{|cccc}
1 & & & \\
& T R_{C} & T R_{E} & \\
& T R_{W} & T R_{C} & T R_{E} \\
& & T R_{W} & T R_{C}
\end{array}|\bullet| \begin{gathered}
T_{1}^{n+1} \\
T_{2}^{n+1} \\
T_{3}^{n+1} \\
T_{4}^{n+1}
\end{gathered}\left|=-\frac{\alpha}{\Delta t}\right| \begin{gathered}
T_{\text {tub }}^{n} \\
T_{2}^{n} \\
T_{3}^{n} \\
T_{4}^{n}
\end{gathered} \mid
$$

The boundary conditions for this system are as follows;

- $T(r, 0)=T_{e i}$

- $T\left(r=r_{t}, t\right)=T_{f}(t)$

- $T(r=\infty, t)=T_{e i}$

Here tubing outer radius is given by $r_{t}$. Notice that the first temperature value on the right hand side vector, $T_{1}$ is specified and is provided by the analytic temperature solution explained before.

The final form of the equation to calculate temperature in the tubing does not account for the heat accumulation or increase in temperature in the first annulus. The general form of the heat transfer coefficient used in this formulation is; 


$$
\frac{1}{U_{t o}}=\frac{1}{h_{c}+h_{r}}+\frac{r_{t o} \ln \left(r_{t o} / r_{1 i}\right)}{k_{t}}+\frac{r_{t o} \ln \left(r_{c o} / r_{c i}\right)}{k_{c a s}}+\frac{r_{t o} \ln \left(r_{h} / r_{c o}\right)}{k_{c e m}}
$$

The temperature rise in the annulus will slow down the net heat transfer rate from tubing fluid to the surrounding formation. The impact of change in annulus heat transfer rate can be approximated by continuously evaluating heat transfer coefficients relevant to conduction and convection in the annulus. That is

$$
\frac{1}{U_{a n n}}=\frac{1}{h_{c}+h_{r}}
$$

Heat entering from tubing to the annulus is

$$
Q=2 \pi r_{t o} U_{a n n}\left(T_{f}-T_{a n n}\right)
$$

Eq.4.30 is used to update the annulus heat transfer coefficient. The annulus temperature is calculated using the methodology given above. After the calculation of annulus heat transfer coefficient, it is incorporated back into the general overall heat transfer coefficient and tubing fluid temperature is calculated again with the analytic model. 


\section{CHAPTER V}

\section{FIELD APPLICATIONS}

In this section, we discuss examples from both oil and gas wells. The first example consists of drawdown and buildup tests in a gas well. Different mathematical solutions for the analytical temperature model and their corresponding effect on temperature profiles are explored in this context. The second example is a buildup test from an oil well. In this case, the simulator is used to reproduce the afterflow upon well shut-in. Both examples point out the importance of accounting for changes in heat transfer rate between formation and wellbore fluid during transient testing.

\subsection{GAS-WELL DRAWDOWN}

The wellbore model is initially used to simulate a drawdown test for a gas well from the Gulf of Mexico (Kabir et al. 1996). The duration of the drawdown period is about 6 hours. The reservoir temperature is $407^{\circ} \mathrm{F}$ and the depth of producing formation is given as $22,500 \mathrm{ft}$. The wellbore is divided into 19 segments and two different segment lengths used in the model are given as 1,000 and 1,500 ft.

Figs. 5.1 and 5.2 compare the measured and calculated wellhead temperature and bottomhole pressures as a function of time.

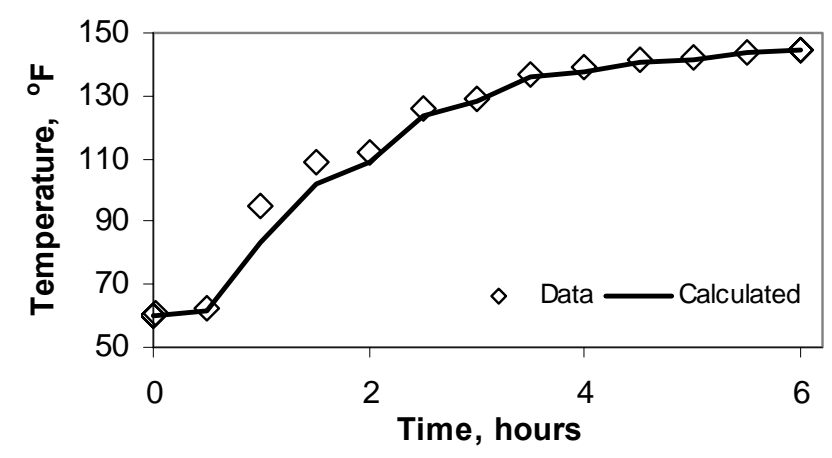

Fig. 5.1 - Wellhead temperature during a gas-well drawdown test. 


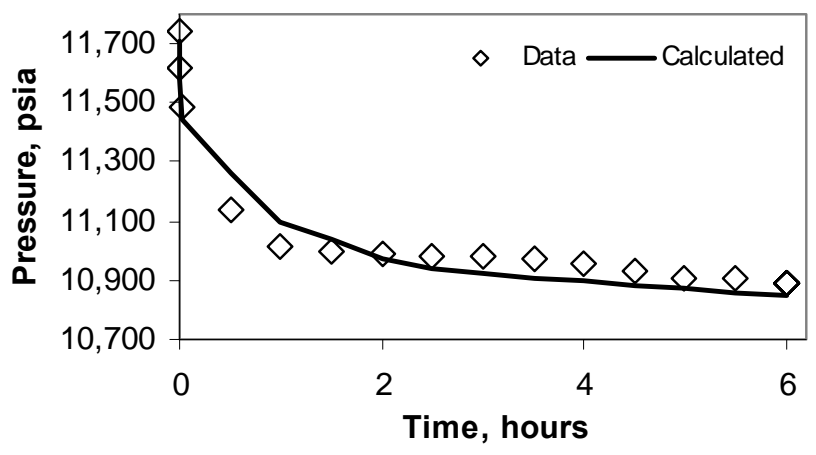

Fig. 5.2 - Bottomhole pressure during a gas-well drawdown test.

After about six hours of production, the temperature at the wellhead increases from $60{ }^{0} \mathrm{~F}$ to $145^{0} \mathrm{~F}$. Continuously changing temperature profile during production also provides a changing density profile throughout the wellbore, as depicted in Fig. 5.3.

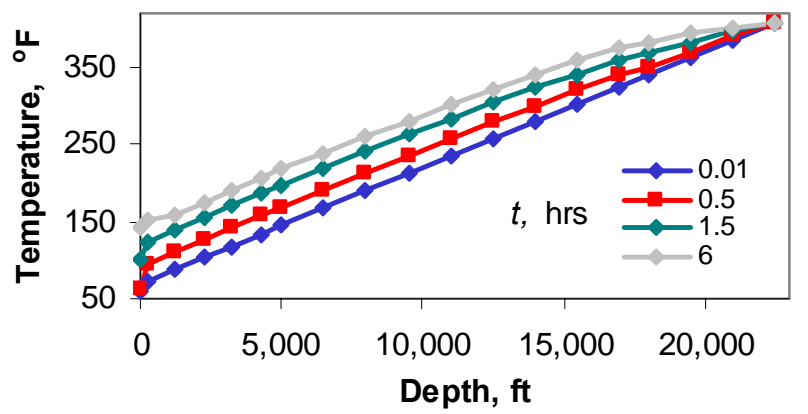

Fig. 5.3 - Temperature profile during gas-well drawdown test.

According to Fig. 5.4, the wellbore fluid becomes lighter as the production continues. In contrast, during buildup, produced fluid becomes dense at the wellhead owing to heat loss to the surrounding formation. 


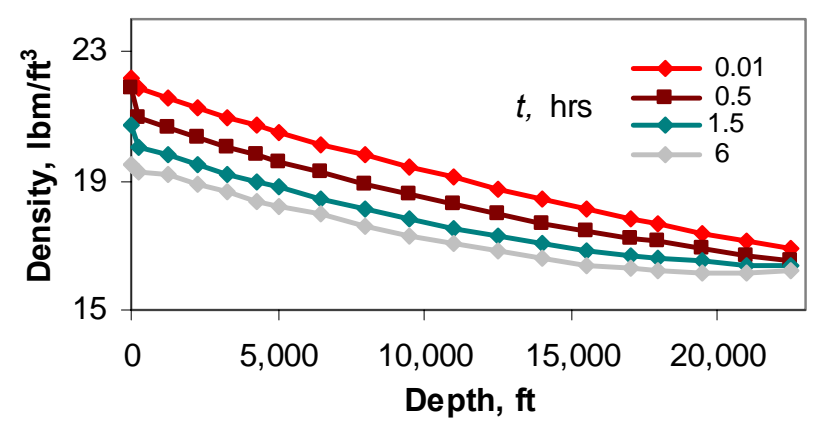

Fig. 5.4 - Density profile during a gas-well drawdown test.

Figs. 5.5 and 5.6 show the changes in relaxation parameter $\left(L_{R}\right)$ during drawdown and buildup tests, respectively. $L_{R}$ is evaluated as a function of time for each segment of the wellbore for heat-transfer calculations. While the constant- $L_{R}$ assumption is viable in buildups, the same is untrue for drawdowns. Consequently, we developed a numericaldifferentiation scheme to eliminate this limiting assumption in the solution of analytic fluid-temperature model.

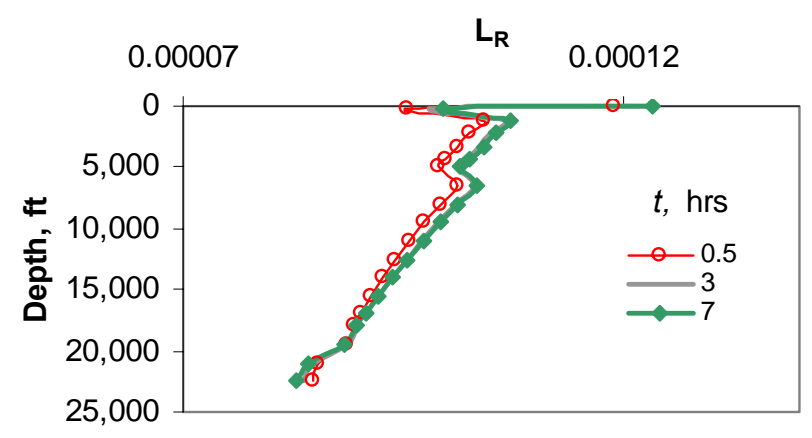

Fig. 5.5 - Changes in $L_{R}$ during gas-well buildup test. 


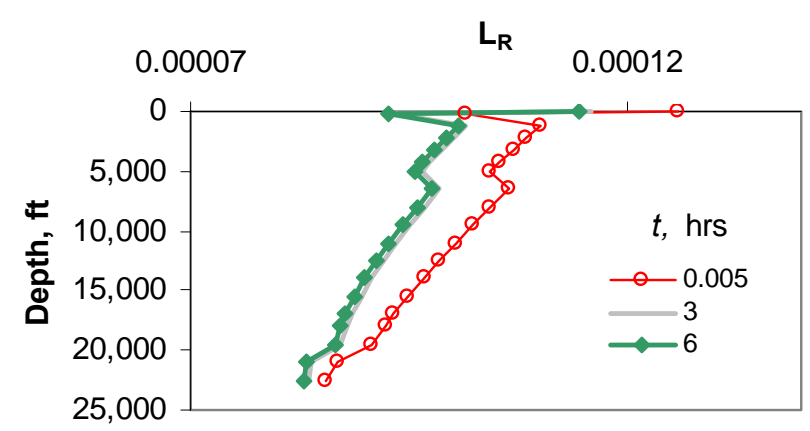

Fig. 5.6 - Changes in $L_{R}$ during a gas-well drawdown test.

Fig. 5.7 compares the percentage error on calculated wellhead temperatures for each methodology. These are; pure analytic temperature solution, analytic solution with numerical differentiation and numerical differentiation scheme combined with formation temperature updating scheme. The error on calculated wellhead temperature oscillates and grows with time, if analytic temperature model with constant $L_{R}$ is used for heattransfer calculations. The combination of numerical differentiation scheme with the variable-formation-temperature approach provides the best results for analytic heattransfer calculations.

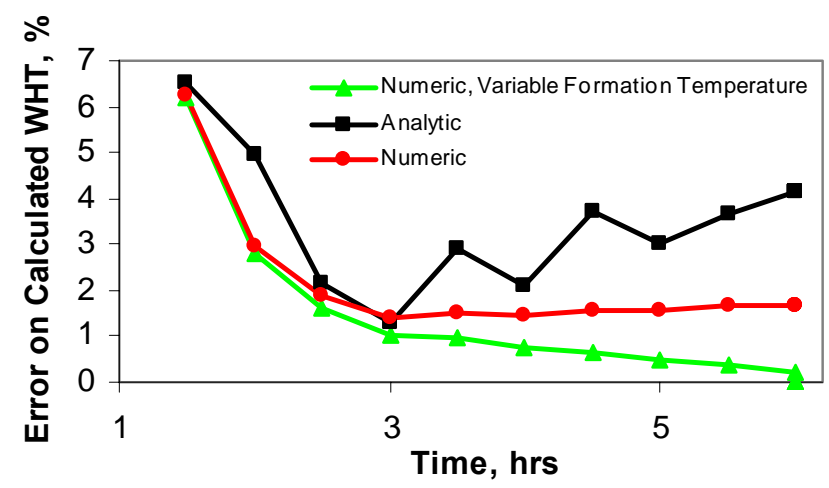

Fig. 5.7 - Error on calculated WHT during gas-well drawdown test.

Fig. 5.8 shows the formation temperature profiles calculated for different volumeelement thicknesses, as discussed in previous sections. For this particular case, best matches with field data are obtained using a volume-element thickness of one foot. 
During drawdown, the net heat-transfer rate going through the formation volume element increases with time. This fact implies that decreasing thickness of the volume element provides an increasing formation temperature around the wellbore.

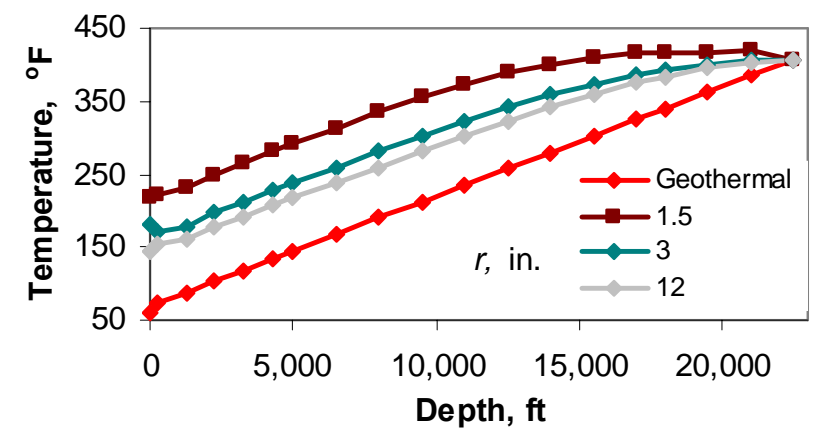

Fig. 5.8 - Formation temperature profiles calculated at different locations around the wellbore during drawdown.

Accurate representation heat transfer processes in the wellbore is crucial because the temperature profile has a big impact on the density profile, which, in turn affects the calculated pressure response.

\subsection{OIL-WELL BUILDUP}

\subsubsection{Forward simulation}

The second field example is a buildup test on an oil well, which lasts about one hour. Fluid production above the bubblepoint occurs even at the wellhead. Fig. 5.9 compares the calculated and measured wellhead pressure with forward simulation.

During buildup, wellbore fluid begins to lose heat to the formation, and with increasing shut-in times, fluid temperature profile becomes closer to the geothermal gradient.

Steady-state simulators assume zero mass flux in the wellbore after surface shutin. In reality, depending on the compressibility of the reservoir fluid, flow at the sandface does not cease immediately. As long as the warm reservoir fluid enters into the wellbore 
at sandface, both conductive heat loss to the formation and convective heat transfer owing to fluid flow should be considered for an accurate estimation of wellboretemperature profile.

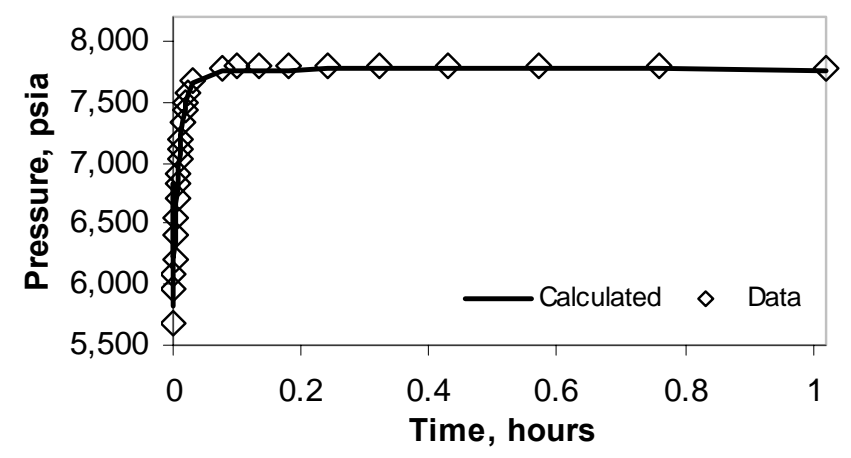

Fig. 5.9 - Wellhead pressure of oil well \#1 during buildup.

Fig. 5.10 compares the calculated wellhead temperatures from a steady-state and transient model during pressure buildup. Transient model accounts for the afterflow effects; whereas, zero mass flux is assumed in a steady-state model.

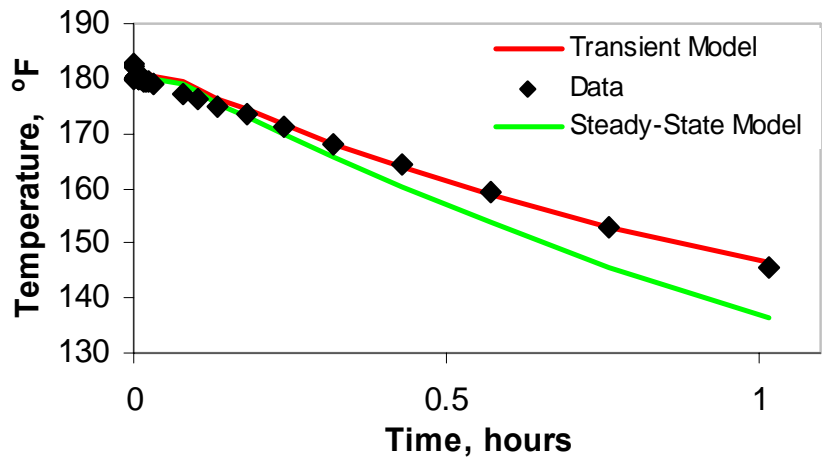

Fig. 6.10 - WHT of oil well \#1 during buildup.

Fig. 5.11 shows the velocity profile in the wellbore after shut-in. High $k h$ value and low-fluid compressibility of the system result in a short afterflow period, lasting about 10 minutes. 
According to Fig. 5.10, the deviations from measured wellhead temperatures are $15{ }^{\circ} \mathrm{F}$ for steady-state and $3{ }^{\circ} \mathrm{F}$ for transient models. Perhaps implication of this temperature difference is best understood by hypothetical reverse simulations. In this exercise, the bottomhole pressures generated from the wellhead pressures show a maximum difference occurring at the end of the test: the transient model shows only 1.5 psi difference with field data, whereas the steady-state model has an error of 10 psi.

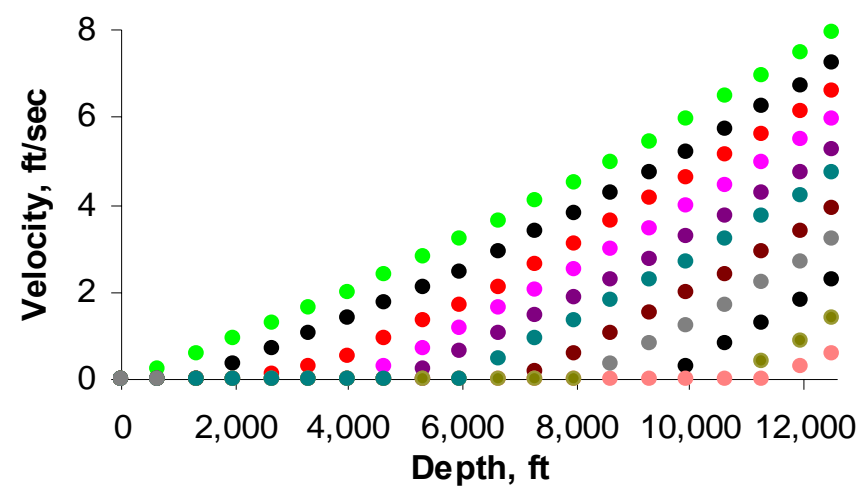

Fig. 5.11 - Velocity profile in the wellbore during shut-in.

Figs. 5.12 and 5.13 show the changing temperature and density profiles in the wellbore after surface shut-in. Heat loss to the formation throughout the wellbore leads to an increasingly denser fluid with time. These time-dependent nonlinear profiles underscore their importance in the context of wellhead to bottomhole pressure conversion.

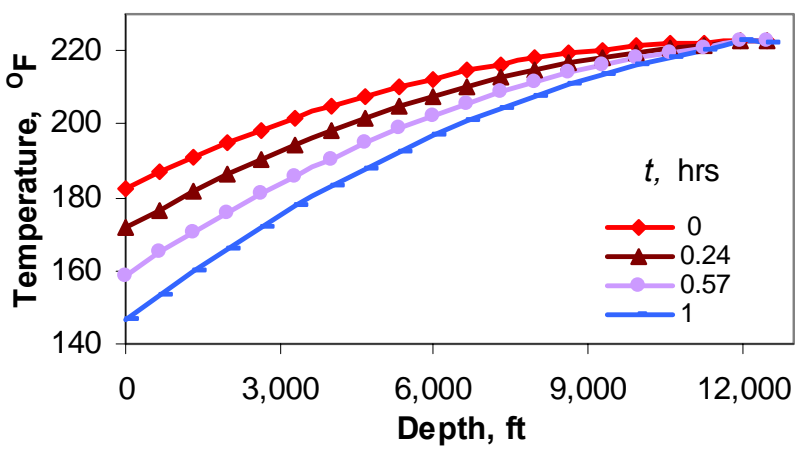

Fig. 5.12 - Temperature profile in the wellbore during an oil-well buildup test. 


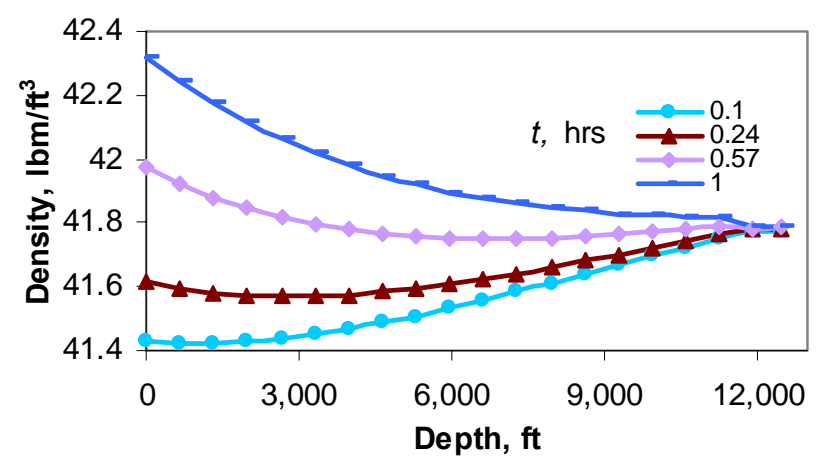

Fig. 5.13 - Density profile in the wellbore during an oil-well buildup test.

During buildup, similar to the heat transfer process described in drawdown, the amount of heat transfered to the formation does not remain constant with time. The changes in heat transfer rate during buildup can be accounted for using the formationtemperature updating scheme. Contrary to the application of formation updating scheme in drawdown, one should increase the thickness of the volume element, shown in Fig.2.5, to get closer to the geothermal gradient. As the thickness of the volume element increases, the impact of net incoming heat on the designated wellbore segment reduces.

Fig. 5.14 compares the formation temperature profiles in the near-wellbore region for different volume-element thicknesses. As shown in the figure, the largest thickness of 5 inches provides the same results as initial formation temperature.

Fig. 5.15 presents an oil-well buildup test lasting about four hours. Single-phase oil rate of 5,817 STB/D was recorded during the flow period lasting about eight hours. Reservoir parameters were obtained after doing the usual diagnosis with the derivative plot. To a large degree, reverse simulation replicated the measured response quite satisfactorily. However, the late-time match representing radial flow was less than satisfactory. Let us explore this point. 


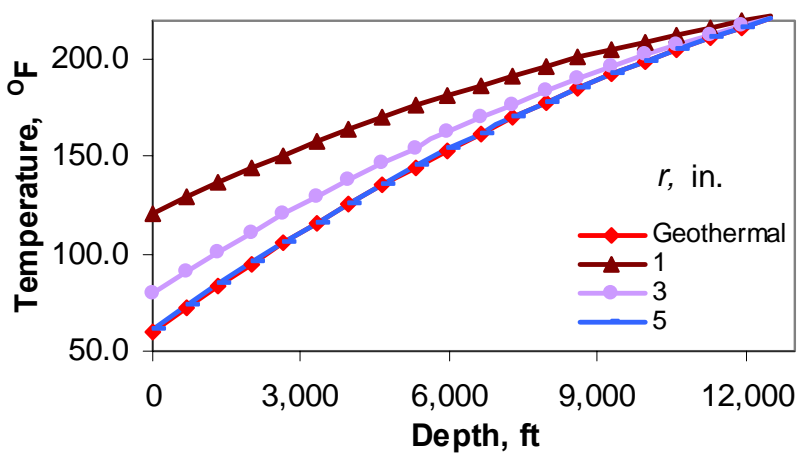

Fig. 5.14 - Changes in formation temperature profiles around the wellbore calculated from volume elements with different sizes.

\subsubsection{Reverse simulation}

In reverse simulations, the wellhead pressure data are converted into bottomhole pressure. This computation requires reliable estimation of wellbore temperature profile because changes in density develop as a function of temperature and pressure. Therefore, good estimates of wellhead temperature that are used as one of the boundary conditions in the model are imperative. Note that the measured wellhead temperature is not used explicitly in these calculations; they are used for comparison only to gain confidence in computed solutions.

Let us illustrate this point with Fig. 5.15, which compares wellhead temperature using both the steady-state and temperature-update formulations for a buildup test in an oil well, both approaches compare favorably with the measured data; however, the one proposed here does a better job in reproducing field response, particularly at late times. 


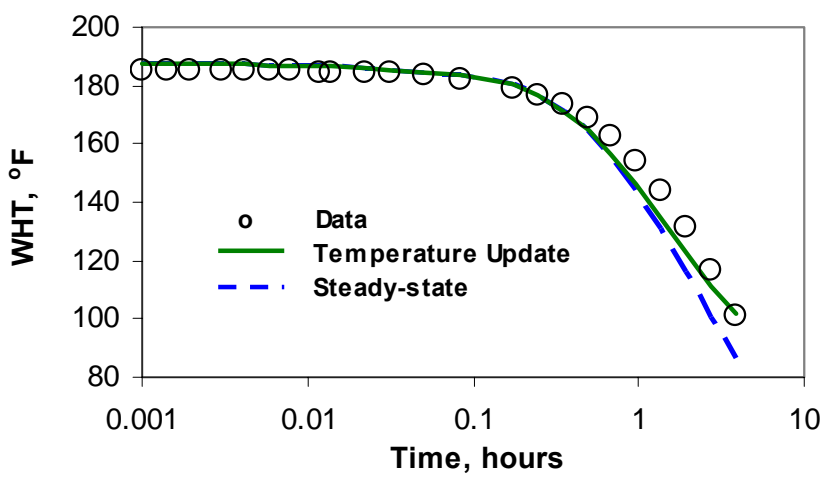

Fig. 5.15 - Comparison of WHT with the computed values in reverse simulation, oil well \#2.

Fig. 5.16 compares the bottomhole pressure response for this well, which produced at $5,817 \mathrm{STB} / \mathrm{D}$ for eight hours before shutting it in for about four hours. Reservoir parameters were obtained after doing the usual diagnosis with the pressure-derivative plot. Reverse simulation replicated the measured response quite satisfactorily, particularly that at late times. However, the early-time match representing afterflow is less than satisfactory because this formulation does not attempt to model this phenomenon.

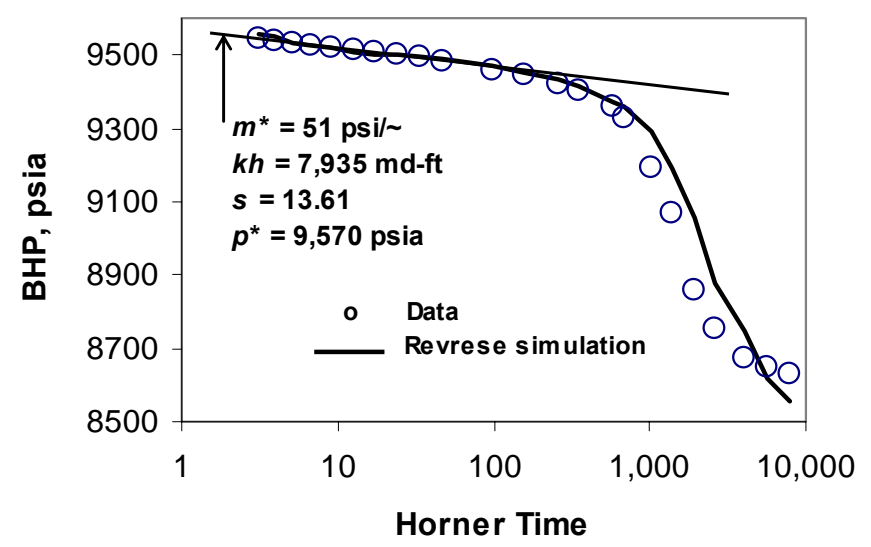

Fig. 5.16 - Comparison of BHP with that translated from WHP by reverse simulation, oil well \#2. 
We did forward simulations to compare and contrast these results with those from reverse simulations. Fig. 5.17 compares the results of measured and computed values for the same well. Oddly enough one observes divergence of wellhead pressure after about 0.1 $\mathrm{hr}$, although wellhead temperature was reproduced very well by the temperature-update formulation during the entire test. Because the same wellhead pressure reproduced the measured bottomhole pressure in Fig. 5.15, we concluded that the two sets of pressures are consistent. However, divergence of wellhead pressure after $0.1 \mathrm{hr}$ can only be explained by a slow developing leak at the wellhead wing valve. Let us explore this point.

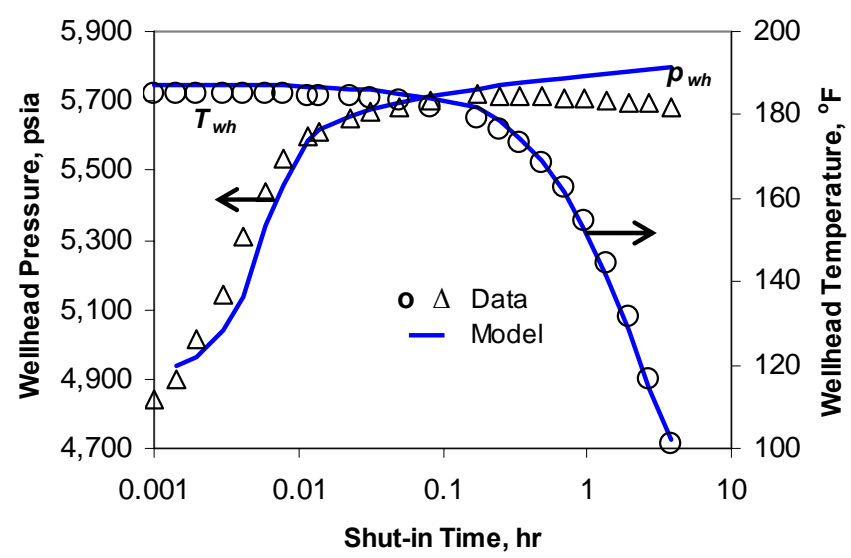

Fig. 5.17 - Comparison of WHP and WHT obtained by forward simulation, oil well \#2.

Wellhead leaks across wing valves can precipitate changes in wellhead pressure when a certain threshold value is exceeded during buildup. In this case, we surmise that the wing valve downstream to the point of wellhead pressure measurement gave away when the flowline was bled at the other end, thereby creating increasing pressure-drop with time. Fig. 5.18 provides the description of the situation. Note that the master valve is left open to allow wellhead pressure measurement. Slow leak of this nature also clouds the authenticity of bottomhole pressure measurements in that the rate of buildup decreased 
with time, perhaps leading to a lower value of semilog slope and correspondingly higher $k h$ than the true value.

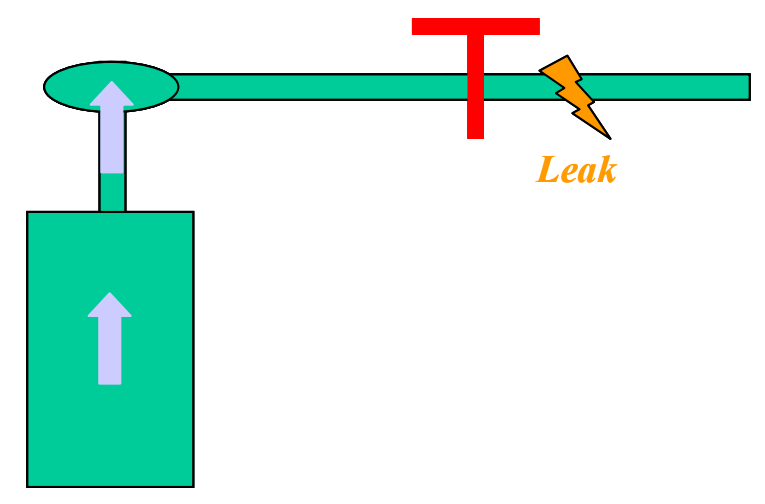

Fig. 5.18 - Wellhead leak during a shut-in test

We demonstrated the value of both types of simulations whenever measurements are available at the wellhead and sandface. For example, the buildup test in oil well \#2 identified incoherence between the model and field observations, which led to the logical conclusion of a possible leak at the wing valve. This observation will lead to corrective procedure in future testing programs.

Although reverse simulation is a powerful approach, we should be aware of some of its caveats. First, for the reverse simulation to work, both the surface and downhole gauges must have the same character in terms of resolution and absolute accuracy. Unless planned carefully, the surface gauge will typically offer resolution perhaps an order-ofmagnitude lower than its downhole counterpart. Second, changes in ambient condition, such as cooling, during the test also present challenge in wellhead pressure conversion, especially when tests go through a day-and-night time cycle. For this situation, convective heat transport in the variable-temperature environment needs modeling. 


\subsection{MULTIRATE TEST ON AN OFFSHORE OIL WELL}

In this section, we will reproduce a multi-rate test from a deepwater asset to demonstrate the models capabilities. Tahiti Field sits in more than $4,000 \mathrm{ft}$ of water in the Gulf of Mexico and is a three-way anticlinal structure trapped against salt. The primary pays are Miocene age turbidite sheet sands at depths ranging from 24,000 to 27,000 feet TVD. The field was discovered in April, 2002 by the GC 640 \#1 and appraised in 20032004 with the drilling of two additional wells, both with major sidetracks. In addition, a surface flow test was conducted in the original discovery well over a seven day period in August, 2004. The flow test data was used to verify the simulation model described in this work.

The high reservoir pressure (19,500 psi) and depth $(26,000 \mathrm{ft}$ TVD) of the Tahiti completions required the development of several new equipment designs to successfully perforate, fracpac and flow test the well (Chandler et al. 2005). In a lower pressure environment the use of a feed-through packer system would have allowed placement of the downhole pressure gauges just above the perforations. However, the high Tahiti bottomhole pressures and formation depth necessitated the use of a conventional permanent packer system, resulting in the placement of the gauge mandrel at a point some $517 \mathrm{ft}$ above the perforations. To date, neither retrievable nor permanent packer systems have been developed to meet the 15,000 psi differential requirement for Tahiticlass applications.

Operational contingencies overcome while drilling the original discovery well at Tahiti resulted in this well having several sealed casing annuli and the possibility that annular pressure buildup could burst or collapse casing strings. To mitigate annular pressure buildup potential, the Project Team designed a vacuum insulated subsea production tubing string for use in producers (Nowinka et al. 2005). During the flow test, a subsurface mandrel with a memory-only gauge was placed at the base of the vacuum insulated portion of the tubing string $(9,600 \mathrm{ft} \mathrm{MD})$ to acquire pressure and temperature 
data, which is useful to calibrate and verify wellbore flow models. The location of the mandrel was 1,000 ft below the top of a massive tabular salt feature. Fig. 5.19 shows the wellbore modeled during this study.

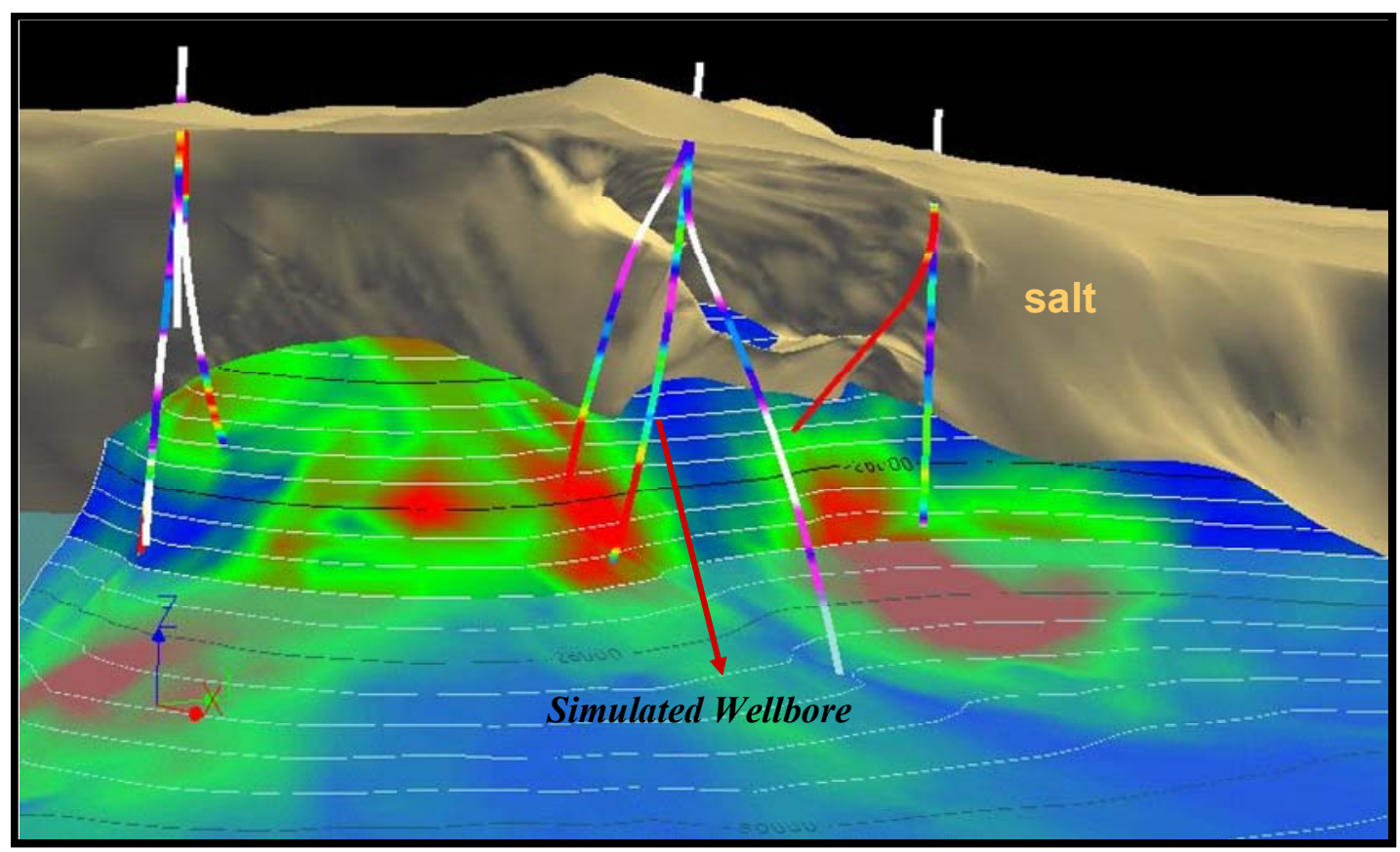

Fig. 5.19 - Simulated wellbore during a multi-rate test

A multi-rate test has been run on this well. Fig. 5.20 presents raw pressure/rate data for the entire test, including the cleanup period. As shown, multiple drawdown tests were conducted in a decreasing rate sequence before the final buildup occurred. Conventional analysis of two major shut-in periods and multirate drawdown tests are presented in Appendix B. Parameters so derived became the starting point for subsequent analysis, as discussed here. The rigorous approach of tackling both downhole and offbottom pressure and temperature matching is detailed in the next section. 


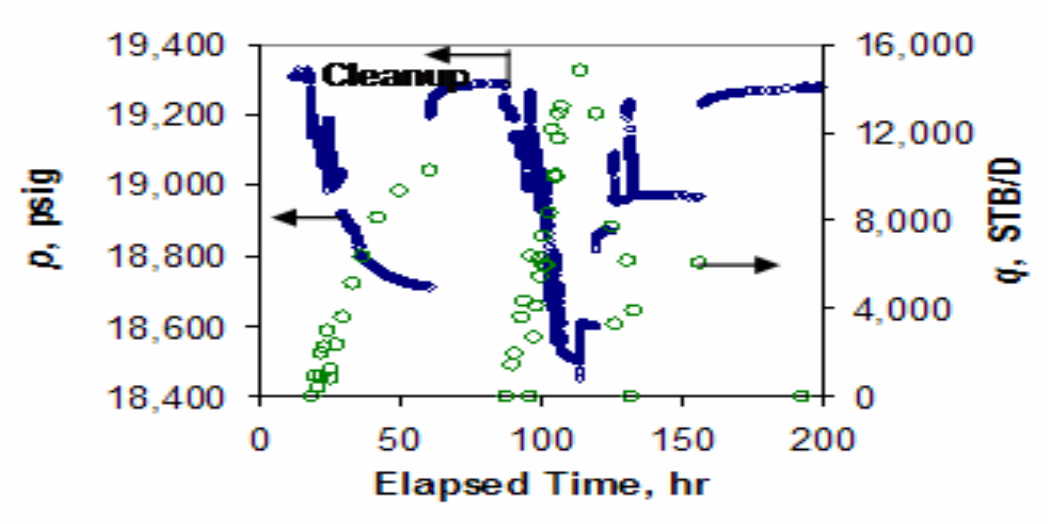

Fig. 5.20 - Test history showing cleanup period.

\subsubsection{Modeling field data}

The $26,500 \mathrm{ft}$ well is represented by 46 grid cells in the simulator, each of which is about $650 \mathrm{ft}$ long. Reservoir pressure is $19,530 \mathrm{psi}$ and reservoir temperature is $200{ }^{\circ} \mathrm{F}$. The geothermal gradient and seawater temperature profiles used in the model are given by Fig. 5.21.

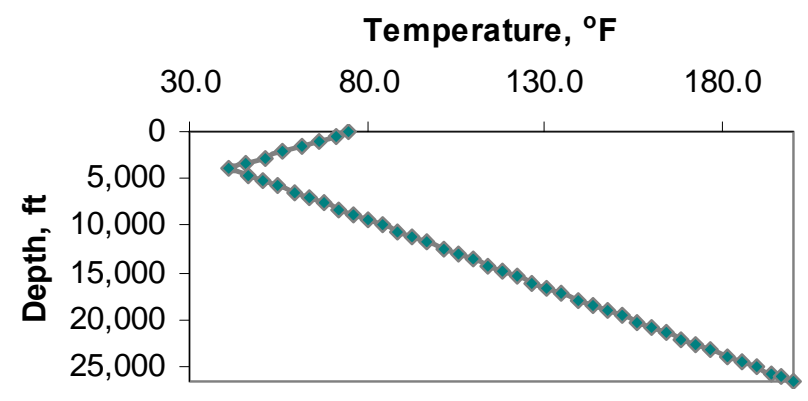

Fig. 5.21 - Geothermal gradient and sea water temperature profile.

The seawater temperature profile is linear from $40^{\circ} \mathrm{F}$ at the mudline to $75{ }^{\circ} \mathrm{F}$ at the surface. The mudline of the well is located at approximately $4,000 \mathrm{ft}$ water depth. This water column acts as a heat sink and the produced fluid will cool considerably while passing through this region, regardless of the producing rate.

This well also passes through $10,500 \mathrm{ft}$ of salt layer. A vacuum insulated tubing section is installed to prevent annulus-pressure buildup owing to thermal expansion of 
fluids. The vacuum insulated tubing has been accounted for in the simulation model for accurate heat-transfer calculations. Beyond the cleanup period, data collected during the 60 hour test period were bottomhole pressue, surface wellhead pressure and temperature, and flow rates. Fig. 5.22 shows the measured and input production rates. The surface wellhead pressure and temperature measurements occur at 9,625 $\mathrm{ft}$ from the surface, roughly called midpoint of the flow string.

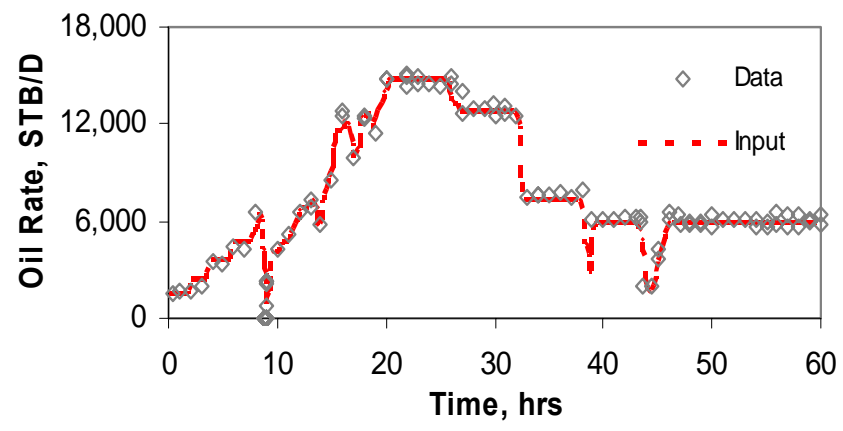

Fig. 5.22 - Mimicking oil production rate input.

Fig. 5.23 compares the measured and simulated bottomhole pressures for the 60hour multirate test. Fig. 5.24 compares the measured and calculated temperature response. The temperature data was collected at the midpoint of the flow string. The initial discrepancy between the measured and calculated temperature profiles is the result of another flow and subsequent shut-in period that were not simulated. As shown in Fig.5.20, a cleanup period involving flow and shut-in lasted about 42 hours. Consequently, the wellbore-fluid temperature distorted the thermal equilibrium between the formation and the wellbore. No attempt was made to match the cleanup period because predominantly completion fluids were produced. 


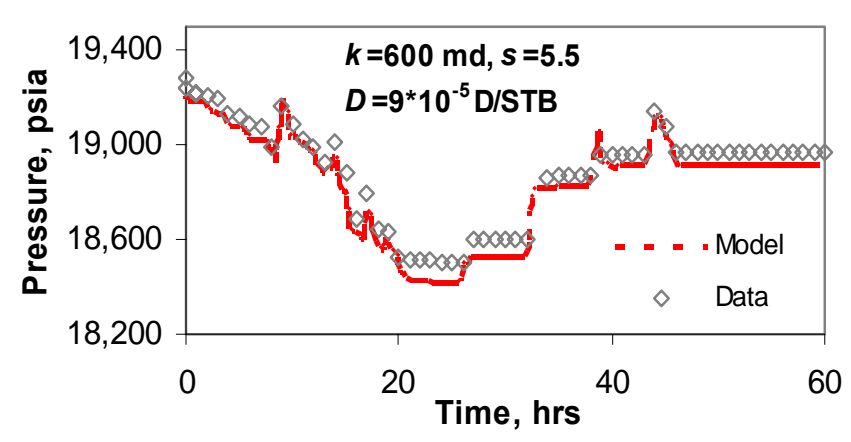

Fig. 5.23 - Matching bottomhole pressure.

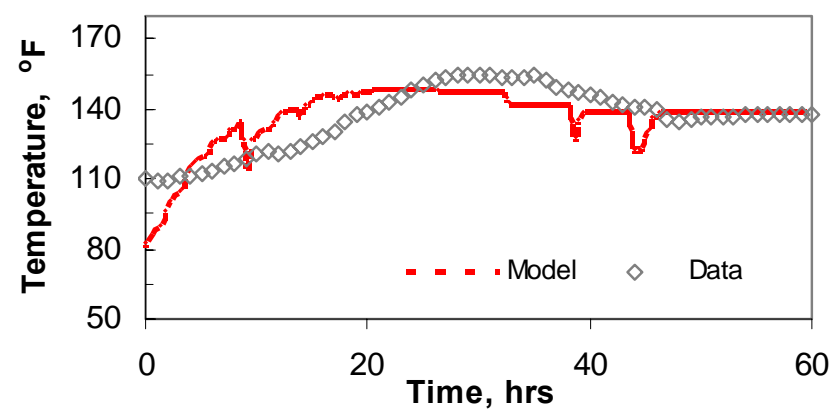

Fig. 5.24 - Matching temperature at the midpoint of the flow string.

Fig. 5.25 showing the pressure match at the same location does not reveal any serious issues even though we ignored the cleanup period. Overall, our ability to reproduce pressure response at both bottomhole and wellbore midpoint and temperature at the wellbore midpoint instilled a great deal of confidence to move forward with parametric studies.

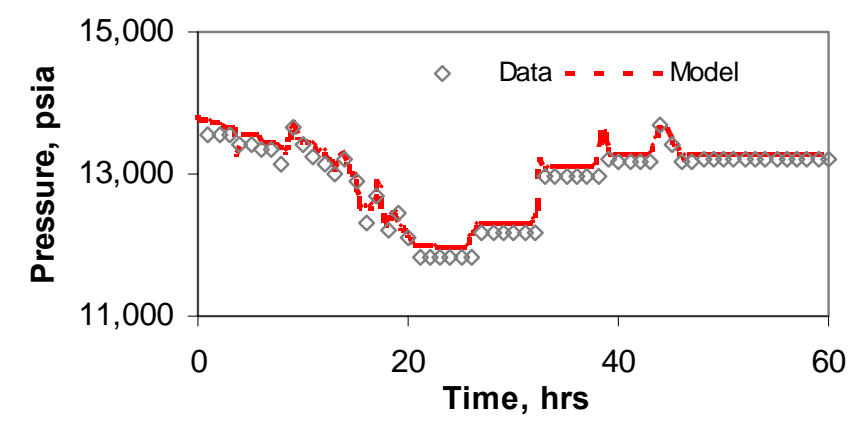

Fig. 5.25 - Matching pressure at the midpoint of the flow string. 


\subsubsection{Optimal location of permanent downhole gauge}

Ideally, pressure gauges should be placed as close to perforations as possible to ensure that data remain unaffected by thermal effects, friction in the tubing between the perforations, and the gauge and phase segregation during shut-ins. In addition, restrictions in internal diameter of the tubing string associated with downhole equipment may add to pressure drop at high rates. For most types of downhole pressure gauge installations without sand control, one can place a mandrel with pressure gauges near the perforated zone using a feed-through packer, as depicted on the left side of Fig. 5.26. In a set of stacked completions (without sand control), the gauges can be run in the specific producing zone by using multiple feed-through packers.

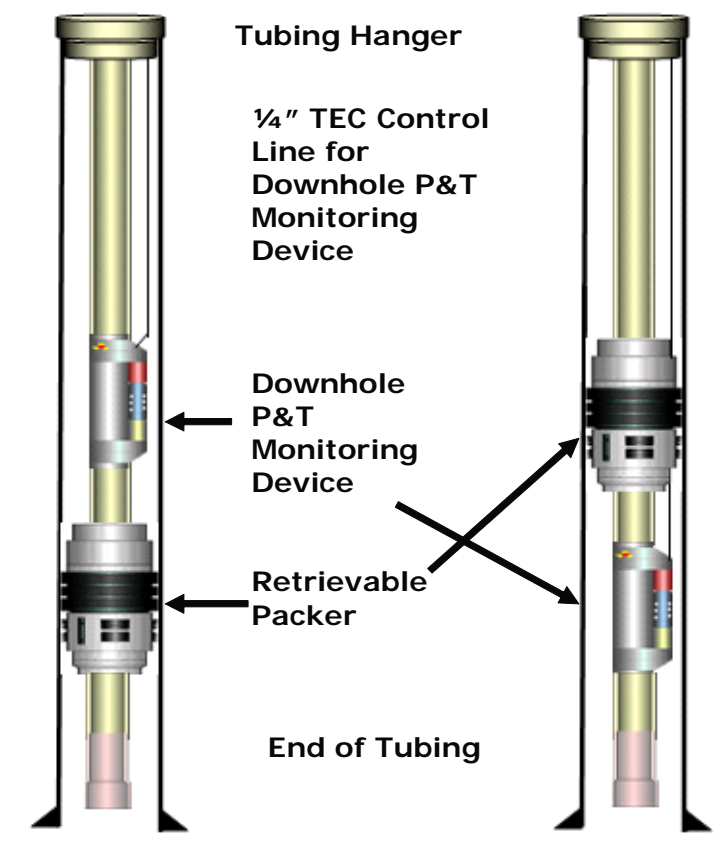

Fig. 5.26 - Downhole gauge placement configurations.

Getting gauges close to the perforations in a frac-packed well is challenging in that a service packer below the production packer does not allow feed-through applications. The location of the service packer dictates the depth of the bottom most downhole pressure gauge, as shown on the right side of Fig. 5.26. 
In addition, there are some circumstances for which a feed-through packer system may be unavailable (the Tahiti example above) and some operational conditions for which a simpler and robust equipment design may be chosen, such as in high-pressure high-temperature environment. Also, although some high-profile exploratory flow tests will use a permanent downhole gauge installation for surface readout in lieu of running wireline in the hole, the decision may be made to place the gauge mandrel above the packer so that the gauge and control lines may be retrieved to surface when the well is suspended.

In all of these cases, the value of better quality data must be weighed against the practicality of the completion design, the increase in risk with additional completion complexity and the cost incurred. The simple correlations for design of gauge placement developed in this paper should prove to be beneficial in making decisions when planning a new completion or coping with the effect of gauge placement on analysis results, if the preferred placement proves impractical.

\subsection{EFFECT OF GAUGE LOCATION ON PRESSURE-TRANSIENT ANALYSIS}

A well model similar to the Tahiti offshore well with $4,000 \mathrm{ft}$ of water depth is used for drawdown and buildup simulations. We investigated the effect of gauge location on calculated formation parameters by analyzing pressure data at increasing distances away from the sandface.

\subsubsection{Oil well}

A well model similar to the Tahiti offshore well with $4,000 \mathrm{ft}$ of water depth is used for drawdown and buildup simulations. We investigated the effect of gauge location on calculated formation parameters by analyzing pressure data at increasing distances away from the sandface. 


\subsubsection{Drawdown response}

Continuously changing flowing fluid temperature during both drawdown and shut-in affects the wellbore density profile. Fig. $\mathbf{5 . 2 7}$ shows fluid temperature and density profile when the well was producing at 5,000 STB/D.

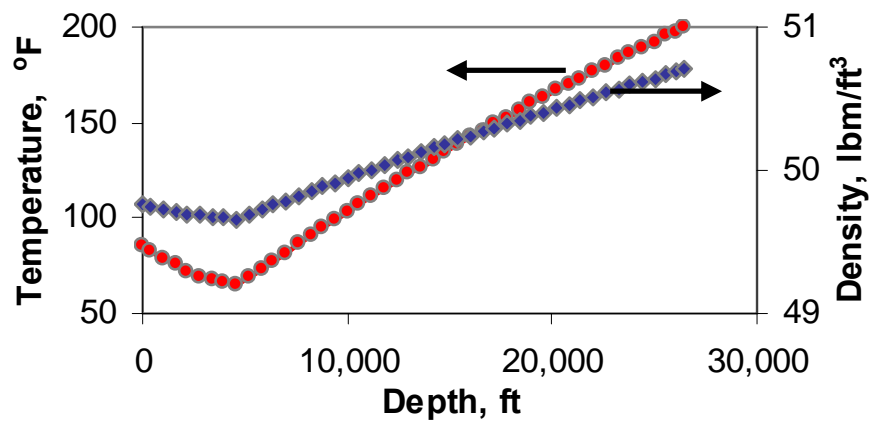

Fig. 5.27 - Temperature and density profiles in the wellbore.

As the produced fluid approaches the mudline, the temperature difference between the fluid and the formation is maximized, leading to the maximum changes in flowing fluid properties. Above the mudline, sea water temperature begins to increase as a function of depth, resulting in change of slope in temperature curve. Fig. 5.28 shows the increasing viscosity profile around the mudline in relation to the decreasing fluid temperature. The combined effects of increased density and viscosity around the mudline cause some fluctuations, even in steady-state flow profile. As a consequence of thermal effects, the rate of pressure change at any point in the wellbore does not necessarily reflect the same at the sandface for single-phase oil. Therefore, we cannot readily use pressures at any point of the column to extract formation parameters at all times. 


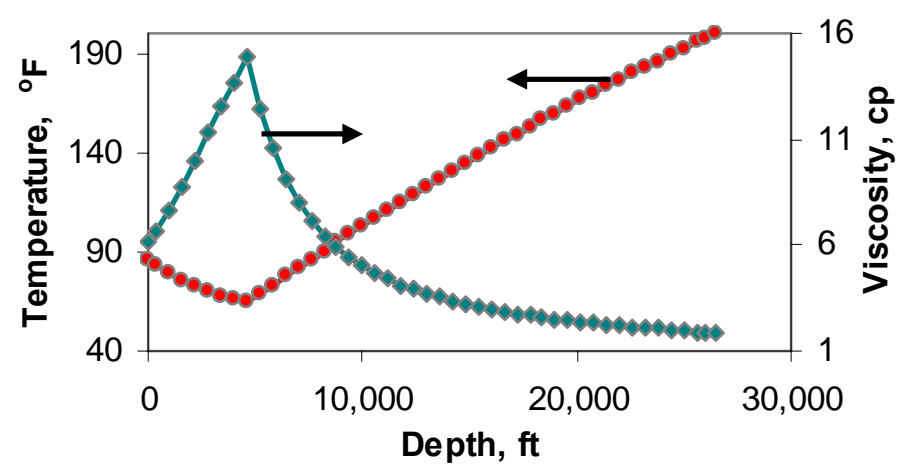

Fig. 5.28 - Temperature and viscosity profiles in the wellbore.

For single-phase oil experiencing drawdown, we demonstrate this point by plotting the changes in semilog slope as the virtual gauge moves up in the wellbore. Fig. 5.29 shows the calculated error in semilog slope as a function of depth. The percentage error in the slope increases with decreasing depth and reaches to its maximum around mudline. Thereafter, the error remains constant. For this particular case, it was possible to identify the radial flow region on the derivative plot up to the mudline, unlike some of the buildup runs as we discuss later.

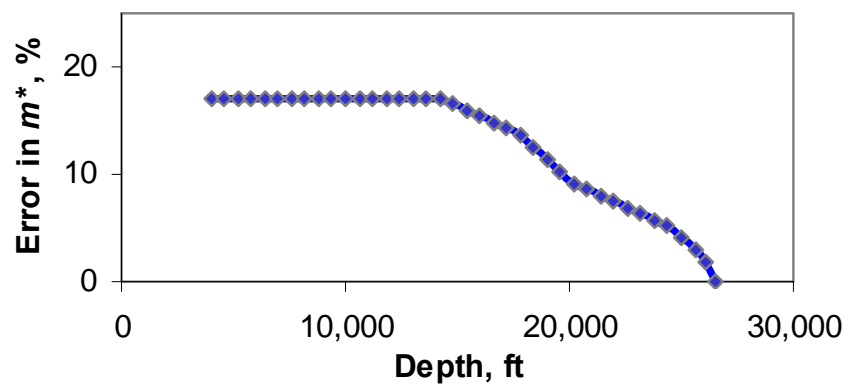

Fig. 5.29 - Error in semilog slope as a function of depth.

We used experimental design to investigate the effect of different variables on the semilog slope. The variables used in experimental design are, perforation-to-gauge distance $\left(D_{G}\right)$, permeability-thickness product $(k h)$, geothermal gradient $\left(g_{T}\right)$, flow rate $(q)$, oil gravity $\left(\gamma_{o}\right)$, deviation angle $(\theta)$, and thermal conductivity of annular fluid $\left(k_{a}\right)$. 
Table 5.1 provides the range of variables used to generate the experimental design table. This table attempts to capture the reservoir properties generally encountered in the Gulf of Mexico. Note that the entire range of variables cannot be encapsulated because nonphysical reservoir/wellbore models are generated that do not lend themselves for any solution.

Table 5.1 - Range of sensitivity variables for design of experiments for oil

\begin{tabular}{|cccc|}
\hline Variable & $\mathbf{p - 1 0}$ & $\mathbf{p}-\mathbf{5 0}$ & $\mathbf{p - 9 0}$ \\
\hline$k h, \mathrm{md}-\mathrm{ft}$ & $50^{\star} 250$ & $80^{\star} 250$ & $600^{\star} 200$ \\
$q, \mathrm{STB} / \mathrm{D}$ & 5,000 & 10,000 & 25,000 \\
$\gamma_{0}$ & 25 & 30 & 32 \\
$D_{G}, \mathrm{ft}$ & 20,000 & 1,500 & 400 \\
$k_{\text {an }}, \mathrm{Btu} / \mathrm{hr}-\mathrm{ft}-{ }^{\circ} \mathrm{F}$ & 0.1 & 0.2 & 0.3 \\
$g_{T},{ }^{\circ} \mathrm{F} / \mathrm{ft}$ & 1 & 1.2 & 1.4 \\
$\theta$, degree & 45 & 30 & 0 \\
\hline
\end{tabular}

Fig. 5.30 displays the Pareto chart for drawdown using the Plackett-Burman (1943) statistical design of experiments. Similar approach is described by Hasan et al. (2005). The Pareto chart shows that perforation-to-gauge distance $\left(D_{G}\right)$ has the biggest effect on percent error in semilog slope, followed by permeability-thickness product $(\mathrm{kh})$ and deviation angle $(\theta)$. Note that the vertical line signifies $95 \%$ confidence interval. In other words, one can develop a simple linear correlation with the first three variables influencing the semilog slope, $m^{*}$. 


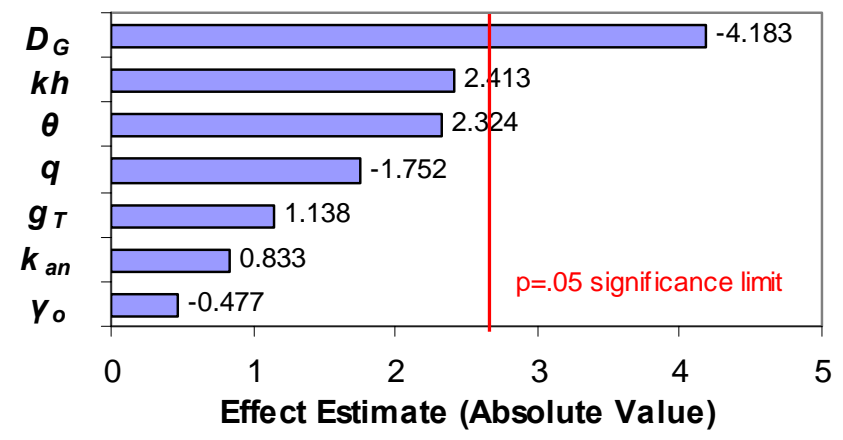

Fig. 5.30 - Pareto chart for oil-well drawdown for the dependent variable $E_{m^{*}}$

The following correlation includes all the variables studied for completeness:

$$
\begin{aligned}
& E_{m} *=-2.36-4.009 * 10^{-4} * q+7.327 * 10^{-4} * D_{G}+ \\
& 7.706 * 10^{-5} * k h+0.039 * g_{T}-0.234 * \gamma_{O}+14.302 * k_{\text {an }}- \\
& 0.177 * \theta
\end{aligned}
$$

As long as radial flow can be identified on the derivative plot, one can calculate the error on semilog slope by using this correlation for the variable range presented in Table 5.1.

\subsubsection{Buildup response}

In buildup simulations, we observed that the radial flow regime becomes difficult to identify as pressure is gathered at increasing distances from the sandface. The reason for this kind of behavior is twofold. After the valve at the mudline is completely closed, the mass flow rate at the upper parts of the wellbore diminishes rapidly. By contrast, the incoming flow at the sandface maintains a velocity profile up to certain depth, thereby creating a fully transient profile throughout the wellbore. Once mass flow rate ceases, the temperature of the wellbore fluid decreases rapidly, especially around the mudline, thereby triggering rapid changes in fluid properties. 
For a buildup test, continual changes in fluid properties combined with afterflow may mask the radial flow regime, or lead to an erroneous interpretation on a log-log plot. Presence of gas, such as in two- or three-phase flow makes the situation even more complicated. Fig. 5.31 presents the percentage error on semilog slope for a buildup test conducted at different locations in the wellbore. Also, the error on slope from a drawdown run, as shown in Fig. 5.29, is included for comparison.

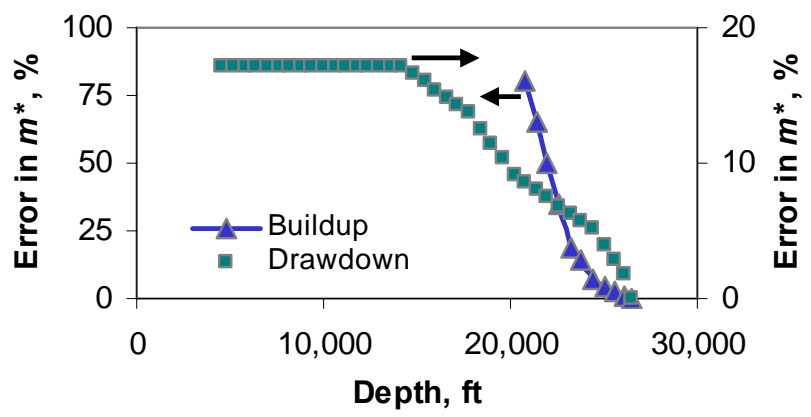

Fig. 5.31 - Error in semilog slope for drawdown and buildup as a function of depth.

Notice that the error curve for the buildup tests disappears after reaching a certain depth. That is because radial flow cannot be identified beyond 3,000 ft from the sandface, implying that no meaningful information can be extracted. Fig. 5.32 shows the derivative plot generated at 3,000 $\mathrm{ft}$ above the sandface. Duration of the buildup test would not change the signature on the log-log plot in this case because at the end of the run the bottomhole pressure is only one psia lower than the initial-reservoir pressure.

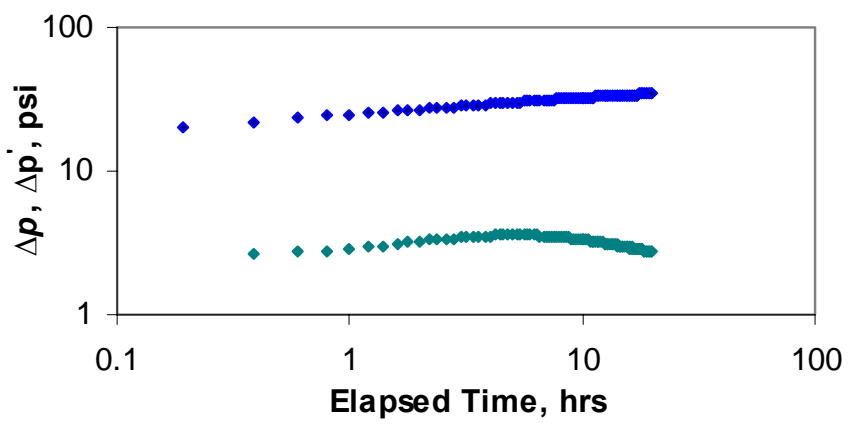

Fig. 5.32 - Log-log plot for buildup in an oil well. 
Fig. 5.33 presents a Pareto chart for buildup tests using the Plackett-Burman design, with the same variables identified earlier in Table 1. Note that only the upper limit for perforation-to-gauge distance needed to be adjusted because radial flow did not develop beyond 3,000 ft.

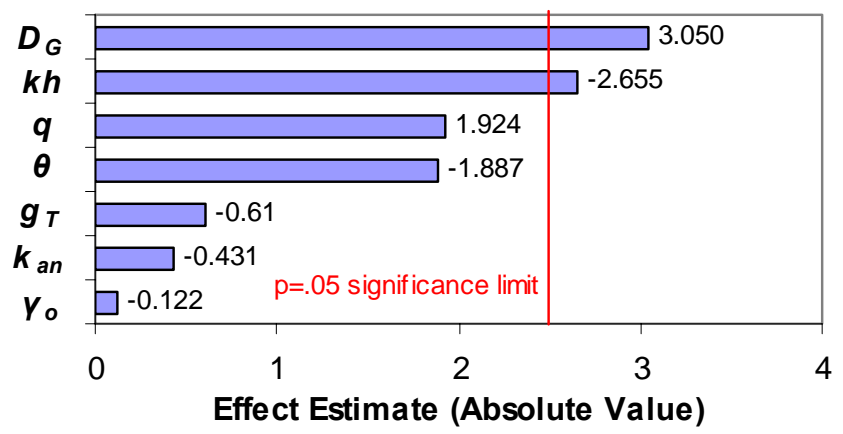

Fig. 5.33 - Pareto chart for oil-well buildup for the dependent variable $E_{m^{*}}$

For the buildup runs, the most influential variables affecting the dependent variable $m^{*}$ are the perforation-to-gauge distance and permeability-thickness product, as signified by the $95 \%$ confidence limit. However, the third important variable for buildup runs turned out to be the production rate just before the shut-in as opposed to deviation angle in drawdown runs. The resultant correlation that can be used to estimate the error on semilog slope for a builup test is given by

$$
\begin{aligned}
& E_{m} * 5.584+1.681 * 10^{-3} * q-3.588 * 10^{-3} * D_{G}- \\
& 7.555 * 10^{-5} * k h-0.019 * g_{T}-0.053 * \gamma_{O}-6.592 * k_{\text {an }}+ \\
& 0.128 * \theta
\end{aligned}
$$

\subsubsection{Gas well}

For the single-phase gas simulations, we used an offshore wellbore model with the same water depth to investigate mudline issues during gas production. Table 6.2 
presents the range of variables considered in this study. Flow and shut-in periods of 30 and 20 hours, respectively, were used for all simulation runs.

Table 5.2 - Range of sensitivity variables for design of experiments for gas
\begin{tabular}{cccc}
\hline Variable & $\mathbf{p}-\mathbf{1 0}$ & $\mathbf{p}-\mathbf{5 0}$ & $\mathbf{p}-\mathbf{9 0}$ \\
\hline$k h, \mathrm{md}-\mathrm{ft}$ & $10^{\star} 250$ & $80^{\star} 250$ & $60{ }^{\star} 200$ \\
$q, \mathrm{MMscf} / \mathrm{D}$ & 10 & 25 & 50 \\
$\gamma_{\mathrm{g}}$ & 0.5 & 0.6 & 0.7 \\
$D_{G}, \mathrm{ft}$ & 20,000 & 1,500 & 400 \\
$k_{a n}, \mathrm{Btu} / \mathrm{hr}-\mathrm{ft}-{ }^{\circ} \mathrm{F}$ & 0.1 & 0.2 & 0.3 \\
$g_{T},{ }^{\circ} \mathrm{F} / \mathrm{ft}$ & 1 & 1.2 & 1.4 \\
$\theta$, degree & 45 & 30 & 0 \\
\hline
\end{tabular}

Because gas PVT properties are much more sensitive to the changes in temperature, both flow and shut-in periods exhibited trend reversals during simulations at increasing distances from the sandface. Because gases have intrinsically much lower heat capacity and, therefore, lower enthalpy than a liquid, heat dissipation occurs much faster, leading to trend reversal of pressure. Fig. 5.34 compares the bottomhole and mudline pressures for flow and shut-in periods.

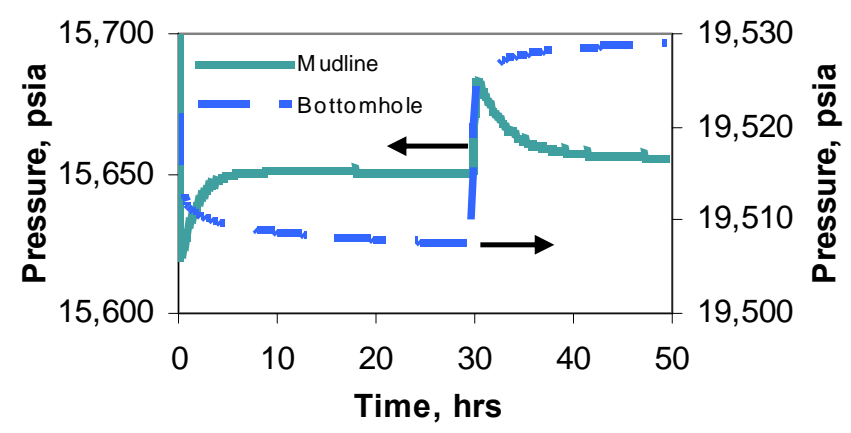

Fig. 5.34 - Pressure at the mudline and bottomhole for a deepwater gas well.

During drawdown, pressure at the mudline increases even though the bottomhole pressure declines in accord with normal behavior. Conversely, during shut-in period, pressure at the mudline declines continuously. This trend reversal at the mudline is a 
direct consequence of temperature response, which eliminates the possibility of extracting any formation parameters with conventional pressure-transient analysis. Similarly, this inverted pressure behavior precludes one from doing wellhead-tobottomhole pressure conversion or reverse simulation. Fig. $\mathbf{5 . 3 5}$ shows the derivative plot for the shut-in period generated with pressure data collected at 3,000 $\mathrm{ft}$ above the sandface. Here, the radial flow is hard to discern.

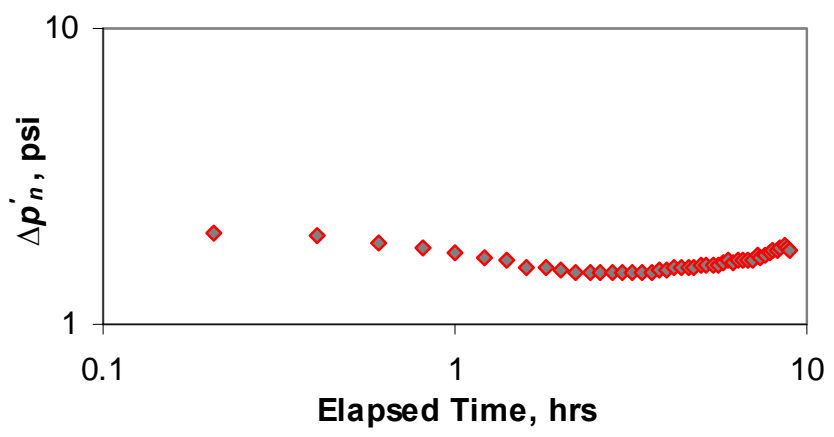

Fig. 5.35 - Derivative diagnosis of gas-well buildup for a gauge at $3,000 \mathrm{ft}$ away from sandface.

Fig. 5.36 shows the changes in mudline pressure in relation to temperature. The similarity in pressure and temperature trends clearly demonstrates the strong connection between the two responses, as one may surmise intuitively from the real-gas law. One consequence of this gas-well behavior is that significant heat loss not only occurs at the seabed, but its effect gets transmitted thousands of feet below the mudline. Fig. $\mathbf{5 . 3 7}$ shows the temperature and pressure profiles during gas production at 2,000 $\mathrm{ft}$ below the mudline. 


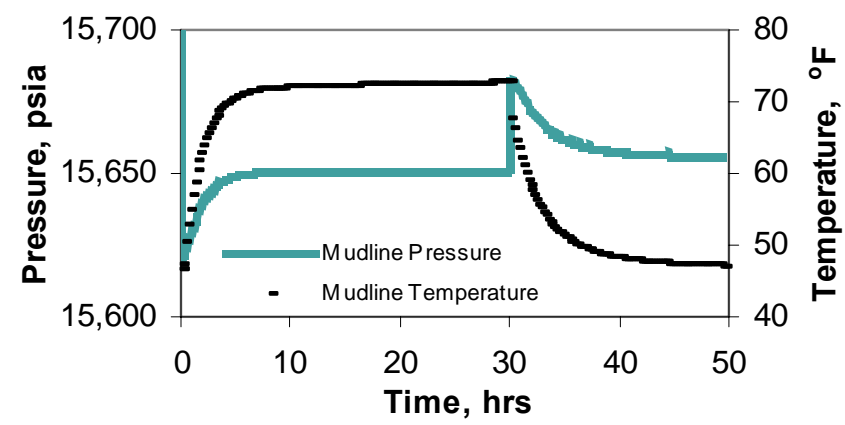

Fig. 5.36 - Pressure and temperature behavior at the mudline.

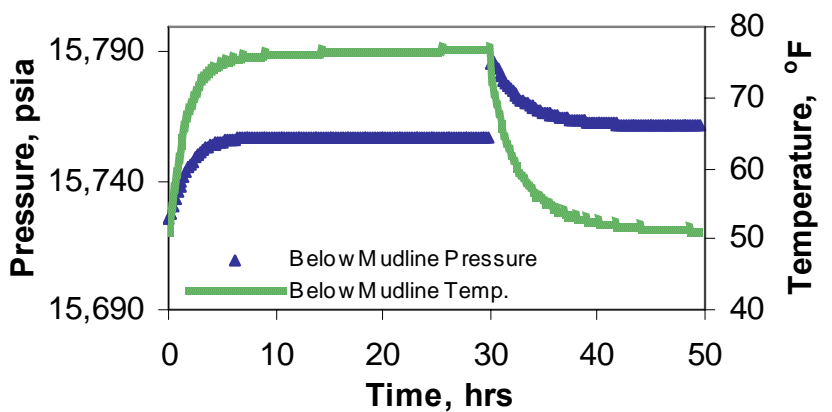

Fig. 5.37 - Pressure and temperature behavior $2,000 \mathrm{ft}$ below the mudline.

We found that the trend reversal for drawdown pressure is a strong function of gas production rate and duration of the production period. The initial pressure trend reversal takes place regardless of the production rate. However, duration of this reverse-trend period depends on the rate, and with continued production the trend gradually begins to mimic that of the bottomhole pressure. Again, placing the gauge close to the sandface is the only way to ensure data quality. Similar to the oil flow problem, we generated the Pareto chart with the data presented in Table 5.2. Fig. 5.38 presents the chart. 


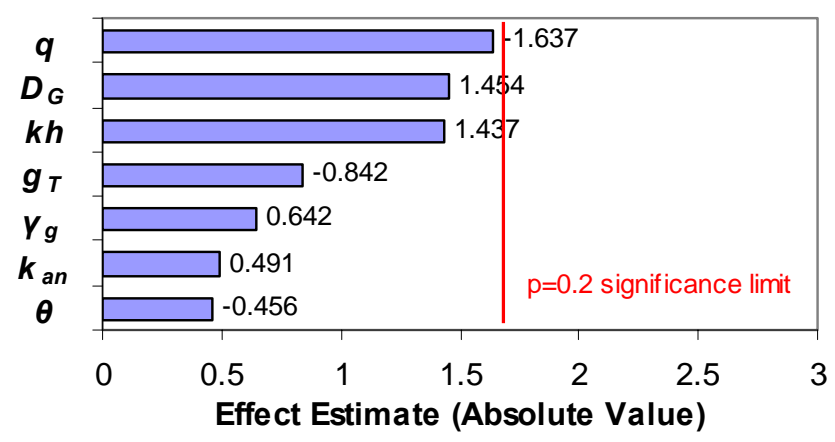

Fig. 5.38 - Pareto chart for gas-well drawdown for the dependent variable $E_{m^{*}}$

The resultant correlation that can be used to estimate the error in semilog slope for a drawdown test in a gas well is given by

$$
\begin{aligned}
& E_{m} * 9.247-6.478 * 10^{-7} * q-8.853 * 10^{-3} * D_{G}+ \\
& 1.935 * 10^{-4} * k h-33.339 * g_{T}+50.824 * \gamma_{g}+38.874 * k_{a n}+ \\
& 0.16 * \theta
\end{aligned}
$$

We have already discussed issues pertaining to data gathered in off-bottom gauges. While that discussion is helpful in designing future installations, questions arise what to do with current installations where potential problems exist. To mitigate this situation, we explored the notion of translating off-bottom pressures into bottomhole pressure with the reverse-simulation technique (Izgec et al. 2006; Hasan et al. 2005). Fig. 5.39 shows such an attempt for a gas well where pressure data are collected at the mudline and 2,000 $\mathrm{ft}$ above the perforations in a drawdown test. Although absolute pressure values are acceptably close, the data do not lend themselves for transient analysis. Clearly, the early-time semilog slope suffers as the gauge moves away from the sandface. 


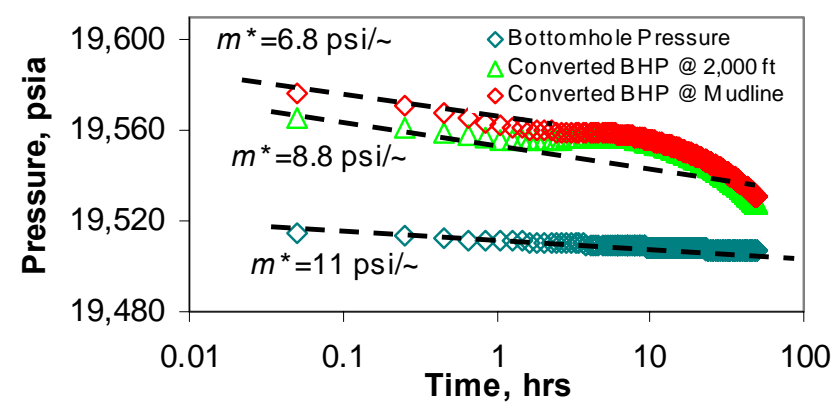

Fig. 5.39 - Comparison of converted BHP responses (2,000-ft off-bottom and the mudline) with the true response.

Note that we considered favorable drawdown tests because buildup responses have considerably higher error bar, as Fig. 5.31 demonstrates. Although not shown, single-phase oil system responds more favorably than its gas counterpart, as far as pressure conversion is concerned. Therefore, to mitigate off-bottom pressure measurements, we think the better approach is forward simulations, wherein one has to honor both pressure and temperature measurements from one or more locations in the borehole. This point was made earlier in the field example section.

Besides thermal effects, wellhead pressure measurements may sometimes be affected by wellbore hydrodynamics, such as slugging, associated with two-phase flow. Fig. 5.40 illustrates this point with a field example, where slugging persists over days after initiating flow, following a short shut-in period. The rate fluctuation is roughly $4 \%$ about its mean value. We surmise that the overall increasing wellhead pressure trend at the mudline in this high-GOR well is similar to a gas well, shown earlier in Fig. 5.34. Obviously, any attempt to translate wellhead pressure to bottomhole pressure will be severly challenged, unless unstable flow physics is modeled implicitly in addition to thermal effects. 


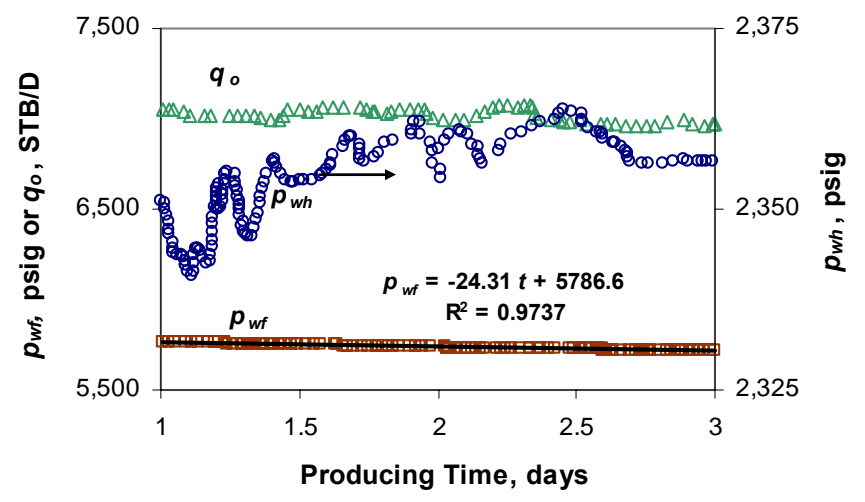

Fig. 5.40 - Wellhead pressure response shows both slugging and thermal effects.

\subsection{ANNULAR PRESSURE BUILDUP FOR AN ONSHORE WELL}

For this onshore well pressure buildup was observed in the 7-in. production casing owing to heating of annular fluid by the producing fluid in the tubing string. As Fig. 5.41 shows, the rise in wellhead temperature is directly related to increase in flow rate.

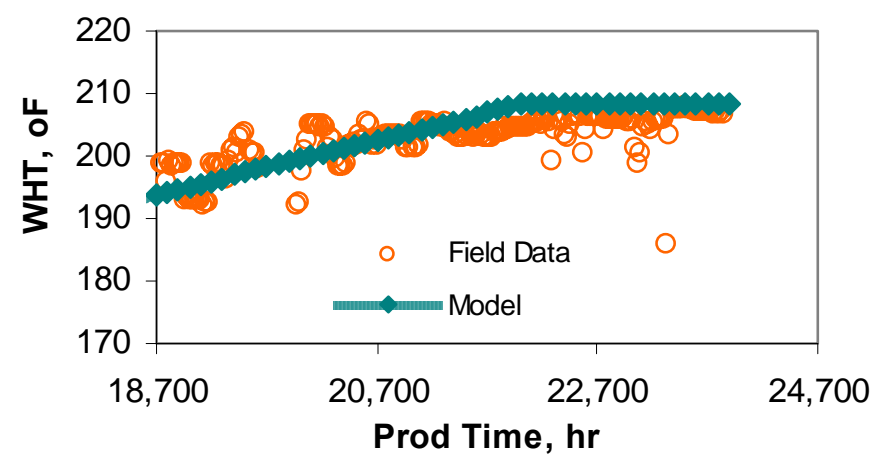

Fig. 5.41 - Wellhead temperature during production.

With increased rate the available energy for heat transfer increases proportionately, leading to the increased annular pressure. Fig. $\mathbf{5 . 4 2}$ makes this point amply clear. Thermal expansion of annular fluid appears to be solely responsible for the APB behavior in this closed-annular system. 


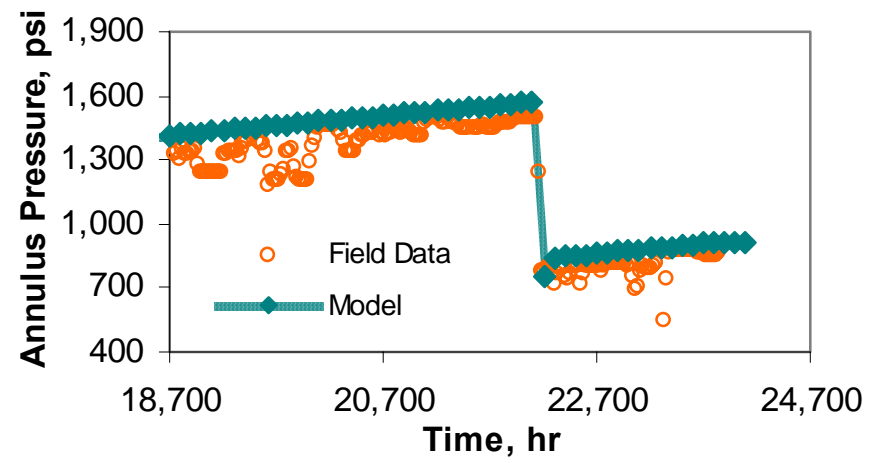

Fig. 5.42 - Annulus pressure during production.

According to Fig.5.42 some annular liquid was bled off to relieve pressure. As a consequence, higher producing rate was restored while annulus pressure decreased.

This bleed-off volume was not reported, however. When we used a bleed-off volume of 300 liters, the model was able to reproduce the annular pressure decline quite accurately. The corresponding temperature match at the wellhead was shown in Fig. 5.41. 


\section{CHAPTER VI \\ CONCLUSIONS}

This study presents a finite-difference wellbore model coupled with an improved semianalytic fluid-temperature formulation for transient simulations of flow and shut-in tests. Three major improvements to previous studies are offered to gain computational speed, accuracy and stability:

- A new analytic temperature model including mass influx upon shut-in and heat conduction in vertical direction is developed.

- The hybrid numerical-differentiation scheme removes limitations imposed by the constant-relaxation-parameter assumption, used in previous analytic heat-transfer formulations.

- The variable-formation-temperature scheme improves estimation of temperature by accounting for the changes in heat-transfer rate between the wellbore fluids and formation, which in turn, improves the pressure calculations when forward and reverse simulations are sought.

The simulation model is extended for temperature calculations in multiple annuli and is capable of predicting trapped fluid expansion in each of them as a function of time. The ABP model also predicts the surrounding formation temperature at every timestep up to a user specified distance into the reservoir.

Verification of pressure and temperature computation with field data is demonstrated with both forward and reverse simulations for single-phase oil and singlephase gas wells. The usefulness of both approaches during a test is demonstrated by an example wherein suspected wellhead leak was uncovered. 
The notion of thermally induced pressure distortion is investigated with a deep offshore wellbore model after matching the pressure and temperature data from 60 hours of multirate test. The results show that gauge location is the key factor in collecting analyzable data and data quality suffers as the gauge is moved away from the perforations.

The final part of this work presents simple correlations to check the validity of subsurface pressure data yielding reliable formation parameters in accord with gauge placement. These correlations, in turn, provide guidance for placing both temporary and permanent downhole gauges in a specific wellbore/reservoir environment. 


\title{
NOMENCLATURE
}

\author{
$A=$ drainage area or area exposed to flow, $f t^{2}$ \\ $a=$ lumped parameter \\ $B=$ formation volume factor, $R B / S T B$ \\ $B_{o}=$ formation-volume factor, $R B / S T B$ \\ $C_{A}=$ Dietz shape factor for drainage area, dimensionless \\ $c_{p}=$ specific heat capacity of fluid, Btu/lbm- ${ }^{\circ} \mathrm{F}$ \\ $c_{t}=$ total system compressibility, $1 / p s i$ \\ $C_{T}=$ thermal storage parameter $\left(=m^{\prime} E^{\prime} / m E\right)$, dimensionless \\ $D=$ non-Darcy flow coefficient, D/STB \\ $D_{G}=$ perforation-to-gauge distance, $f t$ \\ $E=$ internal energy of the wellbore fluid, Btu/lbm \\ $E^{\prime}=$ internal energy of the wellbore system, Btu/lbm \\ Em* $=$ error in semilog slope, percent \\ $G_{p}=$ cumulative gas production, Bscf \\ $g_{G}=$ geothermal gradient, ${ }^{\circ} \mathrm{F} / \mathrm{ft}$ \\ $g=$ gravitational acceleration, $\mathrm{ft} / \mathrm{sec} 2$ \\ $g c=$ conversion factor, $32.17 \mathrm{lbm}-\mathrm{ft} / \mathrm{lbf} / \mathrm{sec} 2$ \\ $h=$ formation thickness, $f t$ \\ $H=$ Enthalpy, Btu/lbm \\ $J=$ productivity index, $M M s c f / D-p s i$ \\ $k=$ permeability, $m d$ \\ $k_{e}=$ thermal conductivity of earth, Btu/hr-ft- ${ }^{\circ} \mathrm{F}$
}




$$
\begin{aligned}
& L_{R}=\text { relaxation parameter } \\
& m=\text { semilog slope }(=162.6 \mathrm{~B} \mu / \mathrm{kh}), \mathrm{psi} / \log \text {-cycle } \\
& m(p)=\text { pseudopressure, } p \mathrm{si}^{2} / \mathrm{cp} \\
& m=\text { mass offluid, } l \mathrm{lbm} \\
& m^{\prime}=\text { mass of wellbore system per unit length, lbm/ft } \\
& m^{*}=\text { semilog slope }(=162.6 \mathrm{~B} \mu / \mathrm{kh}), \text { psi/log-cycle } \\
& m_{v e}=\text { mass of formation volume element, } \mathrm{lbm} \\
& n_{w}=\text { number of wells } \\
& N=\text { cumulative production of a well, STB } \\
& N_{p}=\text { cumulative production of the field, STB } \\
& p_{D}=\left\{k h\left(p_{i}-p(x, y, t)\right\} / 141.2 q_{r e f} B \mu\right. \\
& p_{w h}=\text { flowing wellhead pressure, } \text { psig } \\
& \bar{p}=\text { average drainage-area pressure, } p \text { sia } \\
& p^{*}=\text { Horner extrapolated pressure, psia } \\
& p_{D}=\text { dimensionless pressure } \\
& p_{i}=\text { initial pressure, } p \text { sia } \\
& p_{w h}=\text { wellhead pressure, psia } \\
& p_{w f}=\text { flowing bottomhole pressure, psia } \\
& q=\text { sandface flow rate, } S T B / D \\
& q_{D}=q(t) / q_{r e f} \\
& q_{g}=\text { gas rate, } M M s c f / D \\
& q_{k}=\text { well rate, } S T B / D \\
& q_{T}=\text { total field rate, } S T B / D
\end{aligned}
$$


$Q(t)=$ instantaneous cumulative production, $\quad$ MMscf

$Q=$ heat flow rate from or to the wellbore, Btu/hr

$r_{w}=$ wellbore radius, $f t$

$r_{w a}=$ apparent wellbore radius, $f t$

$r=$ thickness of the control volume, $f t$

$R=$ residual form of backward Euler formulation

$R_{g_{o}}=$ producing gas/oil ratio, scf/STB

$R_{s}=$ solution gas/oil ratio, scf/STB

$s=$ mechanical skin, dimensionless

$S_{g i}=$ initial gas saturation, fraction of pore space

$S_{o i}=$ initial oil saturation, fraction of pore space

$S_{w i}=$ initial water saturation, fraction of pore space

$t=$ producing time, $h r$

$t_{D}=$ dimensionless time, hours

$T_{D}=$ dimensionless temperature

$t_{e}=$ equivalent producing time $\{=Q(t) / q(t)\}, h r$

$\bar{t}_{t o t}=$ total field material-balance time, $h r$

$t_{D A}=$ dimensionless time $\left(=0.00633 \mathrm{kt} / \phi \mu c_{t} A\right)$

$t_{\text {tot }}=$ material-balance time, $\mathrm{hr}$

$T_{s c}=$ temperature at standard conditions, ${ }^{\circ} \mathrm{F}$

$T_{f}=$ fluid temperature, ${ }^{\circ} \mathrm{F}$

$T_{e}=$ earth or formation temperature, ${ }^{\circ} \mathrm{F}$

$T_{e i}=$ undisturbed earth or formation temperature, ${ }^{\circ} \mathrm{F}$ 
$T_{w b}=$ wellbore/earth interface temperature, ${ }^{\circ} \mathrm{F}$

$T_{w h}=$ wellhead temperature, ${ }^{\circ} \mathrm{F}$

$U_{t o}=$ overall-heat-transfer coefficient, Btu/hr-ft ${ }^{2}-{ }^{\circ} \mathrm{F}$

$w=$ mass rate, $\mathrm{lbm} / \mathrm{hr}$

$x=$ rectangular coordinate distance, $f t$

$x_{D}=x / \sqrt{ }$ A, dimensionless

$y=$ rectangular coordinate distance, $f t$

$y_{D}=y / \sqrt{ } A$, dimensionless

$z=$ variable well depth from surface, $f t$

$\gamma o=$ oil gravity, $o A P I$

$\gamma g=$ gas gravity (air $=1)$, dimensionless

$\mu=$ fluid viscosity, $c p$

$\gamma=0.577216$, Euler's constant

$\rho_{e}=$ earth density, $l \mathrm{lbm} / \mathrm{ft} \mathrm{t}^{3}$

$\phi=\left(1 / c_{p} \rho\right)(d p / d z)$

$\phi=$ porosity, fraction

$\psi=g_{G} \sin \theta+\phi-\left(g \sin \theta / c_{p} J g_{c}\right)$

$\theta=$ well inclination from horizontal, degree

$\tau=$ dummy integration variable

\section{SubSubscripts}

$i=$ well number index

$j=$ timestep index

$k=$ well position index or iteration index 
$n=n t h$ flow period

$0=$ initial condition

1, 2, 3=indices of flow period 


\section{REFERENCES}

Almehaideb, R.A., Aziz, K., and Pedrosa, O.A. 1989. A Reservoir/Wellbore Simulator for Multiphase Injection and Pressure Transient Analysis. Paper SPE 17941 presented at the SPE Middle East Oil Show, Manama, Bahrain, 11-14 March.

Alves, I.N., Alhanati, F.J.S., and Shoham, O. 1990. A Unified Model for Predicting Flowing Temperature Distribution in Wellbores and Pipelines. Paper SPE 20632 presented at the SPE Annual Technical Meeting, Manama, Bahrain, 23-26 April.

Chandler, R.B., Hensley, J. R., Gonzalez, M. E., Muradov, A., and Jellison, M. J. 2005. Project-Specific, High-Pressure Completion Tubular for ChevronTexaco's Tahiti Project. Paper SPE/IADC 92497 presented at the IADC/SPE Drilling Conference, 2325 February, Amsterdam, Netherlands.

Fairuzov, Y.V., Guevara, J.G., Barradas, G.L., Velazquez, R.C., and Nucamendi, F.F. 2002. A Lumped-Parameter Model for Transient Two-Phase Gas-Liquid Flow in a Wellbore. SPEPF 17 (1): 36-41.

Fan, L., Lee, W.J., and Spivey, J.P. 2000. Semianalytical Model for Thermal Effect on Gas Well Pressure-Buildup Tests. SPEREE 3 (6): 480-491.

Hagoort, J. 2004. Ramey's Wellbore Heat Transmission Revisited. Paper SPE 87305 presented at the SPE Annual Technical Meeting, Manama, Bahrain, 13-16 August.

Hasan, A.R. and Kabir, C.S. 2002. Fluid Flow and Heat Transfer in Wellbores, SPE, Richardson, Texas.

Hasan, A.R., Kabir, C.S., and Lin, D. 2005. Analytic Wellbore-Temperature Model for Transient Gas-Well Testing. SPEREE 8 (3) 240-247.

Izgec, B., Kabir, C.S., Zhu, D., and Hasan, A.R. 2006. Transient Fluid and Heat Flow Modeling in Coupled Wellbore/Reservoir Systems. Paper SPE 102070 presented at the Annual Technical Conference and Exhibition, San Antonio, TX, 24-27 September.

Kabir, C.S. 2006. What is the Real Measure of Gas-Well Deliverability Potential? SPEREE 9 (2): 126-134. SPE-84469-PA.

Kabir, C.S., Hasan, A.R., Jordan, D.L., and Wang, X. 1996. A Wellbore/Reservoir Simulator for Testing Gas Wells in High-Temperature Reservoirs. SPEFE 11 (2): $128-134$. 
Miller, C.W. 1980. Wellbore Storage Effects in Geothermal Wells. SPEJ 8 (3) 555-566.

Nowinka, J., Kis, P., Hensley, R., Gonzalez, M. E. and Williams, D. 2005. Vacuum Insulated Tubing Design and Performance Evaluation for Deepwater Completions. Paper SPE/IADC 92448 presented at the IADC/SPE Drilling Conference, 23-25 February, Amsterdam, Netherlands.

Plackett, R.L. and Burman, J.P. 1943. The Design of Optimum Multifactorial Experiments. Biometrika XXXIII, University Press, Cambridge, England, 305.

Ramey, H.J., Jr. 1962. Wellbore Heat Transmission. JPT 6 (2) 427-435; Trans., AIME, 225.

Sagar, R., Doty, D.R. 1991. Predicting Temperature Profiles in a Flowing Well. Paper SPE 19702 presented at the Annual Technical Conference and Exhibition, San Antonio, TX, 24-27 September.

Satter, A.,1965. Heat Losses During Flow of Stream Down a Wellbore. JPT (July) 845851; Trans., AIME, 235.

Sharma, Y., Shoham, O. 1989. Simulation of Downhole Heater Phenomena in the Production of Wellbore Fluids. Paper SPE 16904 presented at the Annual Technical Conference and Exhibition, Dallas, TX, 27-30 September.

Shiu, K.C., Beggs, H.D. 1980. Predicting Temperatures in Flowing Oil Wells. JPT (July) 635-640; Trans., AIME, 215.

Winterfeld, P.H. 1989. Simulation of Pressure Buildup in a Multiphase Wellbore/Reservoir System. SPEFE 4 (2): 247-252.

Willhite, G.P. 1989. Overall Heat Transfer Coeeficents in Steam and hot water Injection Wells. SPEFE 5 (3): 230-242. 


\section{APPENDIX A \\ ANALYTICAL SOLUTION OF DIFFUSIVITY EQUATION IN THE FORMATION}

An energy balance on the formation leads to the partial differential equation, derived in cylindrical coordinates, for the variation of formation temperature with radial distance from the well.

$$
\frac{\partial^{2} T_{e}}{\partial r^{2}}+\frac{1}{r} \frac{\partial T_{e}}{\partial r}=\frac{c \rho_{e} \rho_{e}}{k_{e}} \frac{\partial T_{e}}{\partial t}
$$

In Eq. A. $1 T_{e}$ is the formation temperature at an arbitrary depth at time, $t$, and distance, $r$, measured from the center of the wellbore. Heat capacity, density and conductivity are given with $c_{e}, \rho_{e}$ and $k_{e}$. The solution of the equation requires three boundary conditions. At very early times, the formation temperature retains its initial value, except near the wellbore. As time increases, heat transferred from the warm wellbore fluid will raise the formation temperature in its vicinity. The heat flow rate at the wellbore/formation interface is governed by Fourier's law of heat conduction.

Eq. A.1 can be solved in terms of dimensionless variables. Hasan and Kabir solved the resulting equation with the Laplace transform, following the approach suggested by van Everdingen and Hurst for a similar set of equations used for pressure transients. For estimating flowing fluid temperature the formation temperature and its spatial derivative at the wellbore/formation interface are needed.

According to their solution if $t_{D}>1.5$

$$
T_{D}=\left[0.4063+\frac{1}{2} \ln t_{D}\right]\left[1+\frac{0.6}{t_{D}}\right]
$$


And if $t_{D}<1.5$

$T_{D}=1.1281 \sqrt{t_{D}}\left(1-0.3 \sqrt{t_{D}}\right)$

The above expressions for dimensionless temperature become discontinuous around 1.5. The continuous expression for the same expression is provided as

$T_{D}=\ln \left[e^{(-0.2 t)}+\left(1.5-0.3719 e^{-t}{ }_{D}\right)\right] \sqrt{t_{D}}$ 


\section{APPENDIX B \\ CONVENTIONAL ANALYSIS OF FIELD DATA}

Fig. B1 presents temperature data along with pressure. Temperature increase during flow tests is precipitated by Joule-Thompson heating that the fluid experiences owing to significant pressure drop at the sandface. Conversely, temperature decrease during shut-in periods is tied to energy dissipation, particularly in this slightly off-bottom gauge, $517 \mathrm{ft}$ away from perforations.

Fig. B2 compares the two major buildup tests, one at the end of the cleanup period and the other at the end of the whole sequence of testing. Permeability so derived is used to anchor drawdown analysis to discern the non-Darcy or rate-dependent skin component, as shown in Fig. B3. The possibility of non-Darcy skin can be discerned by inspecting Fig. B1, where separation of the two pressure curves occurs. Note that the two shut-in tests are preceded by very dissimilar oil rates: 10, $275 \mathrm{STB} / \mathrm{D}$ after the cleanup and $6,129 \mathrm{STB} / \mathrm{D}$ before the final buildup.

Fig. B3 shows data from three flow periods, including the one just before the final buildup test. As discussed elsewhere (Kabir 2006), buildup-derived slope is superimposed on drawdown data to discern the intercepts, leading to the separation of skin components, as shown in Fig. B4. Permeability and the two skin components became the starting point for overall history matching, as described in the text. 


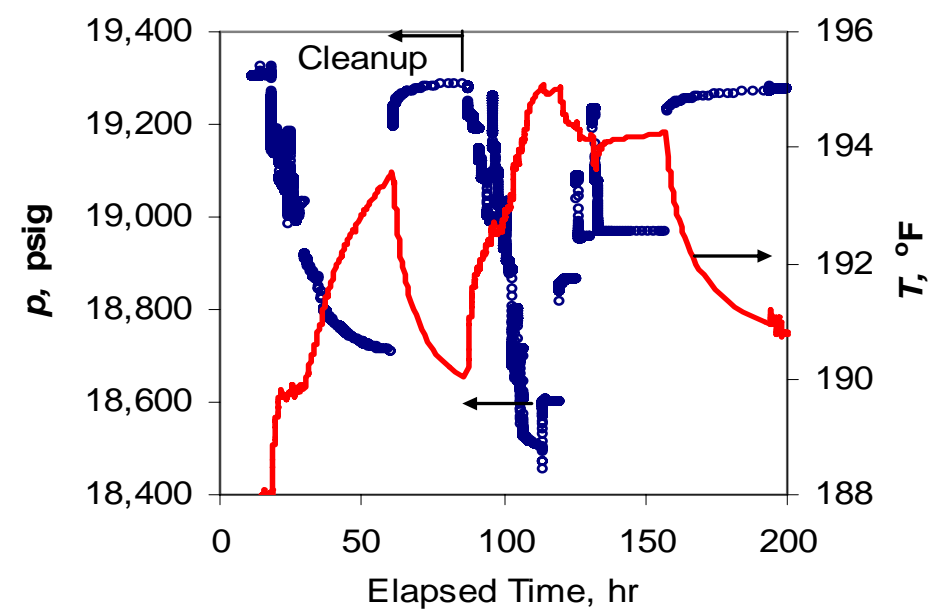

Fig. B1 - Pressure and temperature history of test data.

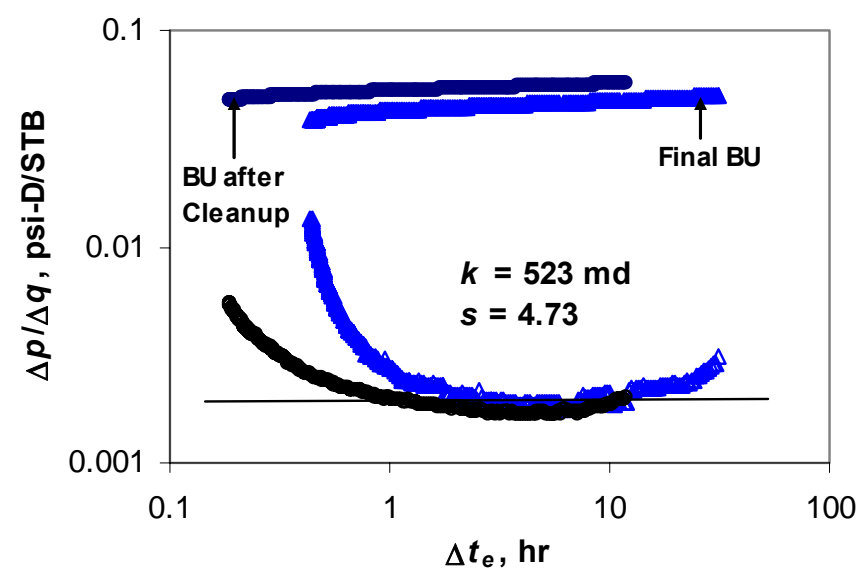

Fig. B2 - Comparison of shut-in tests suggest non-Darcy skin. 


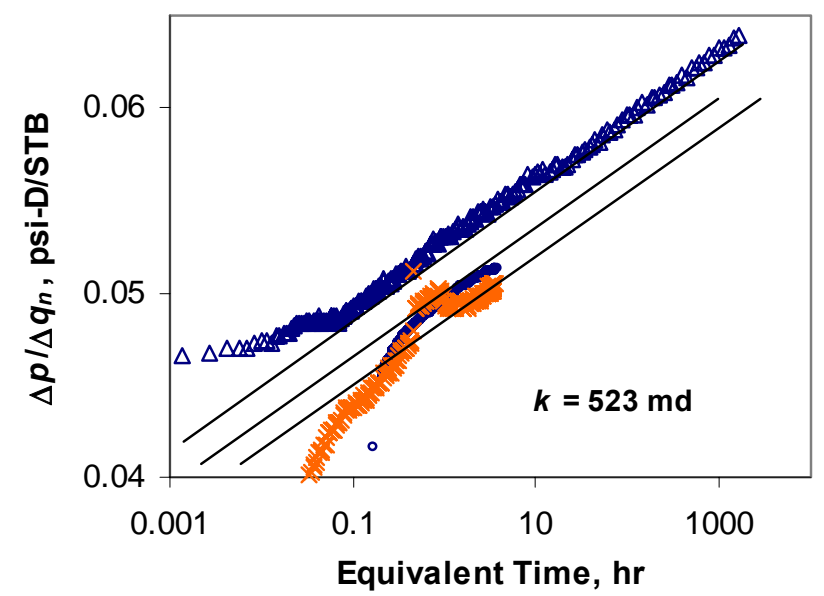

Fig. B3 - Analysis of noisy drawdown data aided by buildup-derived permeability.

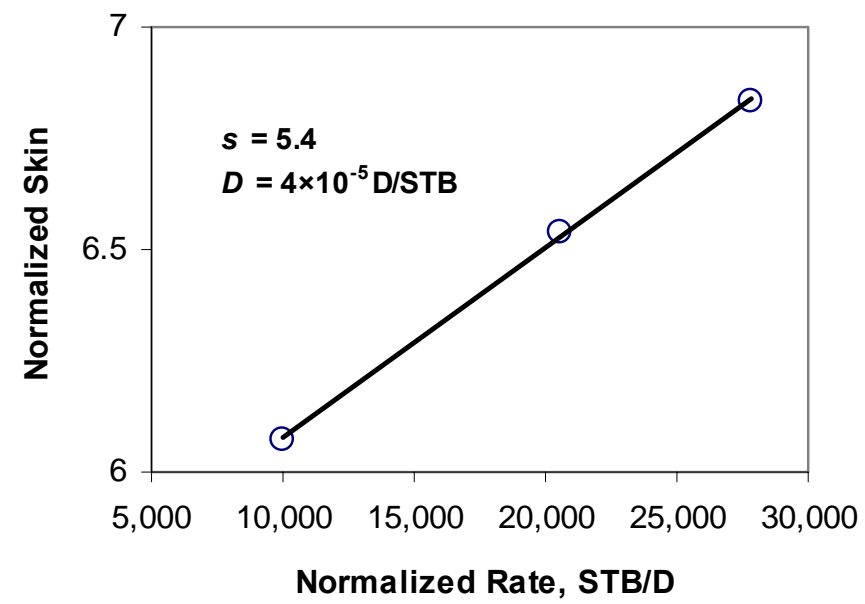

Fig. B4 - Separation of skin components. 


\section{VITA}

Bulent Izgec is a petroleum engineer at Chevron Energy Technology Company on the PE Consulting Services Team. He holds a B.S. degree in Geophysical Engineering from University of Ankara, Turkey and an M.S. degree in Petroleum Engineering from Texas A\&M University. He may be reached at 1500 Louisiana Street, Room \# 19022c, Houston, TX, 77002. 